Universidade de São Paulo

Instituto de Física

\title{
Implementação e desenvolvimento de algoritmo eficiente para deformação intramolecular com o método Monte Carlo
}

\author{
Henrique Musseli Cezar
}

Orientador: Profa. Dra. Kaline Rabelo Coutinho

Tese de doutorado apresentada ao Instituto de Física como requisito parcial para a obtenção do título de Doutor em Ciências.

Profa. Dra. Kaline Rabelo Coutinho (IFUSP)

Prof. Dr. Mario José de Oliveira (IFUSP)

Prof. Dr. Ataualpa Albert Carmo Braga (IQUSP)

Prof. Dr. Laurent Emmanuel Dardenne (LNCC)

Prof. Dr. William Ricardo Rocha (UFMG)

São Paulo

2018 


\section{FICHA CATALOGRÁFICA \\ Preparada pelo Serviço de Biblioteca e Informação do Instituto de Física da Universidade de São Paulo}

Cezar, Henrique Musseli

Implementação e desenvolvimento de algoritmo eficiente para deformação intramolecular com o método de Monte Carlo. São Paulo, 2018.

Tese (Doutorado) - Universidade de São Paulo. Instituto de Física. Depto. de Física Geral

Orientador: Profa. Dra. Kaline Rabelo Coutinho.

Área de Concentração: Física Atômica e Molecular.

Unitermos: 1. Física computacional; 2. Física molecular; 3. Solvatação; 4. Espectroscopia. 
University of São Paulo

Institute of Physics

\title{
Implementation and development of an efficient Monte Carlo method for intramolecular deformation
}

\author{
Henrique Musseli Cezar
}

Supervisor: Profa. Dra. Kaline Rabelo Coutinho

Thesis submitted to the Institute of Physics of the University of São Paulo as partial fulfillment of the requirements to obtain the degree of Doctor of Science.

Profa. Dra. Kaline Rabelo Coutinho (IFUSP)

Prof. Dr. Mario José de Oliveira (IFUSP)

Prof. Dr. Ataualpa Albert Carmo Braga (IQUSP)

Prof. Dr. Laurent Emmanuel Dardenne (LNCC)

Prof. Dr. William Ricardo Rocha (UFMG)

São Paulo

2018 



\section{Agradecimentos}

Gostaria de iniciar agradecendo o incentivo e apoio da minha família, especialmente dos meus pais, que foram fundamentais durante toda a minha carreira, por permitirem que o desejo de fazer ciência continuasse vivo e fosse uma realidade. Agradeço à Jéssica, pelo apoio que foi fundamental para a finalização deste trabalho, e por me motivar a seguir em frente após a finalização dessa etapa. Agradeço também aos meus amigos, que sempre estiveram dispostos a ouvir sobre os momentos de frustração e proporcionaram bons momentos para esquecê-los.

Não menos importante, agradeço à Profa. Kaline pela orientação e discussões, que foram fundamentais para o meu desenvolvimento como cientista. Sou muito grato também aos colegas do Grupo de Física Molecular e Modelagem pelas discussões que muito me ensinaram, e pelas sugestões, que acrescentaram em grande maneira ao desenvolvimento do DICE.

Agradeço à infra-estrutura fornecida pelo IFUSP, aos recursos computacionais financiados pela CAPES, CNPq e FAPESP e a manutenção destes, feita pelo CCIFUSP. Agradeço também o apoio financeiro do Conselho Nacional de Desenvolvimento Científico e Tecnológico (CNPq) que financiou essa pesquisa através de bolsa sob o processo 140489/2015-0 concedida pela Pós-Graduação do IFUSP. 

"If you keep proving stuff that others have done, getting confidence, increasing the complexities of your solutions - for the fun of it - then one day you'll turn around and discover that nobody actually did that one!" Richard P. Feynman 



\section{Resumo}

CEZAR, H. M. Implementação e desenvolvimento de algoritmo eficiente para deformação intramolecular com o método Monte Carlo 2018. 131 p. Tese (Doutorado em Ciências) Instituto de Física, Universidade de São Paulo, São Paulo, 2018.

Com o avanço do poder computacional nas últimas décadas, a modelagem molecular de problemas em diversas áreas se tornou mais acessível, sendo hoje uma ferramenta fundamental para o entendimento de diversos processos. Em especial, simulações moleculares com campos de força clássicos vem sendo importante para a amostragem de propriedades termodinâmicas, para a determinação de estruturas e população de confôrmeros, e seleção de configurações para utilização com métodos que combinam mecânica quântica com mecânica molecular. Os principais métodos de simulação atualmente utilizados são a dinâmica molecular (MD, do inglês molecular dynamics) e o Monte Carlo (MC). Ambos os métodos são a princípio equivalentes quando o objetivo é a amostragem configuracional, tendo a MD a vantagem de permitir a análise da dinâmica e evolução temporal, e o MC a vantagem de poder gerar configurações de forma probabilística, sem a necessidade de seguir um caminho sobre a superfície de energia potencial, o que pode resultar em uma amostragem mais eficiente. Contudo, não há ainda uma metodologia de $\mathrm{MC}$ que possa ser considerada eficiente e bem estabelecida para a amostragem dos graus de liberdade internos de moléculas com complexidade arbitrária. Visando avançar no desenvolvimento de métodos que trabalham nesse sentido, neste trabalho o método apresentado por Shah e Maginn ${ }^{[1]}$ foi implementado e aprimorado. No método, a molécula é fragmentada em partes menores, formadas de graus de liberdade rígidos, que não variam drasticamente durante a simulação. Esses fragmentos por sua vez são conectadas por graus de liberdade maleáveis, os diedros e termos não ligados da energia. Durante a simulação a molécula tem fragmentos apagados, e então é reconstruída utilizando um esquema de Configurational Bias Monte Carlo (CBMC). A contribuição deste trabalho para a metodologia consiste em generalizar os tipos de fragmentos possíveis dentro do método, a simplificação do critério de aceitação e extensões com vieses adicionais, como é o caso do viés no potencial eletrostático e no critério de aceitação da amostragem preferencial com o CBMC. A validade da implementação do método foi avaliada através de simulações em dois sistemas simples: o octano e o 1,2-dicloroetano. Comparando a amostragem e os resultados obtidos para as populações de confôrmeros com resultados de MD e experimentais ou obtidos com outros métodos de $M C$ da literatura foi possível verificar que a implementação reproduz os resultados esperados. Além disso, o equilíbrio conformacional da molécula de óxido mesityl (MOx) que possui duas conformaç̃oes: syn e anti, foi estudado. Graças a barreira de potencial entre as duas conformações de cerca de $10 \mathrm{kcal} / \mathrm{mol}$, a MD não é capaz de realizar uma amostragem ergódica, enquanto o CBMC realiza a amostragem sem problemas. Na simulação CBMC, a inversão da população dominante em fase gasosa e em água foi observada. Simulações do MOx em acetonitrila e metanol mostraram que a 
população de confôrmeros anti de fato aumenta conforme a polaridade do solvente. Entretanto, devido ao estiramento da ligação $\mathrm{C}=\mathrm{O}$ do $\mathrm{MOx}$ em metanol devido as ligações de hidrogênio, a contribuição conformacional à posição do máximo da banda de absorção $\pi-\pi^{*}$ não segue a tendência da polaridade, tendo um deslocamento para o azul maior na acetonitrila do que em metanol. $\mathrm{O}$ estiramento da ligação $\mathrm{C}=\mathrm{O}$ só pode ser observado graças a introdução da amostragem de fragmentos com deslocamentos Cartesianos e algoritmo de Metropolis ao método CBMC original. Esse efeito devido ao estiramento é compensado pelo efeito solvente, de modo que a contribuição total à energia de transição segue a polaridade do solvente. De uma maneira geral, concluímos que o desempenho do método CBMC utilizado é excelente para os casos estudados, e é inclusive superior ao da MD em alguns casos. A implementação no software DICE deixa um legado importante para diversos grupos de pesquisa, não somente por introduzir o CBMC, mas também por melhorias gerais como paralelização, lista de vizinhos e modernização do código, que foram introduzidas ao decorrer do projeto.

Palavras-chaves: Configurational Bias Monte Carlo. Soluto-solvente. Mecânica molecular. Flexibilidade molecular. 


\section{Abstract}

CEZAR, H. M. Implementation and development of efficient Monte Carlo algorithm for intramolecular deformation 2018. 131 p. Tese (Doutorado em Ciências) - Instituto de Física, Universidade de São Paulo, São Paulo, 2017.

With the increase of computational power in the last decades, the molecular modeling of problems in several areas has become more accessible, being today a fundamental tool used to understand several processes. In particular, molecular simulations with classical force fields have been important for the sampling of thermodynamic properties, for the determination of structures and population of conformers, and for the selection of configurations to be used with methods that combine quantum mechanics with molecular mechanics. The most common simulation methods used nowadays are molecular dynamics (MD) and Monte Carlo (MC). Both methods are in principle equivalent when the goal is configurational sampling, with MD having the advantage of allowing the analysis of the dynamics and temporal evolution, while MC has the advantage of generating the configurations in a probabilistic manner, not necessarily following a path in the potential energy surface, possibly resulting in a more efficient sampling. However, there is no MC methodology that can be considered efficient and established to sample the internal degrees of freedom of molecules with arbitrary complexity. In order to advance in the development of methods that want to achieve this goal, in this work the method presented by Shah e Maginn ${ }^{[1]}$ has been implemented and improved. In the method, the molecule is fragmented into smaller parts, each one composed by the hard degrees of freedom, which do not vary dramatically during the simulation. Those fragments are then connected by soft degrees of freedom, the dihedral and non-bonded terms of the energy. During the simulation the molecule has some of its fragments deleted, and is reconstructed using a Configurational Bias Monte Carlo (CBMC) approach. The contribution of this work to the methodology is generalizing the fragment types within the method, the simplification of the acceptance criteria and some extensions with additional biases, such as electrostatic potential bias and the acceptance criterion of the preferential sampling with the CBMC. The implementation was evaluated through simulations in two simple systems: octane and 1,2-dichloroethane. Comparing the sampling and results obtained for the populations of conformers with MD results, experimental data or values obtained with different MC methods present in the literature, we verified that the implementation reproduces the expected results. Beyond that, the conformational equilibrium of the mesityl oxide (MOx) molecule which has two conformers: syn and anti, was investigated. Due to the potential energy barrier between the two conformers of about $10 \mathrm{kcal} / \mathrm{mol}$, the MD does not perform an ergodic simulation, while the CBMC does the same sampling accordingly. In the CBMC simulation, the inversion of the dominant conformer in gas phase and water was observed. The MOx simulation in acetonitrile and methanol showed that the frequency of the anti conformer indeed increases with the solvent polarity. Nonetheless, due to the stretch of the 
$\mathrm{C}=\mathrm{O}$ bond of $\mathrm{MOx}$ in methanol, attributed to the hydrogen bonds formed with the solvent, the conformational contribution to the maximum of the absorption band $\pi-\pi^{*}$ does not follow the polarity tendency, having a larger blue shift in acetonitrile than in methanol. The $\mathrm{C}=\mathrm{O}$ bond stretch can only be seen because the Cartesian displacement sampling with the Metropolis method was introduced to the original CBMC method. This effect attributed to the stretch is compensated by the solvent, in a way that the total contribution to the transition energy follows the solvent polarity. In general, we conclude that the performance of the developed CBMC method is excellent to the studied cases, being even superior to MD in some cases. The implementation in DICE leaves an important legacy to several research groups, not only for introducing the CBMC method, but also due to general improvements such as parallelization, neighbor list and code modernization, which were introduced during the project.

Keywords: Configurational Bias Monte Carlo. Solute-solvent. Molecular mechanics. Molecular flexiblity. 


\section{Lista de figuras}

Figura 1 - Exemplo de fragmentação de uma molécula fictícia . . . . . . . . . . . 32

Figura 2 - Tipos de fragmento do CBMC suportados pelo DICE. . . . . . . . . . . 35

Figura 3 - Fluxograma mostrando a implementação do método CBMC no DICE. . . . 47

Figura 4 - Molécula de octano na configuração trans com átomos numerados e seus fragmentos, e energia potencial de diedro $u_{\text {torsional }}$ para a rotação dos grupos $\mathrm{CH}_{2}$ dos diedros internos da molécula. . . . . . . . . . . . . . 56

Figura 5 - Evolução da porcentagem relativa de configurações gauche durante as simulações. . . . . . . . . . . . . . . . . . . . . . . . 60 60

Figura 6 - Evolução do ângulo de diedro C6-C9-C12-C15 com os passos de simulação para a simulação com o CBMC e MD . . . . . . . . . . . . . . . . . 61

Figura 7 - Molécula de 1,2-dicloroetano (DCE) e seus fragmentos para a simulação com o CBMC . . . . . . . . . . . . . . . . . . . . 62

Figura 8 - Densidade de probabilidades da amostragem do ângulo de diedro $\mathrm{Cl}-\mathrm{C}-\mathrm{C}-\mathrm{Cl}$. 63

Figura 9 - Distribuição dos ângulos $\mathrm{Cl}-\mathrm{C}-\mathrm{C}$ amostrados com o algoritmo de amostragem de branch-point em comparação com a curva ideal. . . . . . . . . . . . . . 64

Figura 10 - Distribuição dos ângulos Cl-C-C amostrados com o algoritmo de amostragem de branch-point e então inseridos com o algoritmo CBMC na molécula. . . 65

Figura 11 - Distribuição dos ângulos H-C-H amostrados com o algoritmo de amostragem de branch-point e então inseridos com o algoritmo CBMC na molécula. . . 65

Figura 12 - Distribuição dos ângulos $\mathrm{Cl}-\mathrm{C}-\mathrm{H}$ amostrados com o algoritmo de amostragem de branch-point e então inseridos com o algoritmo CBMC na molécula. . . 67

Figura 13 - Distribuição dos ângulos C-C-H amostrados com o algoritmo de amostragem de branch-point e então inseridos com o algoritmo CBMC na molécula. . . 67

Figura 14 - Evolução do número de configurações trans amostradas com o CBMC durante diferentes intervalos da simulação. . . . . . . . . . . . . . 68

Figura 15 - Densidade de probabilidades da amostragem do ângulo de diedro $\mathrm{Cl}-\mathrm{C}-\mathrm{C}-\mathrm{Cl}$ para o líquido de DCE. . . . . . . . . . . . . . . . . . . . . . . . . . . . 69 
Figura 16 - Distribuição dos ângulos $\mathrm{Cl}-\mathrm{C}-\mathrm{C}$ amostrados com o algoritmo de amostragem de branch-point e então inseridos com o algoritmo CBMC na molécula e também dos ângulos amostrados com MD. . . . . . . . . . . . . . . . 70

Figura 17 - Numeração dos rótulos atômicos e configurações syn e anti do MOx. . . . 72

Figura 18 - Potencial da rotação do grupo $\mathrm{C}=\mathrm{C}-\mathrm{C}=\mathrm{O}$ do $\mathrm{MOx} \ldots \ldots$

Figura 19 - Fragmentos do MOx utilizados para as simulações CBMC. . . . . . . . . . 75

Figura 20 - Potencial torsional ao redor da ligação dupla $\mathrm{C} 6-\mathrm{C} 1=\mathrm{C} 2-\mathrm{C} 3$ do $\mathrm{MOx}$. 76

Figura 21 - Histograma normalizado da frequência de amostragem do ângulo de diedro $\mathrm{C} 1=\mathrm{C} 2-\mathrm{C} 3=\mathrm{O} 4$ do $\mathrm{MOx}$ em fase gasosa com o CBMC. . . . . . . . . . . 78

Figura 22 - Evolução do ângulo de diedro $\mathrm{C}=\mathrm{C}-\mathrm{C}=\mathrm{O}$ do $\mathrm{MOx}$ em fase gasosa com os passos de simulação. . . . . . . . . . . . . . . . . . . . . . . . . 79

Figura 23 - Evolução do ângulo de diedro $\mathrm{C}=\mathrm{C}-\mathrm{C}=\mathrm{O}$ do $\mathrm{MOx}$ em água com os passos de simulação. . . . . . . . . . . . . . . . . . . . . . . . 80 80

Figura 24 - Convergência do momento de dipolo do MOx em acetonitrila com o processo iterativo de polarização com simulações e ASEC.

Figura 25 - Convergência do momento de dipolo do MOx em metanol com o processo iterativo de polarização com simulações e ASEC . . . . . . . . . . . . . . 83

Figura 26 - Potencial da rotação do grupo $\mathrm{C}=\mathrm{C}-\mathrm{C}=\mathrm{O}$ do $\mathrm{MOx}$ utilizando as cargas polarizadas nos solventes acetonitrila e metanol.

Figura 27 - Convergência da energia de transição média da banda $\pi-\pi^{*}$ com o número de configurações da simulação CBMC utilizadas para o cálculo do espectro de absorção.

Figura 28 - Espectros de absorção do MOx nos ambientes: molécula isolada na conformação syn, em fase gasosa, em metanol e em água. . . . . . . . . . . . . . 89

Figura 29 - Grafo de chamadas do Valgrind do programa DICE na versão 2.9. . . . . . 108

Figura 30 - Speedup $S$ da paralelização em função no número de threads para os dois sistemas teste: com 4000 e 10000 moléculas de água SPC/E. . . . . . . . 109 


\section{Lista de tabelas}

Tabela 1 - Populações relativas de configurações gauche obtidas com simulações de CBMC e dinâmica molecular. . . . . . . . . . . . . . . . . . . . . 59

Tabela 2 - Porcentagem de configurações trans para o DCE em diferentes condições de simulação e solvente. . . . . . . . . . . . . . . . . . . 63

Tabela 3 - Parâmetros de Fourier para os diedros de rotação em torno da ligação entre $\mathrm{C}=\mathrm{C}-\mathrm{C}=\mathrm{O}$ do $\mathrm{MOx}$, ajustados para obter as diferenças de energia em fase gasosa. . . . . . . . . . . . . . . . . . 73

Tabela 4 - Médias dos parâmetros geométricos do MOx analisados nas simulações CBMC e MD em fase gasosa e água. . . . . . . . . . . . . . . . . . . . 77

Tabela 5 - Dados sobre as ligações de hidrogênio entre a molécula de MOx (rígida e flexível) e as moléculas de água partindo das conformações iniciais syn e anti. 78

Tabela 6 - População syn:anti do MOx amostrada em fase gasosa e em diferentes solventes utilizando CBMC, e em fase gasosa e água também utilizando MD. 84

Tabela 7 - Energia de transição $\pi-\pi^{*}$ do MOx em fase gasosa e nos solventes água, metanol e acetonitrila. 



\section{Lista de abreviaturas e siglas}

\begin{tabular}{ll} 
MC & Monte Carlo \\
MD & Dinâmica Molecular \\
QM & Mecânica Quântica \\
MM & Mecânica Molecular \\
CBMC & Configurational Bias Monte Carlo \\
LJ & Lennard-Jones \\
DCE & 1,2-dicloroetano \\
MOx & Óxido mesityl \\
ARM & Método de taxa de aceitação \\
PES & Superfície de energia potencial \\
BFS & Algoritmo de busca em largura \\
DFS & Algoritmo de busca em profundidade \\
PME & Particle Mesh Ewald \\
DFT & Teoria do funcional da densidade \\
TD-DFT & Teoria do funcional da densidade dependente do tempo \\
KS & Kohn-Sham \\
\hline
\end{tabular}





\begin{tabular}{|c|c|}
\hline$N$ & Número de átomos do sistema \\
\hline $\mathbf{r}^{N}$ & Coordenadas atômicas \\
\hline $\mathcal{U}$ & Energia potencial de interação \\
\hline$N_{\text {passos }}$ & Número de passos de $\mathrm{MC}$ \\
\hline$k$ & Constante de Boltzmann \\
\hline$T$ & Temperatura \\
\hline$\beta$ & Temperatura inversa, dada por $1 / k T$ \\
\hline $\mathcal{N}$ & Distribuição de estados \\
\hline$\pi(o \rightarrow n)$ & Probabilidade de transição entre os estados $o$ e $n$ \\
\hline$\alpha(o \rightarrow n)$ & Probabilidade de ocorrer movimento que leva do estado $o$ para o estado $n$ \\
\hline $\operatorname{acc}(o \rightarrow n)$ & $\begin{array}{l}\text { Probabilidade de aceitação do movimento que leva do estado } o \text { para o } \\
\text { estado } n\end{array}$ \\
\hline$\left\{\theta^{n}\right\}$ & Coordenadas internas dos graus de liberdade rígidos \\
\hline$\left\{\phi^{n}\right\}$ & Coordenadas internas dos graus de liberdade maleáveis \\
\hline$N_{\text {frag }}$ & Número total de fragmentos da molécula \\
\hline$\tau$ & Número pseudo-aleatório gerado uniformemente no intervalo $[0,1]$ \\
\hline$N_{\text {del }}$ & Número de fragmentos apagados a serem reconstruídos com o CBMC \\
\hline$\kappa_{\phi}$ & Número de possíveis diedros de inserção gerados a cada passo do CBMC \\
\hline$W$ & Fator de Rosenbluth \\
\hline
\end{tabular}




\begin{tabular}{|c|c|}
\hline$m$ & Massa \\
\hline $\mathbf{F}$ & Vetor de força \\
\hline $\mathbf{v}$ & Vetor de velocidade \\
\hline$\hat{H}$ & Hamiltoniano de muitos corpos \\
\hline$\Psi$ & Função de onda \\
\hline$\hat{K}_{e}$ & Energia cinética eletrônica \\
\hline$\hat{V}_{n e}$ & Potencial de interação elétron-núcleo \\
\hline$\hat{V}_{e e}$ & Potencial de interação elétron-elétron \\
\hline$E_{x c}$ & Energia de troca e correlação \\
\hline$\phi_{i}^{K S}$ & Orbitais de Kohn-Sham \\
\hline$\hat{h}$ & Hamiltoniano de Kohn-Sham \\
\hline$K$ & Constante de equilíbrio \\
\hline$\Delta G$ & Energia livre de Gibbs \\
\hline$N_{\mathrm{mol}}$ & Número de moléculas do sistema \\
\hline$\Delta H_{\text {vap }}$ & Entalpia de vaporização \\
\hline$\delta E_{\text {conf }}$ & Contribuição conformacional à energia de transição eletrônica \\
\hline$\delta E_{\mathrm{CP}}$ & Contribuição devido às cargas pontuais à energia de transição eletrônica \\
\hline$\delta E_{\mathrm{HB}}$ & $\begin{array}{l}\text { Contribuição devido às moléculas formando ligações de hidrogênio e cargas } \\
\text { pontuais à energia de transição eletrônica }\end{array}$ \\
\hline$\delta E_{\text {solv }}$ & $\begin{array}{l}\text { Contribuição devido às moléculas explícitas e cargas pontuais à energia de } \\
\text { transição eletrônica }\end{array}$ \\
\hline
\end{tabular}




\section{Sumário}

INTRODUÇÃO . . . . . . . . . . . . . . . . . 19

1.1

Motivação e justificativa 19

1.2 Métodos Monte Carlo para o estudo de moléculas flexíveis . . . . . 22

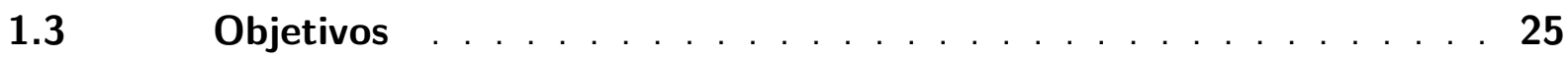

METODOLOGIA . . . . . . . . . . . . . . . . 27

$2.1 \quad$ Energia de interação e campos de força . . . . . . . . . . . . . . . 27

2.2 Metropolis Monte Carlo . . . . . . . . . . . . . . . . . . . . 29

$2.3 \quad$ Configurational Bias Monte Carlo . . . . . . . . . . . . . . . . . . . 31

2.3.1 Separando os graus de liberdade rígidos e maleáveis . . . . . . . . . . . . . 31

2.3.2 Fragmentando a molécula e gerando a biblioteca de fragmentos . . . . . . 34

2.3.3 Unindo fragmentos e critério de aceitação . . . . . . . . . . . . . 36

2.3.4 Viés eletrostático no CBMC . . . . . . . . . . . . . . . . . . . . . . . . . . . 39

2.3.5 Amostragem Preferencial . . . . . . . . . . . . . . . . . . . . . 40

$2.4 \quad$ Implementação do método CBMC no DICE . . . . . . . . . . . . 42

2.4.1 Critério de aceitação no DICE . . . . . . . . . . . . . . . . 42

2.4.2 Detalhes gerais de implementação . . . . . . . . . . . . . . . . . . . . . . 44

2.4.3 Ferramentas do DICEtools . . . . . . . . . . . . . . . . . 46

2.5 Dinâmica Molecular . . . . . . . . . . . . . . . . . . . . 48

$2.6 \quad$ Métodos de mecânica quântica . . . . . . . . . . . . . . . . . . . 50

3 VALIDAC̣ÃO DA IMPLEMENTAC̣ÃO . . . . . . . . . . . . 55

$3.1 \quad$ Octano em fase gasosa . . . . . . . . . . . . . . . . 55

$3.2 \quad 1,2$-Dicloroetano em fase gasosa e em meio solvente . . . . . . . . . 61

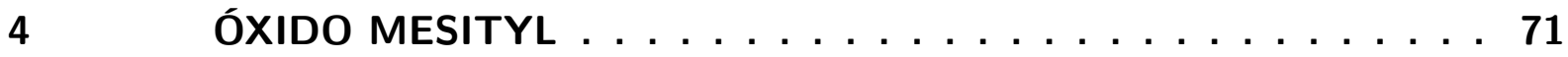

$4.1 \quad$ Motivação . . . . . . . . . . . . . . . . . . . . 71

$4.2 \quad$ Parametrização . . . . . . . . . . . . . . . . . . . 72

$4.3 \quad$ Equilíbrio conformacional em gás e água . . . . . . . . . . . . . . 73

$4.4 \quad$ Efeito da polarização do soluto pelo solvente . . . . . . . . . . 81

$4.5 \quad$ Espectro de absorção e solvatocromismo . . . . . . . . . . . . . . . 85

$5 \quad$ CONCLUSÃO $\ldots \ldots \ldots \ldots \ldots$ 


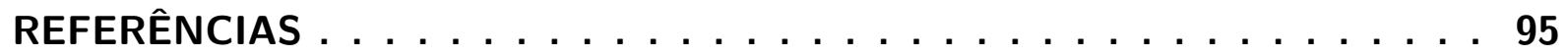

$\begin{array}{ll}\text { APÊNDICES } & 105\end{array}$

APÊNDICE A - DESEMPENHO E PARALELIZAÇÃO DO DICE . . 107 APÊNDICE B $\quad-$ FERRAMENTAS DO DICETOOLS . . . . . 111

APÊNDICE C - ARQUIVOS DE ENTRADA OCTANO . . . . . 115

APÊNDICE D - ARQUIVOS DE ENTRADA 1,2-DICLOROETANO . . 121

APÊNDICE E - ARQUIVOS DE ENTRADA ÓXIDO MESITYL . . . 125 


\section{Capítulo 1}

\section{Introdução}

Neste capítulo, será apresentada a motivação para o estudo de métodos de Monte Carlo aplicados a amostragem configuracional dos graus de liberdade internos de moléculas flexíveis. Também será feita uma breve revisão sobre os métodos atualmente disponíveis e os métodos que motivaram o desenvolvimento desses. Por fim, os objetivos do trabalho e a estrutura do texto serão apresentados.

\subsection{Motivação e justificativa}

A modelagem molecular de problemas com métodos de mecânica quântica ou de mecânica molecular ganhou espaço nas últimas décadas, devido ao aumento de poder computacional e a possibilidade do entendimento de processos no nível atômico. Com os métodos de química quântica, por exemplo, é possível obter conhecimento sobre a estrutura eletrônica e propriedades espectroscópicas da molécula ou material estudado. Entretanto, o custo computacional de cálculos quânticos ainda é alto quando se trata de sistemas com centenas de átomos, mesmo com métodos considerados mais baratos como a teoria do funcional de densidade (DFT, do inglês density functional theory).

Propriedades de moléculas em meio condensado em geral diferem das propriedades de moléculas na fase gasosa. ${ }^{[2]} \mathrm{O}$ efeito causado pelo ambiente sob a molécula de estudo costuma alterar suas propriedades estruturais e eletrônicas, portanto, a inclusão desses efeitos se torna necessária para uma compreensão completa dos fenômenos e predição de propriedades. A inclusão do efeito médio sob a molécula de estudo pode ser feita, por exemplo, com o uso de uma constante dielétrica tratando o solvente como um meio contínuo. A ideia de tratar o solvente como um contínuo tem sua origem nas primeiras décadas do século passado, ${ }^{\left[{ }^{-5}\right]}$ e continua sendo desenvolvida ${ }^{[6,7]}$ por se tratar de uma maneira computacionalmente barata de se incluir o efeito solvente. Contudo, em casos onde interações específicas desempenham um papel importante como, por exemplo, em ligações de hidrogênio ou processos de transferência de carga, a inclusão de moléculas explícitas do solvente é fundamental. Nesses casos, como a inclusão de várias moléculas explícitas torna o custo computacional de cálculos quânticos 
proibitivo, tipicamente somente as moléculas mais próximas formando a microsolvatação, são consideradas. Surge portanto a necessidade de se determinar o número de moléculas explícitas a serem incluídas, e também as suas posições. Uma solução para esse problema se dá através do uso de amostragem configuracional com simulações, de onde configurações podem ser extraídas e subsequentemente utilizadas em cálculos quânticos.

Por outro lado, o custo computacional de cálculos quânticos restringe não só o número de átomos do sistema estudado, como também a duração das simulações realizadas com tal descrição. Simulações de dinâmica molecular (MD, do inglês molecular dynamics) ou Monte Carlo (MC) de primeiros princípios, ${ }^{*}$ em sistemas com algumas dezenas de átomos, costumam ter a duração máxima da ordem de dezenas de pico segundos no caso da $\mathrm{MD}^{[8]}$ ou até centenas de milhares de passos no caso do MC. ${ }^{[9-12]}$ Em sistemas com um grande número de átomos ou onde as escalas temporais dos eventos excede a capacidade atual de simulação com métodos de primeiros princípios, o uso de métodos de mecânica molecular, que utilizam campos de força clássicos, ${ }^{[13,14]}$ aparece como uma opção.

Apesar das simulações de mecânica molecular não descreverem as interações interatômicas com a mecânica quântica, e utilizarem expressões simples para as interações intra e inter moleculares, essas tem um custo computacional muito mais acessível, e fornecem resultados em boa concordância com os dados experimentais se realizadas de maneira adequada. Nesse tipo de simulação milhares de átomos podem ser utilizados sem grandes problemas, podendo também ter uma duração muito maior do que as simulações com métodos de primeiros princípios. Na realidade, apesar de simulações de primeiros princípios terem se tornado mais comuns nos últimos anos, atualmente a grande maioria das simulações continuam sendo realizadas utilizando campos de força clássicos, justamente pelo custo computacional.

Basicamente, duas classes principais de métodos são hoje em dia utilizadas para a simulação molecular: a MD e os métodos de MC. A MD é uma metodologia muito bem estabelecida ${ }^{[13,14]}$ que utiliza forças e equações de movimento para realizar a evolução temporal de trajetórias atômicas. Com o auxílio da mecânica estatística, essas trajetórias são utilizadas para computar as propriedades de equilíbrio e analisar a dinâmica do sistema estudado. Já os métodos de $M C^{[13-15]}$ utilizam-se de números pseudo-aleatórios para gerar configurações, e através de sucessivos testes para a aceitação ou rejeição dessas configurações, constroem amostras de um ensemble. O critério de aceitação, por sua vez, é obtido através da imposição que uma distribuição de equilíbrio que vem do ensemble a ser simulado deve ser amostrada. Nos métodos de MC, diferente da MD, não há informação temporal, e portanto não é possível obter informações sobre a dinâmica do sistema.

Nas últimas décadas, o uso de MD com campos de força clássicos se tornou extremamente popular, e a técnica vem sendo aplicada com grande sucesso. Os sistemas estudados com essa metodologia vão desde biomoléculas como peptídeos, proteínas e bicamadas lipídicas ${ }^{[16-18]}$

\footnotetext{
*Em simulações de primeiros princípios as forças e energias são obtidas com cálculos quânticos.
} 
a nanopartículas em interfaces ${ }^{[19]}$. Parte desse sucesso se deve ao número de implementações estáveis do método que estão disponíveis à comunidade. Códigos como o GROMACS, ${ }^{[20,21]}$ AMBER, ${ }^{[22]} \mathrm{NAMD}^{[23]}$ ou LAMMPS, ${ }^{[24]}$ por exemplo, são desenvolvidos a anos e possuem uma grande base de usuários e diversas ferramentas de análise disponíveis.

Contudo, apesar da popularidade dos métodos com MD, se a dinâmica ou a cinética do sistema não é de interesse, métodos de MC podem ser mais vantajosos. Por exemplo, o método sequencial $\mathrm{QM} / \mathrm{MM}{ }^{[25]}$ que mescla o uso de métodos de mecânica quântica e mecânica molecular para a descrição do sistema, tipicamente utiliza as configurações de equilíbrio da mecânica molecular para cálculos de mecânica quântica de propriedades. Nesse caso, o interesse sob a simulação reside em encontrar as configurações de equilíbrio no ensemble desejado, e não em obter propriedades cinéticas ou observar a dinâmica dos átomos. Para esses tipos de situações, simulações com MC podem ser vantajosas por não exigirem que forças sejam computadas, reduzindo o custo computacional, e também por permitirem movimentos "não físicos" que podem acelerar o processo de amostragem.

O número de códigos com MC existentes é muito grande, a maioria deles focado em aplicações específicas e com a distribuição restrita apenas dentro do grupo de pesquisa desenvolvedor. Para simulação molecular, alguns códigos se destacam como, por exemplo, o BOSS, ${ }^{[26]}$ CASSANDRA, ${ }^{[27]}$ Towhee, ${ }^{[28]}$ DICE$^{[29]}$ e DIADORIM. ${ }^{[30]}$ Esses dois últimos são desenvolvidos por grupos brasileiros. Não existe no entanto um código que seja apontado como referência em simulações moleculares com MC, especialmente quando o objetivo é a simulação de moléculas flexíveis em ensembles fechados.

Existem trabalhos como os de Jorgensen e Tirado-Rives ${ }^{[31]}$ e Ulmschneider, Ulmschneider e Nola ${ }^{[32]}$ que fazem uma comparação direta entre MC e MD para amostragem conformacional de alguns sistemas. Em outros estudos realizados de maneira independente, como os de Hernandes et al. ${ }^{[33]}$ e Oliveira et al. ${ }^{[34]}$ com MC e Murugan e Ågren ${ }^{[35]}$ com MD de primeiros princípios, também chegam a resultados similares para mudanças conformacionais em diferentes solventes. De uma maneira geral, os resultados de simulações de MC e MD para estudos conformacionais concordam comparativamente, conforme o esperado. Esses estudos, no entanto, tratam de sistemas com barreiras conformacionais de até $4 \mathrm{kcal} / \mathrm{mol}$. Um estudo comparativo de ambas as metodologias para sistemas com barreiras conformacionais de $10 \mathrm{kcal} / \mathrm{mol}$ ou maiores é importante, pois, listando alguns exemplos, existem resultados experimentais de estudos de equilíbrio conformacional com populações axial/equatorial de $50 \%$ com barreiras de $\sim 10 \mathrm{kcal} / \mathrm{mol}^{[36]}$ razão de população syn $/$ anti de $95 \%$ com barreira de $\sim 11 \mathrm{kcal} / \mathrm{mol}^{[37]}$ e razão de população cis $/$ trans de $85 \%$ com barreira de $\sim 17 \mathrm{kcal} / \mathrm{mol}^{[38]}$ 


\subsection{Métodos Monte Carlo para o estudo de moléculas flexíveis}

A primeira simulação com MC foi feita por Metropolis et al. ${ }^{[15]}$ que cunharam o termo Monte Carlo devido ao uso de números aleatórios em sua simulação de esferas rígidas. Desde então, o método vem sendo utilizado para a simulação dos mais variados sistemas, desde modelos de spin na rede, ${ }^{[39]}$ passando por gases e líquidos ${ }^{[13,14]}$ e indo até sistemas sólidos como clusters e nanopartículas. ${ }^{[40,41]} \mathrm{O}$ coração do método se mantém intacto ao longo dos anos, um método de amostragem de cadeia de Markov que se utiliza de uma regra para a aceitação ou rejeição de novos estados, gerando uma distribuição de equilíbrio. Contudo, limitações do método original proposto por Metropolis em sistemas com superfícies de energia potencial complexas, ou quanto aos movimentos realizados, levaram ao aprimoramento da técnica em algumas situações.

Por exemplo, o método de Metropolis MC convencional é, em geral, ineficiente para a amostragem conformacional de moléculas. Isso ocorre devido às diferentes escalas de energia envolvidas nos campos de força intramoleculares. Tipicamente, variações em comprimentos de ligação levam a diferenças de energia muito maiores que variações angulares, que por sua vez levam a variações de energia maiores que variações em ângulos de diedro. Por esse motivo, deslocamentos atômicos aleatórios costumam ser ineficientes, já que de maneira geral mudanças em ângulos de diedro centrais de uma molécula envolvem diversos movimentos coletivos, enquanto o comprimento de ligação pode ser drasticamente alterado com um único deslocamento. Essa é a razão pela qual novas propostas de movimentos e métodos vem sendo feitas, para alcançar uma amostragem eficiente e ergódica de configurações intramoleculares, e também permitir a simulação em diferentes ensembles.

Historicamente, os algoritmos propostos para novos movimentos para mudanças conformacionais moleculares no método de $M C$ são dependentes do sistema, já que a proposta de um algoritmo geral não é trivial. Além disso, focando em uma classe específica de sistemas físicos, é possível desenvolver movimentos de $\mathrm{MC}$ que tornem a amostragem daquele tipo de sistema mais eficiente. Um sistema simples e de interesse físico que permite o desenvolvimento de algoritmos desse tipo são cadeias do tipo poliméricas. Nesse tipo de sistema diversos monômeros são conectados uns aos outros, no caso mais simples átomos são conectados de maneira linear, formando um polímero. Em cadeias não lineares, em geral a complexidade do algoritmo também aumenta. Nos próximos parágrafos será feita uma breve revisão sobre alguns algoritmos para polímeros, pois os mesmos servem de base, ou ao menos de inspiração, para algoritmos que podem ser generalizados para o estudo de moléculas quaisquer em solução, que por sua vez é o objetivo de estudo deste trabalho. Vale mencionar no entanto, que irei me ater a algoritmos que possuem versões aplicáveis a sistemas fora da rede, apesar de muitos desses mesmos algoritmos terem também versões que podem ser aplicadas na rede. Para uma revisão de métodos de amostragem de cadeias na rede, veja Kremer e Binder. ${ }^{[42]}$ 
Diversos algoritmos foram e vem sendo propostos para o estudo de sistemas poliméricos simples, a maioria deles, utilizando formas criativas para realizar o movimento dos átomos na cadeia, ou ainda reconstruir parcialmente a cadeia. ${ }^{[43]}$ Alguns desses algoritmos não são interessantes quando o objetivo é a generalização dos métodos para a aplicação em sistemas mais gerais, como moléculas em sistemas soluto-solvente, por se limitarem a modelos simples sem ramificações, ou por alterarem não somente a forma, mas também a conectividade das cadeias. * Esses são o caso, por exemplo, de algoritmos como o reptation, ${ }^{[4]}$ end-bridging Monte Carlo[45] ou double-bridging Monte Carlo. ${ }^{[46]}$ Outros algoritmos, no entanto, exibem ideias que parecem mais promissoras no objetivo da construção de algoritmos de amostragem conformacional para moléculas mais complexas. Um desses algoritmos é conhecido como CONROT (do inglês, concerted rotations), ${ }^{[47]}$ e tem como objetivo alterar o interior de cadeias através de mudanças nos ângulos torcionais, mantendo as extremidades fixas. $\mathrm{O}$ desenvolvimento desse algoritmo juntamente a outros algoritmos, como o Configurational Bias Monte Carlo (CBMC) que será descrito a seguir, permitiu com que cadeias mais complexas, incluindo peptídeos cíclicos fossem estudados. ${ }^{[48,49]}$ A dificuldade de utilização do algoritmo CONROT, no entanto, reside no fato de que é necessário o conhecimento prévio dos jacobianos associados ao conjunto de coordenadas onde são realizados os movimentos, o que além de não ser trivial na maioria dos casos, introduz um custo computacional extra.

Outra classe de algoritmos que tem mostrado potencial para a simulação de moléculas em geral, são os métodos de CBMC. ${ }^{[14]}$ Esses métodos surgiram com um artigo de Siepmann e Frenkel ${ }^{[50]}$ e tem como base as ideias de Rosenbluth e Rosenbluth ${ }^{[51]}$, onde as novas configurações são obtidas com a construção e reconstrução de uma cadeia de monômeros. A grande diferença no método CBMC frente ao algoritmo de Rosenbluth, é que as configurações são amostradas da distribuição de Boltzmann. No método de Rosenbluth os pesos das configurações, conhecidos como fatores de Rosenbluth, são utilizados para os cálculos dos valores médios de propriedades, de modo que os valores esperados obtidos refletem a média do ensemble. No CBMC, o fator de Rosenbluth aparece como um viés na aceitação do movimento proposto, que surge do balanço detalhado.

De maneira geral, os algoritmos de CBMC quebram a cadeia em algum ponto aleatório e realizam a reconstrução de um dos lados partindo desse ponto, removendo (apagando) os monômeros e os inserindo em novas posições. Esse tipo de movimento costuma afetar mais as extremidades da molécula. Durante a reconstrução, os monômeros são inseridos de maneira aleatória, porém com um bias (daqui em diante chamado de viés) que tende a gerar estruturas mais favoráveis, levando em consideração a energia de interação com o ambiente, até o ponto onde todos os monômeros antes apagados são finalmente inseridos. A dificuldade na utilização desse tipo de algoritmo para moléculas que não são cadeias simples, se dá com as ramificações

\footnotetext{
* Alterar a conectividade ou o tamanho das cadeias é um problema nesse caso, pois normalmente só há uma molécula de soluto em sistemas soluto-solvente, e se espera que essa se mantenha a mesma, o que limita o uso desses algoritmos a moléculas com monômeros idênticos.
} 
e ciclos presentes na cadeia. No caso de ramificações, a abordagem usualmente adotada pelos algoritmos CBMC é a inserção simultânea dos átomos que compõem o ramo, o que na prática se mostra ineficiente. ${ }^{[14]}$ Tentativas de melhorar a eficiência da inserção dos átomos em ramos continuam sendo feitas, ${ }^{[52]}$ de modo que a eficiência tem aumentado drasticamente.

Dois algoritmos propostos no final do século passado ${ }^{[53,54]}$ se mostram promissores para a simulação de moléculas com ramificações e anéis. Ambos os algoritmos se baseiam na decomposição dos graus de liberdade internos da molécula em rígidos e maleáveis. $A$ ideia é que graus de liberdade rígidos, como comprimentos de ligação e ângulos de ligação, tem a energia sensível a pequenas mudanças, enquanto graus de liberdade maleáveis, como ângulos de diedro e termos não ligados, são menos sensíveis a pequenas variações e possuem muitas vezes mais de um mínimo local.

Um desses algoritmos foi proposto por Martin e Siepmann ${ }^{[14,53]}$ em um esquema chamado "coupled-decoupled", que é de certa forma similar a um método chamado parallel Monte Carlo ${ }^{[55]}$ reportado alguns anos antes. Nesse algoritmo, os graus de liberdade são separados e um viés diferente é aplicado em cada um deles. No caso dos graus de liberdade rígidos, um novo vetor que define o ângulo do monômero inserido com o restante da cadeia é gerado com um esquema decoupled, onde um único ângulo é selecionado a partir de um conjunto de ângulos selecionados aleatoriamente. Partindo desse ângulo, novos ângulos de diedro são gerados com um esquema enviesado (biased) coupled, que gera não somente um ângulo de diedro, mas vários.* Esses ângulos de diedro, por sua vez, são passados para serem selecionados (com um novo viés) baseado na energia dos termos não ligados. Esse esquema tem a vantagem de que gera a distribuição correta mesmo em cadeias com ramos, e é na verdade uma alternativa mais eficiente do que o esquema de rejeição que insere todos os átomos do ramo simultaneamente. ${ }^{[14]}$ Contudo, a limitação de que não é possível simular moléculas que possuam anéis em sua cadeia permanece nessa metodologia. Além disso, um grande número de configurações é gerado a cada passo, das quais a maior parte é rejeitada e serve apenas como possível configuração nos fatores de Rosenbluth, o que torna o algoritmo computacionalmente ineficiente. Wick e Siepmann ${ }^{[56]}$ desenvolveram um algoritmo baseado no esquema "coupled-decoupled" que é capaz de modificar o interior de cadeias e moléculas cíclicas, contudo não fica claro no algoritmo como lidar com anéis ligados a cadeias lineares. Um trabalho similar ao de Wick e Siepmann ${ }^{[56]}$ feito por Chen e Escobedo ${ }^{[57]}$ também não deixa claro como lidar com esses casos. Somente mais recentemente que melhorias ao método que endereçam o problema de moléculas com ramificações e anéis, além de melhorar a eficiência do método, foram desenvolvidas. ${ }^{[58-60]}$

O outro algoritmo surge de um método CBMC chamado branch-point sampling, proposto por Macedonia e Maginn ${ }^{[54]}$ e que faz a amostragem de ramificações. No branch-point sampling as moléculas são fragmentadas em partes menores, compostas dos graus de liberdade rígidos,

\footnotetext{
*Esses ângulos de diedro são gerados de maneira independente.
} 
que são amostradas de maneira independente antes da simulação, formando um conjunto de configuraç̃ões disponíveis. A esse conjunto é dado o nome de biblioteca de configurações ou biblioteca de fragmentos. Essas partes, chamadas de fragmentos, são selecionadas a cada passo de reconstrução da molécula e são unidas por movimentos de CBMC feitos sobre os graus de liberdade maleáveis. A ideia de um reservatório de configurações também foi explorada mais tarde, mas no conceito de ensembles abertos e com a utilizações de moléculas inteiras e não fragmentadas nas bibliotecas, permitindo inclusive o uso de moléculas cíclicas com modelos de átomos unidos. ${ }^{[61,62]}$ Alguns anos mais tarde, o algoritmo e a ideia do branch-point sampling foram generalizados por Shah e Maginn ${ }^{[1]}$, permitindo a amostragem de fragmentos de anéis simples nas bibliotecas, formando então um algoritmo para simulação de moléculas com um número qualquer de ramos e anéis simples. Esse algoritmo foi implementado no código Cassandra, ${ }^{[27,63]}$ onde mais detalhes sobre a implementação estão disponíveis.

\subsection{Objetivos}

O objetivo deste trabalho é o desenvolvimento de um método de Monte Carlo, implementado no programa DICE, ${ }^{[29]}$ para a amostragem dos graus de liberdade internos de moléculas em meio solvente. Com essa finalidade em mente, o algoritmo CBMC de Shah e Maginn ${ }^{[1,27]}$ foi modificado e implementado. Visando a aplicação em sistemas soluto-solvente e a utilização com moléculas de complexidade ainda maior, não somente compostas de cadeias e anéis simples, o algoritmo foi estendido para a utilização com fragmentos de qualquer complexidade. Essa nova versão do algoritmo, permite também que partes das moléculas possam ser mantidas completamente rígidas, simplificando o arquivo de entrada com a topologia nesses casos. Durante o processo da implementação do algoritmo, o código DICE foi otimizado, modernizado e paralelizado com o esquema de memória compartilhada OpenMP, ${ }^{[64]}$ impactando positivamente o desempenho do código de maneira geral. Detalhes sobre o algoritmo e sua implementação são apresentados no capítulo 2.

Para a validação do método e da implementação, dois sistemas foram estudados. Simulações de octano $\left(\mathrm{C}_{8} \mathrm{H}_{18}\right)$ em fase gasosa foram feitas com o algoritmo CBMC e com dinâmica molecular, visando a comparação entre as duas metodologias e permitindo verificar a consistência dos resultados obtidos para as geometrias em cada caso. Além disso, simulações de 1,2-dicloroetano ( $D C E, \mathrm{C}_{2} \mathrm{H}_{4} \mathrm{Cl}_{2}$ ) em gás, líquido puro e nos solventes acetonitrila e ciclohexano, foram também realizadas com as duas metodologias. Para o caso do DCE, resultados experimentais e de outras simulações de $M C$ também foram utilizados na comparação. De maneira geral, os resultados condizem com o esperado, e mostram que a implementação está correta. Os resultados para essas simulações são apresentados no capítulo 3.

A molécula de óxido mesityl $\left(\mathrm{MOx},\left(\mathrm{CH}_{3}\right)_{2} \mathrm{C}=\mathrm{CHC}(=\mathrm{O}) \mathrm{CH}_{3}\right)$ será estudada no capítulo 4 por meio de simulações CBMC e MD e cálculos do espectro de absorção com DFT 
dependente do tempo. A MOx, que é um modelo para cetonas maiores, possui dois mínimos em sua superfície de energia potencial, referente às conformações syn e anti. As populações dessas conformações são dependentes do solvente, assim como o máximo da banda de absorção $\pi-\pi^{*}$. Por esse motivo, a MOx foi estudada em fase gasosa e nos solventes acetonitrila, metanol e água. Utilizando o CBMC obtivemos que a população de confôrmeros anti aumenta conforme a polaridade do solvente, como esperado. Mostramos também que devido a barreira da ordem de $10 \mathrm{kcal} / \mathrm{mol}$ entre as duas conformações acessíveis, a MD não consegue fazer uma amostragem ergódica em tempos de simulação típicos de até 400 ns. Esse problema devido à barreira de energia não é observado na simulação CBMC, indicando que para barreiras dessa ordem, o uso da metodologia pode ser mais adequado do que o da MD sem técnicas de aprimoramento da amostragem. Analisando o espectro de absorção, vemos que a contribuição conformacional é fundamental para uma boa descrição da energia de transição da banda mais intensa.

As conclusões referentes ao método desenvolvido e aplicação nos sistemas estudados são apresentadas no capítulo 5 .

Neste texto o ponto será utilizado como separador decimal, ao invés da vírgula usualmente empregada no Brasil. 


\section{Capítulo 2}

\section{Metodologia}

Neste capítulo, será introduzido o método de Monte Carlo utilizado para adicionar a flexibilidade intramolecular ao programa DICE. O método chamado de Configurational Bias Monte Carlo, fragmenta a molécula em partes menores, e reconstrói a molécula baseado nessas partes. Uma breve descrição do método de dinâmica molecular também será apresentada.

\subsection{Energia de interação e campos de força}

Antes de iniciar a descrição dos métodos utilizados, e descrever o desenvolvimento da metodologia, é necessário definir como é dada a interação entre os átomos das moléculas estudadas. Como já é conhecido, a energia de interação entre moléculas e átomos é descrita pela mecânica quântica. A simulação de sistemas moleculares deveria, portanto, ser feita utilizando métodos de mecânica quântica, também conhecidos como métodos de primeiros princípios ou métodos ab-initio, para o cálculo das energias de interação utilizadas pelos métodos de amostragem de configurações. Contudo, a descrição da interação utilizando métodos ab-initio ou ainda a teoria do funcional de densidade, se torna inviável quando levado em consideração o número de átomos presentes no sistema, e que milhões de configurações são necessárias para garantir uma boa amostragem. Simulações com dinâmica molecular ab-initio, por exemplo, costumam estar restritas a sistemas com até algumas centenas de átomos e em simulações da ordem de pico segundos. Como o objetivo desse trabalho é o estudo de sistemas soluto solvente com tamanhos que tipicamente excedem os limites que tornariam viáveis o uso de métodos de primeiros princípios, campos de força clássicos serão utilizados.

A maior parte dos campos de força atualmente utilizados têm uma forma funcional parecida. ${ }^{[13,14,65]}$ Energias de interação de ligação e ângulo são em geral descritas por um potencial harmônico, enquanto a descrição das energia de diedro podem ser descritas por uma forma funcional de Fourier ou Ryckaert-Bellemans. Já as interações não ligadas costumam ter a mesma forma funcional, considerando a energia de Coulomb e Lennard-Jones. Portanto, a energia total de interação de um sistema utilizando os potenciais clássicos mais comumente 
utilizados para sistemas moleculares, tem a forma

$$
\mathcal{U}\left(\mathbf{r}^{N}\right)=u_{\text {bond }}+u_{\text {angle }}+u_{\text {torsional }}+u_{\text {improper }}+u_{\mathrm{nb}},
$$

onde $\mathbf{r}^{N}$ representa a configuração dos $N$ átomos do sistema, $u_{\text {bond }}$ é o potencial que descreve a vibração entre átomos ligados (interação 1-2), $u_{\text {angle }}$ é o potencial que descreve a vibração

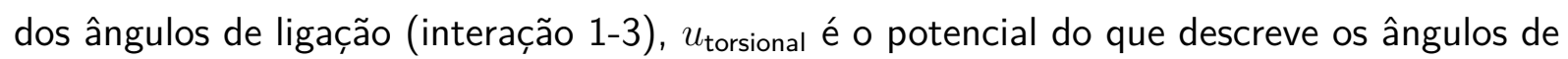

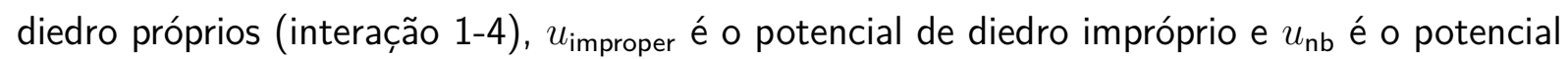
de interação de átomos não ligados.

A atual implementação das formas funcionais de campos de força no DICE considera os campos de força OPLS-AA ${ }^{[66,67]}$ e AMBER. ${ }^{[68,69]}$ Nesses campos de força, a energia de interação de ligações, ângulos e diedros impróprios têm, respectivamente, a forma funcional

$$
\begin{aligned}
u_{\text {bond }} & =\sum_{\text {bonds }} K_{\mathrm{r}}\left(r-r_{\mathrm{eq}}\right)^{2}, \\
u_{\text {angle }} & =\sum_{\text {angles }} K_{\theta}\left(\theta-\theta_{\mathrm{eq}}\right)^{2}, \\
u_{\text {improper }} & =\sum_{\text {improper }} K_{\phi}\left(\phi-\phi_{\mathrm{eq}}\right)^{2},
\end{aligned}
$$

sendo $K_{\mathrm{r}}, K_{\theta}$ e $K_{\phi}$ as constantes que determinam a profundidade do poço de interação e $r_{\text {eq }}$, $\theta_{\text {eq }}$ e $\phi_{\text {eq }}$ os pontos de equilíbrio. Os parâmetros são específicos de cada conjunto de átomos envolvidos na interação. Já os diedros próprios são dados por

$$
u_{\text {torsional }}=\sum_{i \in \text { dihedrals }} \frac{V_{1}^{i}}{2}\left[1+\cos \left(\phi_{i}+f_{1}^{i}\right)\right]+\frac{V_{2}^{i}}{2}\left[1+\cos \left(2 \phi_{i}+f_{2}^{i}\right)\right]+\frac{V_{3}^{i}}{2}\left[1+\cos \left(3 \phi_{i}+f_{3}^{i}\right)\right],
$$

com os coeficientes $V_{1}^{i}, V_{2}^{i}$ e $V_{3}^{i}$ determinados pelos tipos de átomos envolvidos nos diedros, enquanto as fases $f_{1}^{i}, f_{2}^{i}$ e $f_{3}^{i}$ costumam ser nulas para os potenciais OPLS-AA e AMBER. Por fim, as interações não ligadas, tanto intra quanto inter molecular, são dadas por

$$
u_{\mathrm{nb}}=\sum_{i} \sum_{j}\left[f_{i j}^{\mathrm{C}} \frac{q_{i} q_{j} e^{2}}{r_{i j}}+f_{i j}^{\mathrm{LJ}} 4 \epsilon_{i j}\left(\frac{\sigma_{i j}^{12}}{r_{i j}^{12}}-\frac{\sigma_{i j}^{6}}{r_{i j}^{6}}\right)\right]
$$

com a soma sendo feita para $i<j$, as constantes $f_{i j}^{C}$ e $f_{i j}^{L J}$ assumindo diferentes valores dependendo do tipo de interação, $e$ sendo a carga elementar, $r_{i j}$ a distância entre os átomos $i$ e $j, q_{i}$ um parâmetro que dá a carga do átomo e os $\epsilon_{i j}$ e $\sigma_{i j}$ sendo parâmetros do potencial de Lennard-Jones, sendo esses últimos melhor descritos abaixo. Para interações intermoleculares $f_{i j}^{C}=f_{i j}^{L J}=1$. Já para as interações intramoleculares, o valor da constante depende do número de ligações entre os átomos, por exemplo, os átomos que definem as extremidades de um ângulo de diedro possuem três ligações entre eles, e definem uma interação chamada de $1-4$. No caso do campo de força OPLS-AA ${ }^{[66]}$, os valores das constantes para as interações intramoleculares são dadas por

$$
f_{i j}^{\mathrm{C}}=f_{i j}^{\mathrm{LJ}}= \begin{cases}0, & \text { se interações } 1-3 \text { e menores; } \\ 0.5, & \text { se interações } 1-4 \\ 1, & \text { se interações } 1-5 \text { ou maiores. }\end{cases}
$$


O campo de força $A M B E R^{[68]}$ por outro lado, tem valores diferentes para $f_{i j}^{C}$ e $f_{i j}^{L J}$, sendo estes dados por

$$
f_{i j}^{C}= \begin{cases}0, & \text { se interações } 1-3 \text { e menores; } \\ 1 / 1.2, & \text { se interações } 1-4 ; \\ 1, & \text { se interações } 1-5 \text { ou maiores }\end{cases}
$$

e

$$
f_{i j}^{\mathrm{LJ}}= \begin{cases}0, & \text { se interações } 1-3 \text { e menores; } \\ 0.5, & \text { se interações } 1-4 \\ 1, & \text { se interações } 1-5 \text { ou maiores. }\end{cases}
$$

As cargas $q_{i}$ e os parâmetros do potencial de Lennard-Jones $\epsilon_{i i}$ e $\sigma_{i i}$ da equação 2.6 são característicos de cada átomo e diferentes para cada campo de força. Para o caso do potencial de Lennard-Jones, a interação entre átomos de espécies diferentes normalmente não tem parâmetros específicos definidos. Por esse motivo, os parâmetros entre pares de átomos para potencial de Lennard-Jones determinados pelas regras de combinação

$$
\begin{aligned}
\epsilon_{i j} & =\sqrt{\epsilon_{i} \epsilon_{j}}, \\
\sigma_{i j} & =\sqrt{\sigma_{i} \sigma_{j}},
\end{aligned}
$$

para o potencial OPLS-AA, e

$$
\begin{aligned}
\epsilon_{i j} & =\sqrt{\epsilon_{i} \epsilon_{j}}, \\
\sigma_{i j} & =\frac{\sigma_{i}+\sigma_{j}}{2},
\end{aligned}
$$

para o AMBER (essas últimas conhecidas como regras de combinação de Lorentz-Berthelot ${ }^{[70,71]}$ ).

\subsection{Metropolis Monte Carlo}

O método de Metropolis Monte Carlo foi introduzido por Metropolis et al. ${ }^{[15]}$ em 1953 como um método que se utiliza de números aleatórios para realizar a amostragem de estados de um sistema com a distribuição de Boltzmann. ${ }^{[13-15]}$ O método é um método de cadeia de Markov Monte Carlo de amostragem por importância, onde novos estados são gerados baseados no estado anterior, e cada novo estado pode ou não ser aceito baseado em um critério de aceitação escolhido para reproduzir a distribuição de Boltzmann.

A amostragem realizada dessa maneira torna possível o cálculo de médias de propriedades como uma média aritmética simples

$$
\langle A\rangle \approx \frac{1}{N_{\text {passos }}} \sum_{i=1}^{N_{\text {passos }}} A_{i},
$$


onde cada $A_{i}$ representa o valor da propriedade para a $i$-ésima configuração, e $N_{\text {passos }}$ é o número de configurações amostradas. Isso é possível devido ao fato que a amostragem das configurações, i.e., os estados, é feita seguindo a distribuição de Boltzmann, onde a probabilidade do sistema estar em um estado $i$ é dada por

$$
\mathcal{N}\left(\mathbf{r}^{N}\right)=\frac{\exp \left[-\beta \mathcal{U}\left(\mathbf{r}^{N}\right)\right]}{\int d \mathbf{r}^{N} \exp \left[-\beta \mathcal{U}\left(\mathbf{r}^{N}\right)\right]},
$$

com $\beta=1 / k T$ dando a temperatura inversa com $k$ sendo a constante de Boltzmann e $T$ a temperatura, $\mathcal{U}\left(\mathbf{r}^{N}\right)$ sendo a energia potencial total de interação da configuração, definida na seção 2.1, e dependente apenas da configuração dos $N$ átomos do sistema. $\mathrm{A} \mathcal{U}\left(\mathbf{r}^{N}\right)$ não inclui a parte cinética da energia, pois nas médias de ensemble essa aparece como a solução analítica do gás ideal, ${ }^{[72]}$ e tem sua contribuição adicionada ao valor médio final das propriedades.

Para encontrar o critério de amostragem que deve ser utilizado para selecionar estados com a equação 2.13 , assume-se que um novo estado é gerado baseado no estado anterior, e que esse novo estado é aceito ou não com uma dada probabilidade. Considere $o$ (de old) como o estado inicial, e $n$ (de new) o novo estado proposto pelo movimento do método de MC, cada um representando um conjunto de posições atômicas. A probabilidade de transição entre o estado $o$ e o estado $n$ é dada por $\pi(o \rightarrow n)=\alpha(o \rightarrow n)$ acc $(o \rightarrow n)$, i.e., o produto da probabilidade $\alpha(o \rightarrow n)$ de gerar o movimento que leva o sistema do estado $o$ para o estado $n$, e $\operatorname{acc}(o \rightarrow n)$ a probabilidade de aceitação desse mesmo movimento.

A condição do balanço detalhado

$$
\mathcal{N}(o) \operatorname{acc}(o \rightarrow n) \alpha(o \rightarrow n)=\mathcal{N}(n) \operatorname{acc}(n \rightarrow o) \alpha(n \rightarrow o)
$$

é uma condição suficiente para a amostragem da distribuição $\mathcal{N}(i),{ }^{[73]}$ e partindo dela o critério de aceitação $\operatorname{acc}(o \rightarrow n)$ para os movimentos pode ser encontrado. No método de Metropolis, ${ }^{[15]}$ a probabilidade de realizar o movimento que leva o sistema do estado $o$ para o $n$ é igual à probabilidade do movimento que leva do estado $n$ para o estado $o$, ou seja, $\alpha(o \rightarrow n)=\alpha(n \rightarrow o)$. Com essa condição e utilizando a condição de Metropolis que faz $\operatorname{acc}(n \rightarrow o)=1$ se $n$ tiver uma energia menor do que $o$, temos

$$
\operatorname{acc}(o \rightarrow n)=\min \{1, \exp [-\beta(\mathcal{U}(n)-\mathcal{U}(o))]\}
$$

Vale ressaltar que o critério de aceitação dos movimentos dado pela equação 2.15 depende apenas da diferença de energia entre os dois estados. Portanto, não é necessário o cálculo da função de partição configuracional, que caso fosse necessária, tornaria inviável esse tipo de simulação já que a mesma depende de todos os estados acessíveis ao sistema. Além disso, vemos que em nenhum momento da utilização do método é necessário o cálculo de forças, o que faz com que o método de Metropolis tenha uma vantagem, ao menos a princípio, frente a dinâmica molecular com relação a custo computacional. 


\subsection{Configurational Bias Monte Carlo}

Os métodos de bias Monte Carlo são baseados no conceito de que, diferentemente do que é proposto no método de Metropolis, as probabilidades de realizar um movimento entre dois diferentes estados não são necessariamente iguais nos movimentos de ida e volta, i.e., $\alpha(o \rightarrow n) \neq \alpha(n \rightarrow o) .{ }^{[14]}$ Esse esquema de amostragem também leva ao balanço detalhado se modificarmos o critério de aceitação dos movimentos da equação 2.15 para compensar o viés introduzido.

Para mostrar isso, partimos do balanço detalhado da equação 2.14. Se escolhermos $\alpha(o \rightarrow n)=f[\mathcal{U}(n)]$, onde $f$ é uma função qualquer da energia, e fizermos de maneira análoga ao método de Metropolis descrito na seção 2.2, obtemos um novo critério de aceitação dos movimentos

$$
\operatorname{acc}(o \rightarrow n)=\min \left(1, \frac{f[\mathcal{U}(o)]}{f[\mathcal{U}(n)]} \exp \{-\beta[\mathcal{U}(n)-\mathcal{U}(o)]\}\right),
$$

onde foi novamente utilizada a distribuição de Boltzmann para os estados da equação 2.13. Os esquemas de bias Monte Carlo então, criam modos de se favorecer a amostragem dos estados mais relevantes através da definição da função $f$, i.e., criando esquemas criativos de amostragem com viés que pode ser removido na aceitação.

\subsubsection{Separando os graus de liberdade rígidos e maleáveis}

Como mencionado no capítulo 1, a estratégia de amostragem com CBMC escolhida neste trabalho é baseada na fragmentação das moléculas em partes que são constituídas dos graus de liberdade rígidos, e unidas por graus de liberdade maleáveis. ${ }^{[1,54]}$ Um exemplo fictício de como é feita a fragmentação pode ser visto na figura 1 , onde uma molécula é fragmentada em 4 fragmentos. O objetivo dessa separação dos graus de liberdade é permitir a construção de uma estratégia de CBMC para a amostragem dos graus de liberdade maleáveis. Com essa estratégia, os graus de liberdade rígidos são amostrados previamente com algoritmos de MC já estabelecidos (que serão descritos na subseção 2.3.2), e posteriormente a molécula é reconstruída unindo tais fragmentos em ligações comuns, com ângulos de inserção selecionados com CBMC. Nesta subseção é discutida a separação dos termos da energia e a composição da probabilidade $\alpha(o \rightarrow n)$, essenciais para a descrição do método.

Em aspectos práticos, a separação dos graus de liberdade consiste da separação da energia entre os termos relevantes. A energia potencial total de um estado $n$ é dada por

$$
\mathcal{U}(n)=\mathcal{U}\left(\left\{\theta^{n}\right\}\right)+\mathcal{U}\left(\left\{\phi^{n}\right\}\right),
$$

onde $\left\{\theta^{n}\right\}$ representa os graus de liberdade rígidos vindos das ligações, ângulos, e também de alguns diedros e interações não ligadas em casos como o de anéis. Já o termo de $\left\{\phi^{n}\right\}$ dá as 


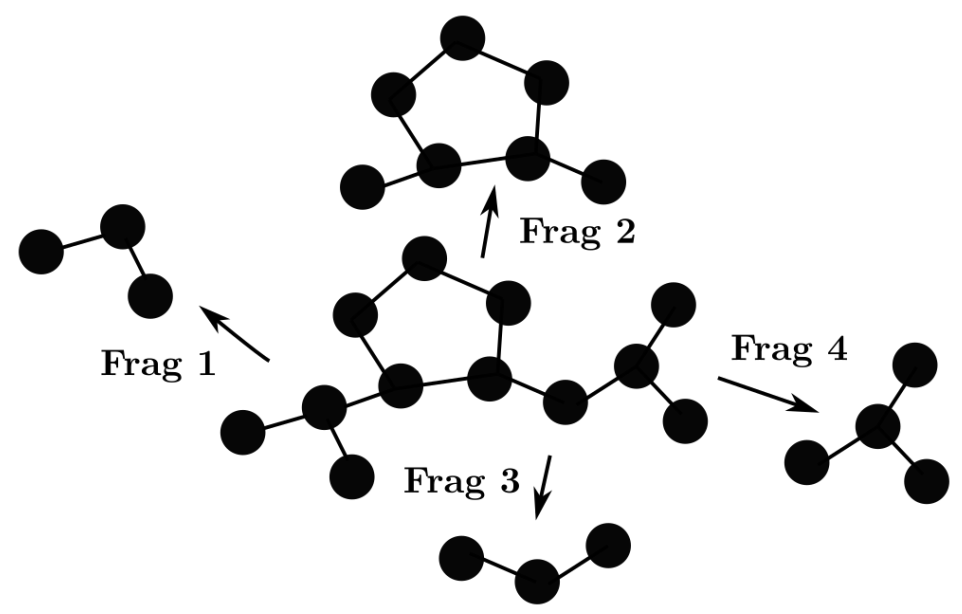

Figura 1 - Exemplo de fragmentação de uma molécula fictícia. Cada um dos círculos pretos representaria um átomo, e as linhas representam as ligações químicas formadas entre eles.

energias de diedro, de interação intramolecular não ligada e intermolecular não ligada. Dentro do esquema de fragmentos, essa energia pode ainda ser separada em termos que compõem a energia potencial total de um fragmento

$$
\begin{aligned}
\mathcal{U}\left(\left\{\theta^{n}\right\}\right) & =\sum_{i=1}^{N_{\text {frag }}} u\left(\left\{\theta_{i}^{n}\right\}\right), \\
\mathcal{U}\left(\left\{\phi^{n}\right\}\right) & =\sum_{i=1}^{N_{\text {frag }}} u\left(\left\{\phi_{i}^{n}\right\}\right),
\end{aligned}
$$

onde $N_{\text {frag }}$ é o número total de fragmentos em que a molécula foi decomposta.

Dada essa separação dos graus de liberdade, podemos construir a probabilidade de gerar um novo estado como um produto de duas probabilidades

$$
\alpha(o \rightarrow n)=P_{o \rightarrow n}^{\text {rígido }} P_{o \rightarrow n}^{\text {maleável }}
$$

onde $P_{o \rightarrow n}^{\text {maleável }}$ vem da amostragem feita com o CBMC e é responsável pela união dos fragmentos, enquanto $P_{o \rightarrow n}^{\text {rígido }}$ vem da probabilidade de seleção de um fragmento dentro de bibliotecas de fragmentos, na qual os graus de liberdade rígidos $\left\{\theta_{i}^{n}\right\}$ são previamente amostrados, e onde

$$
P_{o \rightarrow n}^{\text {ríigio }}=\prod_{i=1}^{N_{\text {frag }}} P_{i}^{\mathrm{frag}}\left(\left\{\theta_{i}^{n}\right\}\right),
$$

sendo $P_{i}^{\text {frag }}$

$$
P_{i}^{\mathrm{frag}}\left(\left\{\theta_{i}^{n}\right\}\right)=\frac{\exp \left[-\beta u\left(\left\{\theta_{i}^{n}\right\}\right)\right] J\left(\left\{\theta_{i}^{n}\right\}\right) \delta\left\{\theta_{i}^{n}\right\}}{Z_{i}},
$$

com $J\left(\left\{\theta_{i}^{n}\right\}\right)$ e $\delta\left\{\theta_{i}^{n}\right\}$ sendo respectivamente o jacobiano e o volume diferencial associados à transformação para o conjunto de coordenadas onde a amostragem é de fato realizada (como será discutido na subseção 2.3.2), e $Z_{i}$ é a função de partição configuracional dada pela integral 
sobre todos os possíveis estados. Entretanto, a seleção de fragmentos com a probabilidade da equação 2.21 é feita através da seleção de uma das configurações dentro de uma biblioteca de tamanho finito. Em um primeiro momento, isso pode parecer uma aproximação, ${ }^{*}$ contudo como será mostrado na subseção 2.3.3, contanto que a mesma biblioteca de fragmentos, constituída dos mesmos $N_{f}$ fragmentos seja considerada nos movimentos de ida e volta, na realidade não há aproximação. O critério de aceitação é, portanto, válido para qualquer número $N_{f}$ de configurações na biblioteca.

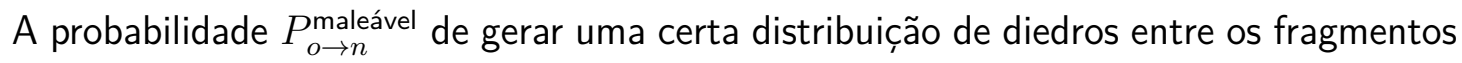
é também selecionada a partir de um conjunto reduzido de possibilidades de inserção. No caso dos graus de liberdade maleáveis, cada conjunto de possíveis ângulos de inserção é gerado separadamente nos movimentos de ida e volta, dando origem ao viés do CBMC. A necessidade de se gerar dois conjuntos de diedros surge do balanço detalhado. Um número $\kappa_{\phi}$ de possíveis

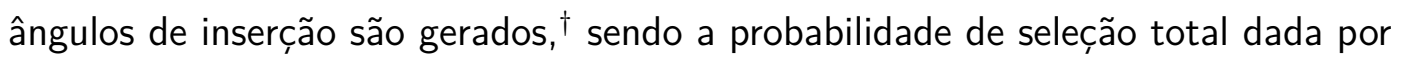

$$
P_{o \rightarrow n}^{\text {maleável }}=\prod_{i=1}^{N_{\text {frag }}-1} P_{i}^{\text {união }}{ }_{i+1}\left(\left\{\phi_{i}^{n}\right\}\right),
$$

onde cada uma das probabilidades de seleção de ângulos entre fragmentos $P_{i}^{\text {união }}{ }_{i+1}\left(\left\{\phi_{i}^{n}\right\}\right)$ é dada por

$$
P_{i-i+1}^{\text {união }}\left(\left\{\phi_{i}^{n}\right\}\right)=\frac{\exp \left[-\beta u\left(\left\{\phi_{i}^{n}\right\}\right)\right]}{\sum_{k=1}^{\kappa_{\phi}} \exp \left[-\beta u\left(\left\{\phi_{i k}^{n}\right\}\right)\right]} .
$$

Em suma, a ideia do método consiste de fazer reconstruções parciais das moléculas, selecionando fragmentos com graus de liberdade rígidos previamente amostrados e unindo-os com o esquema de CBMC que favorece a amostragem de mudanças conformacionais. As reconstruções são parciais pois a probabilidade de aceitação de movimentos parciais é maior do que a probabilidade da reconstrução total da molécula. A reconstrução parcial mantém parte da molécula rígida na nova configuração, alterando somente um subconjunto de fragmentos e ângulos de união. Por exemplo, na figura 1, se os fragmentos 1 e 2 são mantidos rígidos, primeiramente o fragmento 3 é modificado (através da seleção de uma configuração da biblioteca de fragmentos) e reinserido com um novo ângulo de diedro com relação ao fragmento 2, e só então o fragmento 4 é reinserido, selecionando uma nova configuração e reinserindo com um novo ângulo de diedro com relação ao fragmento 3. Quais partes são mantidas rígidas e quais são reconstruídas durante a simulação, são determinadas através de uma seleção aleatória descrita na seção 2.4, onde a implementação é discutida. A mudança na equação 2.19 devido a essa parte rígida, é que as probabilidades de seleção dos fragmentos na biblioteca e de ângulos de inserção das partes rígidas tem um valor idêntico nos movimentos de ida e volta, se cancelando no critério de aceitação final. Antes de encontrar o critério de aceitação do

* No paper original de Shah e Maginn ${ }^{[1]}$ essa seleção é de fato apresentada como uma aproximação.

${ }^{\dagger}$ Apesar de a princípio parecer que um número excessivamente grande de possibilidades de inserção seria necessária, com o uso de uma condição ainda mais restritiva que o balanço detalhado, é possível mostrar que independente do valor de $\kappa_{\phi}$ a amostragem com o CBMC amostra do ensemble correto. ${ }^{[14]}$ 
movimento de CBMC definido na subseção 2.3.3, abordarei os tipos de fragmentos atualmente suportados pela implementação do algoritmo no código DICE, ${ }^{[29]}$ e como a biblioteca de fragmentos para cada um deles é gerada.

\subsubsection{Fragmentando a molécula e gerando a biblioteca de fragmentos}

Apesar do trabalho de Shah e Maginn ${ }^{[1]}$ fragmentar a molécula de estudo no maior número possível de fragmentos com os graus de liberdade rígidos, a princípio esse não é um pré-requisito do método. Como será mostrado na subseção 2.3.3, a única condição necessária para a amostragem satisfazer o balanço detalhado, e portanto ter o mesmo critério de aceitação do movimento CBMC, é que os estados das configurações da biblioteca de fragmentos devem estar distribuídos de acordo com a equação 2.21, ou ainda que o fragmento seja rígido. Por esse motivo, a principio qualquer possível fragmentação da molécula pode ter seus estados amostrados para gerar uma biblioteca de configurações.

Na figura 2 os tipos de fragmentos atualmente permitidos pela implementação desenvolvida no DICE estão ilustrados. Os dois primeiros tipos de fragmentos ("a" e "b") são os mesmos tipos propostos por Shah e Maginn, onde a amostragem de branch-point ${ }^{[54]}$ ou de crank-shaft ${ }^{[74]}$ são realizadas. Já o fragmento de tipo "c" representa uma extensão ao método original, onde uma amostragem com o algoritmo de Metropolis convencional com deslocamento nas coordenadas Cartesianas dos átomos é realizada. Adicionalmente, introduzimos ao algoritmo a possibilidade de não realizar amostragem alguma, e manter o fragmento rígido durante toda a simulação. Fragmentos rígidos são válidos para qualquer tipo de fragmento, e são uma alternativa correta dentro do balanço detalhado, que pode ser útil em diversos casos, como quando não há todos os parâmetros do campo de força disponíveis para certa parte de uma molécula e especialmente para não reduzir taxas de aceitação que já podem ser baixas. As bibliotecas de fragmentos são construídas armazenando configurações periodicamente durante a amostragem cada tipo de amostragem. A configuração inicial de cada fragmento também é armazenada e incluída na biblioteca, e no caso da utilização de fragmentos rígidos, essa é a única configuração disponível na biblioteca. Nos parágrafos abaixo, cada um dos tipos de amostragem será detalhado.

A amostragem de branch-point sobre fragmentos do tipo "a" é feita, com o algoritmo de Metropolis, sendo o movimento realizado em coordenadas esféricas, centralizadas no átomo central. O objetivo dessa amostragem é amostrar os ângulos entre os átomos da maneira mais eficiente possível, mantendo os comprimentos de ligação fixos. Nessas coordenadas, a princípio um jacobiano estaria presente no critério de aceitação da equação 2.15. Contudo, se o comprimento de ligação é mantido constante, e a amostragem do ângulo polar é feita sobre o $\cos \theta$, e não sobre o ângulo $\theta$ propriamente dito, não é necessário acrescentar o jacobiano à equação $2.15 .{ }^{[1]}$ Portanto, os deslocamentos aleatórios que produzem os novos estados na 


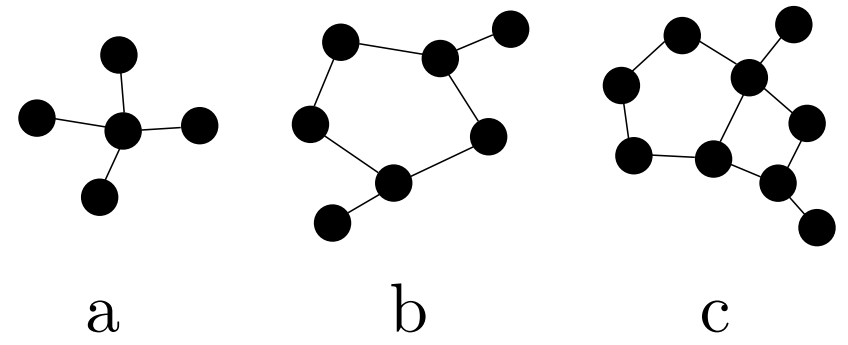

Figura 2 - Tipos de fragmentos suportados pela atual implementação do DICE. O tipo "a" constitui fragmentos compostos por um átomo central, "b" são anéis simples e "c" fragmentos quaisquer. O método de amostragem utilizado para cada tipo de fragmento está descrito no texto.

amostragem branch-point são

$$
\begin{aligned}
\cos \theta_{n} & =\cos \theta_{o}+(2 \tau-1) \cdot \Delta \cos \theta, \\
\phi_{n} & =\phi_{o}+(2 \tau-1) \cdot \Delta \phi,
\end{aligned}
$$

onde $\tau$ indica um número pseudo-aleatório gerado uniformemente no intervalo $[0,1]$ e $\Delta \cos \theta$ e $\Delta \phi$ os deslocamentos máximos para o cosseno do ângulo polar e para o ângulo azimutal, respectivamente. Os deslocamentos máximos são ajustados periodicamente com o método de taxa de aceitação (ARM, do inglês acceptance ratio mathod) de Swendsen ${ }^{[75]}$ para obter uma taxa de aceitação de $50 \%$.

Já a amostragem de anéis simples de fragmentos do tipo "b" é feita com o algoritmo de deslocamento crank-shaft, juntamente com o algoritmo de branch-point para átomos externos ao anel. A ideia da amostragem com o algoritmo crank-shaft é que os átomos do anel são movidos em torno de um eixo, definido pelos dois átomos membros do anel vizinhos do átomo a ser movido. O tamanho do deslocamento angular $\theta=(2 \tau-1) \cdot \Delta \theta$ com relação ao eixo é sorteado de maneira aleatória, sendo o deslocamento máximo $\Delta \theta$ ajustado periodicamente com o algoritmo ARM. O movimento do átomo é então feito alinhando o vetor que une os átomos vizinhos e define o eixo, ao eixo $z$ e então realizando uma rotação de $\theta$ do átomo em torno do eixo $z \cdot{ }^{[76]}$ Durante o movimento em torno do eixo, o átomo movido e os átomos externos ao anel conectados a ele são considerados um corpo rígido, i.e., todos são movidos com relação ao eixo mas mantendo distâncias e ângulos entre eles fixos. A vantagem de se utilizar o movimento de crank-shaft para os anéis, é que esse possui o mesmo jacobiano associado ao movimento de ida e de volta, conforme mostrado por Peristeras, Economou e Theodorou. ${ }^{[74]}$ Por esse motivo, a equação 2.15 é utilizada para aceitação e rejeição dos novos estados gerados.

A amostragem de fragmentos do tipo "c" é realizada com deslocamentos simples nas coordenadas Cartesianas, utilizando o critério de Metropolis convencional. Os deslocamentos são feitos selecionando aleatoriamente algum átomo da molécula, e então fazendo três deslocamentos independentes (cada um em uma coordenada Cartesiana) no átomo, de modo 
que

$$
\begin{aligned}
& x_{n}=x_{o}+(2 \tau-1) \cdot \Delta r \\
& y_{n}=y_{o}+(2 \tau-1) \cdot \Delta r \\
& z_{n}=z_{o}+(2 \tau-1) \cdot \Delta r
\end{aligned}
$$

onde novamente $\tau$ é um número pseudo-aleatório sorteado uniformemente no intervalo $[0,1]$ e $\Delta r$ é o deslocamento máximo, ajustado periodicamente com o algoritmo ARM. Nesse tipo de amostragem, qualquer definição de fragmento pode ser utilizada, contudo, deve ser levado em consideração que a amostragem com deslocamentos simples é pouco eficiente para grandes mudanças conformacionais.* Isto é, se os fragmentos definidos forem constituídos por vários átomos e forem relativamente flexíveis, o algoritmo pode não capturar todas as possíveis conformações. Por exemplo, a amostragem de uma molécula de ciclohexano com deslocamentos cartesianos pode não ser capaz de encontrar as conformações cadeira e barco partindo de uma configuração planar. Feita essa ressalva, esse tipo de amostragem pode ser interessante para fragmentos relativamente rígidos, ou ainda fragmentos pequenos que não são do tipo "a" ou "b". Na implementação do DICE, no caso da necessidade da amostragem de comprimentos de ligação, esse algoritmo deve ser o escolhido.

\subsubsection{Unindo fragmentos e critério de aceitação}

Conforme já mencionado, o método CBMC escolhido reinsere os fragmentos durante uma reconstrução parcial da molécula. A cada passo de $M C$, uma molécula é selecionada, e com uma probabilidade previamente definida um movimento CBMC pode ser realizado caso a molécula seja de um tipo flexível. ${ }^{\dagger} \mathrm{O}$ movimento do CBMC é iniciado selecionando uma das conexões entre fragmentos aleatoriamente, e então apagando os fragmentos que ficam ligados a um dos lados da ligação selecionada. Esses fragmentos apagados são então reconstruídos através de duas etapas. A primeira delas é a seleção de um fragmento da respectiva biblioteca de fragmentos, onde estão armazenadas configurações amostradas por um dos métodos apresentados na subseção 2.3.2. A segunda etapa é a inserção dos fragmentos selecionados na ordem correta, cada um com um ângulo diedro $\phi$ escolhido com um viés. ${ }^{\ddagger}$ Para fazer a escolha do diedro de inserção, são gerados aleatoriamente $\kappa_{\phi}$ diedros, dos quais apenas um é selecionado pelo método com o viés, sendo os outros apenas necessários para o cálculo do fator de Rosenbluth e remoção do viés no critério de aceitação.

\footnotetext{
*Esse, inclusive, é um dos principais motivos para se estudar amostragem com CBMC, já que se sabe que amostragem conformacional com deslocamentos cartesianos é pouco eficiente.

${ }^{\dagger}$ Caso o movimento CBMC não seja selecionado, um simples movimento de rotação ao redor de um eixo aleatório e translação é realizado.

¥ Normalmente mais de um diedro está presente na união entre dois fragmentos, o ângulo $\phi$ é definido como sendo um deles, e os outros são então automaticamente determinados, já que durante a inserção o fragmento é mantido rígido.
} 
Para a derivação do critério de aceitação do movimento CBMC, utilizamos a separação dos termos de energia conforme descrito na subseção 2.3.1. Analogamente à derivação do critério de Metropolis, o balanço detalhado é utilizado como condição para a amostragem de uma distribuição de equilíbrio. Contudo, como queremos utilizar um conjunto finito de possibilidades para os ângulos de inserção, seria necessário garantir que os mesmos estados são acessíveis nos movimentos de ida e volta, o que não é possível devido ao modo que o algoritmo é construído. Outra possibilidade seria computar as infinitas possibilidades de inserção, o que claramente não é viável. A solução para esse problema é a utilização do "super balanço detalhado", ${ }^{[14]}$ uma condição mais restritiva que o balanço detalhado, e que portanto também é uma condição suficiente para amostrar da distribuição desejada. O super balanço detalhado nada mais é do que satisfazer o balanço detalhado para qualquer conjunto de $\kappa_{\phi}$ sorteados nos movimentos de ida e volta. Essa condição é suficiente para garantir que um algoritmo rigorosamente correto e sem aproximações para a amostragem. Portanto, devemos gerar dois conjuntos de ângulos de inserção (para os movimentos de ida e volta) e de toda maneira satisfazer a equação 2.14 para então obter o critério de aceitação.

Os fragmentos são escolhidos da biblioteca aleatoriamente, com probabilidade dada pela equação 2.21. O diedro de inserção é escolhido dentre as opções sorteadas com a probabilidade da equação 2.23. Como será mostrado nos próximos parágrafos, essas escolhas são convenientes para a simplificação do critério de aceitação. Assim, sendo $c_{1}, c_{2}$ e $c_{3}$ constantes que incluem o inverso da função de partição configuracional total, da função de partição dos fragmentos, além de fatores constantes devido a jacobianos e a seleção da ligação que é quebrada inicialmente e probabilidade de gerar ângulos, temos no balanço detalhado dado pela equação 2.14 :

$$
\begin{gathered}
c_{1} \exp (-\beta \mathcal{U}(o)) \operatorname{acc}(o \rightarrow n) \prod_{i=1}^{N_{\text {del }}} c_{2} \exp \left(-\beta u\left(\left\{\theta_{i}^{n}\right\}\right)\right) \prod_{i=1}^{N_{\text {del }}} c_{3} \frac{\exp \left(-\beta u\left(\left\{\phi_{i}^{n}\right\}\right)\right)}{\sum_{k=1}^{\kappa_{\phi}} \exp \left(-\beta u\left(\left\{\phi_{i k}^{n}\right\}\right)\right)}= \\
c_{1} \exp (-\beta \mathcal{U}(n)) \operatorname{acc}(n \rightarrow o) \prod_{i=1}^{N_{\text {del }}} c_{2} \exp \left(-\beta u\left(\left\{\theta_{i}^{o}\right\}\right)\right) \prod_{i=1}^{N_{\text {del }}} c_{3} \frac{\exp \left(-\beta u\left(\left\{\phi_{i}^{o}\right\}\right)\right)}{\sum_{k=1}^{\kappa_{\phi}} \exp \left(-\beta u\left(\left\{\phi_{i k}^{o}\right\}\right)\right)},
\end{gathered}
$$

onde $N_{\text {del }}$ indica o número de fragmentos inicialmente apagados e a serem reconstruídos pelo CBMC. Note que as constantes se cancelam, e justamente por ser uma constante, a estimativa da função de partição configuracional dos fragmentos $\left(c_{2}\right)$ se cancela independentemente do número de configurações salvas na biblioteca, desde que todas as possíveis configurações (inclusive as iniciais providas pelo usuário) estejam contidas na mesma. Definindo o fator de Rosenbluth

$$
W(o)=\prod_{i=1}^{N_{\mathrm{del}}} \sum_{k=1}^{\kappa_{\phi}} \exp \left(-\beta u\left(\left\{\phi_{i k}^{o}\right\}\right)\right)
$$


e fazendo dos produtórios somatórios temos:

$$
\begin{aligned}
& \exp (-\beta \mathcal{U}(o)) \operatorname{acc}(o \rightarrow n) \exp \left(-\beta \sum_{i=1}^{N_{\text {del }}} u\left(\left\{\theta_{i}^{n}\right\}\right)\right) \frac{\exp \left(-\beta \sum_{i=1}^{N_{\text {del }}} u\left(\left\{\phi_{i}^{n}\right\}\right)\right)}{W(n)}= \\
& \quad \exp (-\beta \mathcal{U}(n)) \operatorname{acc}(n \rightarrow o) \exp \left(-\beta \sum_{i=1}^{N_{\text {del }}} u\left(\left\{\theta_{i}^{o}\right\}\right)\right) \frac{\exp \left(-\beta \sum_{i=1}^{N_{\text {del }}} u\left(\left\{\phi_{i}^{o}\right\}\right)\right)}{W(o)}
\end{aligned}
$$

Podemos então simplificar ainda mais a equação 2.28 , deixando somente as probabilidades de aceitação do lado esquerdo:

$$
\begin{aligned}
\frac{\operatorname{acc}(o \rightarrow n)}{\operatorname{acc}(n \rightarrow o)}=\exp (-\beta[\mathcal{U}(n) & -\mathcal{U}(o)]) \exp \left(-\beta \sum_{i=1}^{N_{\text {del }}}\left[u\left(\left\{\theta_{i}^{o}\right\}\right)-u\left(\left\{\theta_{i}^{n}\right\}\right)\right]\right) \\
& \times \exp \left(-\beta \sum_{i=1}^{N_{\text {del }}}\left[u\left(\left\{\phi_{i}^{o}\right\}\right)-u\left(\left\{\phi_{i}^{n}\right\}\right)\right]\right) \frac{W(n)}{W(o)}
\end{aligned}
$$

Agora, se notarmos que podemos separar o somatório da equação 2.18 em uma parte que inclui os termos dos fragmentos apagados (e reconstruídos) e os termos dos fragmentos mantidos intactos:

$$
\begin{aligned}
& \sum_{i=1}^{N_{\text {frag }}} u\left(\left\{\theta_{i}^{n}\right\}\right)=\sum_{i=1}^{N_{\text {frag }}-N_{\text {del }}} u\left(\left\{\theta_{i}^{n}\right\}\right)+\sum_{i=1}^{N_{\text {del }}} u\left(\left\{\theta_{i}^{n}\right\}\right), \\
& \sum_{i=1}^{N_{\text {frag }}} u\left(\left\{\phi_{i}^{n}\right\}\right)=\sum_{i=1}^{N_{\text {frag }}-N_{\text {del }}} u\left(\left\{\phi_{i}^{n}\right\}\right)+\sum_{i=1}^{N_{\text {del }}} u\left(\left\{\phi_{i}^{n}\right\}\right),
\end{aligned}
$$

temos então utilizando a equação 2.17 e a equação 2.30 :

$$
\begin{aligned}
\frac{\operatorname{acc}(o \rightarrow n)}{\operatorname{acc}(n \rightarrow o)}=\frac{W(n)}{W(o)} \exp \left(-\beta \sum_{i=1}^{N_{\text {frag }}-N_{\text {del }}}\left[u\left(\left\{\theta_{i}^{n}\right\}\right)-u\left(\left\{\theta_{i}^{o}\right\}\right)\right]\right) \\
\quad \times \exp \left(-\beta \sum_{i=1}^{N_{\text {frag }}-N_{\text {del }}}\left[u\left(\left\{\phi_{i}^{n}\right\}\right)-u\left(\left\{\phi_{i}^{o}\right\}\right)\right]\right)
\end{aligned}
$$

Nesse ponto, notamos que os somatórios da equação 2.31 são sobre os fragmentos que não foram reconstruídos pelo CBMC, ou seja, os fragmentos que foram mantidos intactos durante o movimento. Por esse motivo, as energias dos fragmentos e das uniões dos fragmentos são as mesmas tanto na configuração antiga como a nova, já que os ângulos, comprimentos de ligações e torcionais são iguais em ambos os casos. Assim, simplificamos nosso critério de aceitação para um critério idêntico ao critério CBMC normalmente utilizado para cadeias simples: ${ }^{[14]}$

$$
\frac{\operatorname{acc}(o \rightarrow n)}{\operatorname{acc}(n \rightarrow o)}=\frac{W(n)}{W(o)}
$$

O desenvolvimento do critério da equação 2.32 não está presente da referência original do método, ${ }^{[1]}$ e de fato a implementação do critério de CBMC utilizado pelos autores no código 
Cassandra ${ }^{[27,63]}$ tem menos simplificações, levando um critério mais sujeito a erros numéricos. Por outro lado, lidar com o fator de Rosenbluth como na equação 2.32 introduz a possibilidade de problemas quanto à precisão numérica dos pontos flutuantes. Esse problema é abordado na seção 2.4 onde uma solução simples a esse problema é apresentada.

\subsubsection{Viés eletrostático no CBMC}

Adicionalmente ao viés de seleção dos ângulos de diedro do CBMC, neste trabalho também introduzimos a possibilidade de utilizar um viés eletrostático, que particiona a energia de interação eletrostática em duas partes, incluindo uma delas no momento de construção da nova configuração e outra na aceitação. A finalidade desse viés é suavizar a superfície de energia potencial (PES, do inglês potential energy surface) de modo que a exploração dessa superfície possa ser realizada de maneira mais eficiente. Isso ocorre pois grande parte da contribuição de energia de interação da molécula tem origem eletrostática, e ao utilizar esse tipo de viés, é possível gerar configurações que durante o processo de reconstrução poderiam não ser tão favoráveis, mas que na conformação total se trata de um mínimo. Por exemplo, em uma cadeia, se um dos fragmentos internos do meio da molécula possui fortes cargas, porem pode ser introduzido em mais de um ângulo que caia em um mínimo, essa abordagem pode ser interessante. Esse viés é removido no critério de aceitação do movimento CBMC.

O viés é introduzido separando a energia dos graus de liberdade maleáveis da equação 2.18 da seguinte maneira:

$$
\begin{aligned}
u\left(\left\{\phi_{i}^{n}\right\}\right) & =u_{\mathrm{dih}}\left(\left\{\phi_{i}^{n}\right\}\right)+u_{\mathrm{LJ}}\left(\left\{\phi_{i}^{n}\right\}\right)+\lambda_{c} u_{c}\left(\left\{\phi_{i}^{n}\right\}\right)+\left(1-\lambda_{c}\right) u_{c}\left(\left\{\phi_{i}^{n}\right\}\right), \\
& =u^{\prime}\left(\left\{\phi_{i}^{n}\right\}\right)+\left(1-\lambda_{c}\right) u_{c}\left(\left\{\phi_{i}^{n}\right\}\right),
\end{aligned}
$$

onde $u_{\text {dih }}$ representa soma das energias de diedro ao redor da ligação, e a energia não ligada é dividida no termo de Lennard-Jones $u_{\mathrm{LJ}}$ e eletrostático $u_{c}$. O fator $\lambda_{c}$ é utilizado para controlar a contribuição do potencial eletrostático que é utilizada na construção das configurações, e assume um valor $\lambda_{c} \in[0,1]$. Os termos de energia de diedro e Lennard-Jones, e a parte do potencial eletrostático que é utilizada na construção das configurações são agrupados como $u^{\prime}\left(\left\{\phi_{i}^{n}\right\}\right)$.

Com a energia escrita como na equação 2.33 podemos escrever o balanço detalhado e encontrar o novo critério de aceitação que utiliza somente $u^{\prime}\left(\left\{\phi_{i}^{n}\right\}\right)$ ao inserir cada fragmento. Se somente $u^{\prime}\left(\left\{\phi_{i}^{n}\right\}\right)$ é contabilizado na inserção dos fragmentos, temos que a probabilidade de seleção da união de um dos graus de liberdade maleáveis, de maneira análoga a equação 2.23, é dada por

$$
P_{i-i+1}^{\text {união }}\left(\left\{\phi_{i}^{n}\right\}\right)=\frac{\exp \left[-\beta u^{\prime}\left(\left\{\phi_{i}^{n}\right\}\right)\right]}{\sum_{k=1}^{\kappa_{\phi}} \exp \left[-\beta u^{\prime}\left(\left\{\phi_{i k}^{n}\right\}\right)\right]} .
$$


Definindo o fator de Rosenbluth como

$$
W^{\prime}(n)=\prod_{i=1}^{N_{\text {del }}} \sum_{k=1}^{\kappa_{\phi}} \exp \left[-\beta u^{\prime}\left(\left\{\phi_{i k}^{n}\right\}\right)\right],
$$

omitindo fatores constantes que se cancelam por estarem em ambos os lados, temos o balanço detalhado

$$
\begin{gathered}
\exp \left[-\beta \mathcal{U}\left(\left\{\phi^{o}\right\}\right)\right] \frac{\prod_{i=1}^{N_{\text {del }}} \exp \left[-\beta u^{\prime}\left(\left\{\phi_{i}^{n}\right\}\right)\right]}{W^{\prime}(n)} \operatorname{acc}(o \rightarrow n)= \\
\exp \left[-\beta \mathcal{U}\left(\left\{\phi^{n}\right\}\right)\right] \frac{\prod_{i=1}^{N_{\text {del }}} \exp \left[-\beta u^{\prime}\left(\left\{\phi_{i}^{o}\right\}\right)\right]}{W^{\prime}(o)} \operatorname{acc}(n \rightarrow o) .
\end{gathered}
$$

Com a decomposição da energia total da equação 2.18 considerando os termos da equação 2.33 temos que o balanço detalhado pode ser escrito como

$$
\begin{aligned}
& \exp \left[-\beta\left(\sum_{i=1}^{N_{\text {frag }}} u^{\prime}\left(\left\{\phi_{i}^{o}\right\}\right)+\left(1-\lambda_{c}\right) \sum_{i=1}^{N_{\text {frag }}} u_{c}\left(\left\{\phi_{i}^{o}\right\}\right)\right)\right] \frac{\prod_{i=1}^{N_{\text {del }}} \exp \left[-\beta u^{\prime}\left(\left\{\phi_{i}^{n}\right\}\right)\right]}{W^{\prime}(n)} \operatorname{acc}(o \rightarrow n)= \\
& \exp \left[-\beta\left(\sum_{i=1}^{N_{\text {frag }}} u^{\prime}\left(\left\{\phi_{i}^{n}\right\}\right)+\left(1-\lambda_{c}\right) \sum_{i=1}^{N_{\text {frag }}} u_{c}\left(\left\{\phi_{i}^{n}\right\}\right)\right)\right] \frac{\prod_{i=1}^{N_{\text {del }}} \exp \left[-\beta u^{\prime}\left(\left\{\phi_{i}^{o}\right\}\right)\right]}{W^{\prime}(o)} \operatorname{acc}(n \rightarrow o) .
\end{aligned}
$$

De maneira análoga às simplificações da subseção 2.3.3, os termos referentes a $u^{\prime}\left(\left\{\phi_{i}^{n}\right\}\right)$ se cancelam, e o balanço detalhado da equação 2.38 pode ser simplificado. Com isso, o critério de aceitação fica

$$
\frac{\operatorname{acc}(o \rightarrow n)}{\operatorname{acc}(n \rightarrow o)}=\frac{W^{\prime}(n)}{W^{\prime}(o)} \exp \left[-\beta\left(1-\lambda_{c}\right) \sum_{i=1}^{N_{\text {frag }}}\left(u_{c}\left(\left\{\phi_{i}^{n}\right\}\right)-u_{c}\left(\left\{\phi_{i}^{o}\right\}\right)\right)\right] .
$$

Contudo, de maneira similar ao feito na equação 2.31, podemos eliminar alguns termos na somatória da equação 2.39 utilizando o fato de que os fragmentos que são mantidos fixos durante o movimento CBMC possuem a mesma energia nos movimentos de ida e volta. Dessa maneira, o critério de aceitação final do movimento CBMC com viés eletrostático controlado pelo parâmetro $\lambda_{c}$ é dado por

$$
\frac{\operatorname{acc}(o \rightarrow n)}{\operatorname{acc}(n \rightarrow o)}=\frac{W^{\prime}(n)}{W^{\prime}(o)} \exp \left[-\beta\left(1-\lambda_{c}\right) \sum_{i=1}^{N_{\mathrm{del}}}\left(u_{c}\left(\left\{\phi_{i}^{n}\right\}\right)-u_{c}\left(\left\{\phi_{i}^{o}\right\}\right)\right)\right]
$$

\subsubsection{Amostragem Preferencial}

Tipicamente, no método de MC os novos estados são gerados através da rotação e deslocamento (das coordenadas Cartesianas) de uma molécula selecionada aleatoriamente na caixa. Contudo, para sistemas soluto-solvente, é desejável que a amostragem em torno do soluto seja mais eficiente, já que a longas distâncias pequenas mudanças nas coordenadas das 
moléculas de solvente não são tão relevantes. Na amostragem preferencial, ${ }^{[77,78]}$ a molécula de soluto e as moléculas de solvente mais próximas ao soluto são sorteadas com maior frequência. Um viés que favorece a seleção de moléculas mais próximas ao soluto, e o próprio soluto, é introduzido, tendo em mente que essa é a região com maior importância a ser amostrada. Esse viés é importante quando o CBMC é utilizado para a amostragem dos graus de liberdade internos do soluto, pois para realizar o movimento CBMC, é necessário que o soluto seja sorteado. Se somente o soluto é flexível, o algoritmo de Owicki ${ }^{[7]}$ não é alterado (já que a probabilidade de seleção do soluto é $1 / N$ na ida e volta do balanço detalhado), contudo, se as moléculas de solvente também são consideradas flexíveis, é necessário corrigir o critério de aceitação CBMC. Devido ao viés introduzido, o critério de Metropolis para a aceitação de novas configurações é alterado mesmo se o CBMC não é utilizado. Antes de modificar o critério do CBMC, a modificação do critério de Metropolis para o MC com moléculas rígidas será mostrada.

O viés que seleciona as moléculas mais próximas ao soluto mais frequentemente consiste em atribuir um peso a cada uma das moléculas

$$
w\left(r_{i}(o)\right)=\frac{1}{r_{i}(o)^{k}},
$$

com $r_{i}(o)$ sendo a distância do centro de massa da molécula $i$ ao soluto para o estado $O$, e $k$ um expoente a ser selecionado como parâmetro, tipicamente 2 ou 4. ${ }^{[78]}$ Dessa maneira, a probabilidade de se selecionar a molécula $i$ dentre as $N$ moléculas do sistema, para uma configuração $o$, é dada por

$$
\mathcal{P}_{i}(o)=\frac{w\left(r_{i}(o)\right)}{\sum_{j=2}^{N} w\left(r_{j}(o)\right)}=\frac{w\left(r_{i}(o)\right)}{\mathcal{S}(o)},
$$

onde vale frisar que a soma é sobre os pesos para o estado $o$, sendo essa iniciada de 2 pois a molécula 1 é considerada o soluto. Justamente do fato de a configuração antiga $o$ ser diferente da nova $n$ no balanço detalhado, que o viés é introduzido e corrigido na aceitação.

Para corrigir o viés, o balanço detalhado é utilizado e um novo critério de aceitação é encontrado. Considerando então que $\alpha(o \rightarrow n) \propto \mathcal{P}_{i}(o)$ temos na equação 2.14

$$
\frac{\operatorname{acc}(o \rightarrow n)}{\operatorname{acc}(n \rightarrow o)}=\frac{\mathcal{N}(n) \mathcal{P}_{i}(n)}{\mathcal{N}(o) \mathcal{P}_{i}(o)}
$$

e fazendo as substituições, temos então

$$
\frac{\operatorname{acc}(o \rightarrow n)}{\operatorname{acc}(n \rightarrow o)}=\exp [-\beta(\mathcal{U}(n)-\mathcal{U}(o))]\left(\frac{r_{i}(o)}{r_{i}(n)}\right)^{k} \frac{\mathcal{S}(o)}{\mathcal{S}(n)},
$$

que é o critério de aceitação modificado pela amostragem preferencial, utilizado com moléculas rígidas ou quando somente o soluto é flexível com o CBMC.

Vale notar que o $\mathcal{S}(n)$ e o $\mathcal{S}(o)$ em geral não se cancelam. Pelo contrário, possuem uma relação entre eles quando somente uma molécula $i$ do solvente é movida

$$
\mathcal{S}(n)=\mathcal{S}(o)-\frac{1}{r_{i}(o)^{k}}+\frac{1}{r_{i}(n)^{k}} .
$$


Essa relação pode ser utilizada no algoritmo para não ser necessário computar o somatório em todo passo.

De maneira similar, a amostragem preferencial pode ser usado com CBMC alterando o $\alpha(o \rightarrow n)$ para incluir o viés da probabilidade de seleção da molécula. Quando o solvente é a única molécula flexível do sistema, como este é selecionado com uma probabilidade $p=1 / N$ independente do estado do sistema, é correto utilizar os critérios de aceitação anteriormente derivados. Entretanto, se o solvente for considerado flexível e amostrado com o CBMC, o critério de aceitação do movimento CBMC precisa ser alterado.

O critério de aceitação do CBMC é encontrado de maneira similar ao da subseção 2.3.3, com a diferença que a probabilidade de seleção das moléculas, que se cancelava antes por ser igual nos dois sentidos do balanço detalhado, aparece explicitamente no critério. Por exemplo, para o critério sem o viés eletrostático da equação 2.48 temos que

$$
\operatorname{acc}(o \rightarrow n)=\min \left(1, \frac{W(n) \mathcal{P}_{i}(n)}{W(o) \mathcal{P}_{i}(o)}\right),
$$

com $\mathcal{P}_{i}$ dado pela equação 2.42 .

Substituindo as probabilidades chegamos finalmente ao critério de aceitação da amostragem preferencial utilizado com o CBMC

$$
\operatorname{acc}(o \rightarrow n)=\min \left[1, \frac{W(n)}{W(o)}\left(\frac{r_{i}(o)}{r_{i}(n)}\right)^{k} \frac{\mathcal{S}(o)}{\mathcal{S}(n)}\right],
$$

onde novamente, a relação entre os $\mathcal{S}$ é dada pela equação 2.45 .

\subsection{Implementação do método CBMC no DICE}

\subsubsection{Critério de aceitação no DICE}

Dada a condição da equação 2.32, podemos definir um critério de aceitação similar ao critério definido por Metropolis ${ }^{[15]}$ e que tem a forma usualmente empregada para métodos $\mathrm{CBMC}^{[14]}$

$$
\operatorname{acc}(o \rightarrow n)=\min \left(1, \frac{W(n)}{W(o)}\right)
$$

com $W(n)$ e $W(o)$ sendo os fatores de Rosenbluth definidos pela equação 2.27. O mesmo pode ser feito sobre a equação 2.40 quando o viés eletrostático é utilizado.

Entretanto, a implementação de tal critério não pode ser feita da maneira trivial, apenas calculando os fatores de Rosenbluth e fazendo a razão. Dada a característica dos fatores de Rosenbluth de serem um produtório de um somatório de exponenciais, não é de se surpreender que problemas numéricos referentes a overflow ou underflow possam ocorrer. Para lidar com 
essa dificuldade, um truque muito simples que pode ser utilizado é lidar com a exponencial do logaritmo da equação 2.48, trabalhando então na escala logarítmica onde problemas numéricos são minimizados. Utilizando esse truque, temos para o lado direito da equação 2.48:

$$
\frac{W(n)}{W(o)}=\exp [\ln W(n)-\ln W(o)]
$$

contudo, como $W(n)$ (e analogamente $W(o)$ ) são dados pela equação 2.27, podemos escrever

$$
\begin{aligned}
\ln W(n) & =\ln \left[\prod_{i=1}^{N_{\mathrm{del}}} \sum_{k=1}^{\kappa_{\phi}} \exp \left(-\beta u\left(\left\{\phi_{i k}^{n}\right\}\right)\right)\right] \\
& =\sum_{i=1}^{N_{\mathrm{del}}} \ln \left[\sum_{k=1}^{\kappa_{\phi}} \exp \left(-\beta u\left(\left\{\phi_{i k}^{n}\right\}\right)\right)\right],
\end{aligned}
$$

nesse momento então podemos utilizar o Log-Sum-Exp. ${ }^{[79]}$

O Log-Sum-Exp nada mais é do que uma forma de prevenir o overflow ou underflow em equações que contenham o logaritmo de uma soma de exponenciais, assim como na equação 2.50. Para isso, separamos o maior termo da exponencial dos outros termos, que por sua vez serão sempre menores que 1 . Sem perda de generalidade, vamos supor que o maior termo da exponencial seja o primeiro termo da soma $x_{1}$, assim podemos fazer:

$$
\begin{aligned}
\ln \sum_{i=1}^{N} e^{x_{n}} & =\ln \left(\sum_{i=1}^{N} e^{x_{n}} \frac{e^{x_{1}}}{e^{x_{1}}}\right) \\
& =\ln \left(e^{x_{1}} \sum_{i=1}^{N} e^{x_{n}-x_{1}}\right) \\
& =x_{1}+\ln \left(1+\sum_{i=2}^{N} e^{x_{n}-x_{1}}\right),
\end{aligned}
$$

onde $\ln (1+x)$ pode ser calculado com grande precisão e sem underflow pela função $\log 1 \mathrm{p}(\mathrm{x})$ disponível na maioria das linguagens de programação. Utilizando então a equação 2.51 na equação 2.50:

$$
\ln W(n)=\sum_{i=1}^{N_{\text {del }}}\left(-\beta u\left(\left\{\phi_{i 1}^{n}\right\}\right)+\ln \left\{1+\sum_{k=2}^{\kappa_{\phi}} \exp \left[-\beta\left(u\left(\left\{\phi_{i k}^{n}\right\}-u\left(\left\{\phi_{i 1}^{n}\right\}\right)\right)\right]\right\}\right),\right.
$$

onde $u\left(\left\{\phi_{i 1}^{n}\right\}\right)$ é na verdade a menor energia (já que há o sinal de menos junto com o $\beta$ ).

Finalmente podemos então escrever o critério de aceitação para o movimento CBMC que lida melhor com problemas numéricos:

$$
\operatorname{acc}(o \rightarrow n)=\exp [\min (0, \ln W(n)-\ln W(o))],
$$

com $\ln W(n)$ e $\ln W(o)$ dados pela equação 2.52. De maneira similar, o critério de aceitação para o CBMC com o viés eletrostático é implementado, nesse caso, o critério final é dado por $\operatorname{acc}(o \rightarrow n)=\exp \left[\min \left(0, \ln W^{\prime}(n)-\ln W^{\prime}(o)-\beta\left(1-\lambda_{c}\right) \sum_{i=1}^{N_{\text {del }}}\left(u_{c}\left(\left\{\phi_{i}^{n}\right\}\right)-u_{c}\left(\left\{\phi_{i}^{o}\right\}\right)\right)\right)\right]$, 
com $\ln W^{\prime}(n)$ e $\ln W^{\prime}(o)$ dados por uma equação similar a equação 2.52, onde ao invés de $u$, a definição de $u^{\prime}$ da equação 2.33 é utilizada.

Utilizamos as equaçãos 2.53 e 2.54 na implementação feita no DICE. Entretanto, vale ressaltar que a implementação do método vai além da simples implementação da equação. Diversos problemas numéricos foram resolvidos, assim como diversos problemas de geometria analítica, paralelização, entre outros. Nos próximos parágrafos, alguns detalhes da implementação referentes a escolha de algoritmo feitas e também sobre algumas ferramentas desenvolvidas serão abordados.

\subsubsection{Detalhes gerais de implementação}

Um detalhe importante da implementação, é o armazenamento das configurações nas bibliotecas de fragmentos. Como os fragmentos são gerados independentemente, e a princípio podem inclusive ser gerados previamente a simulação com o CBMC, é necessário adicionar à biblioteca de fragmentos os fragmentos inciais originados da configuração inicial informada pelo usuário. Quando a simulação é feita com o método um grande número de moléculas flexíveis, cada uma com uma configuração inicial diferente, é necessário adicionar à biblioteca as configurações iniciais dos fragmentos de cada uma das moléculas, originadas da caixa de simulação. Dessa maneira, cada molécula sempre terá associada a si os fragmentos que a compõe, disponíveis na biblioteca de fragmentos de modo idêntico nos movimentos de ida e volta, de maneira que a soma sobre os pesos de Boltzmann de todas as configurações, presente na constante $c_{2}$ da equação 2.26 , é a mesma nos movimentos em ambos os lados da equação e portanto se cancela.

A união dos fragmentos é feita mantendo a mesma sequência de fragmentos da molécula original. Contudo, em moléculas que possuem ramificações, no movimento de reconstrução é necessário definir qual dos ramos é reconstruído primeiro, ou ainda qual a estratégia usada para a reconstrução. No DICE, os fragmentos são inseridos com o uso do algoritmo de busca em largura (BFS, do inglês breadth first search) utilizado para a exploração de grafos. Com esse algoritmo, a inserção de ramificações é feita inserindo primeiramente todos os fragmentos ligados ao fragmento pai. Outra estratégia possível seria a utilização da exploração em profundidade (DFS, do inglês depth first search), onde um dos ramos da ramificação é escolhido, e todos os fragmentos desse ramos são inseridos, antes das inserções no próximo ramo. A estratégia com DFS, foi a estratégia usada na implementação do código Cassandra. ${ }^{[27,63]}$ A princípio, não há vantagens sobre a utilização de um ou outro algoritmo para a reconstrução com ramificações. Entretanto, uma comparação entre as duas estratégias é necessária para uma conclusão definitiva.

Outro detalhe da implementação que merece destaque são os algoritmos de seleção dos $\kappa_{\phi}$ ângulos tentativa de inserção $\left\{\phi_{i}^{n}\right\}$. Note que ao determinar um dos diedros entre 
os fragmentos $\phi$, os $\left\{\phi_{i}^{n}\right\}$ são automaticamente determinados, e portanto para simplificar a notação nos próximos parágrafos, $\phi$ será utilizado para representar esses ângulos. Foram implementadas três maneiras de gerar os ângulos tentativa $\phi$, sendo duas delas completamente aleatórias e uma outra com um viés. A forma mais simples consiste de sortear cada um dos $\kappa_{\phi}$ ângulos aleatoriamente, e independentemente, no intervalo $[0,2 \pi]$. Outra maneira implementada no código, e similar a anterior, é sortear apenas um dos ângulos de maneira aleatória no intervalo $[0,2 \pi]$, e então determinar os outros $\kappa_{\phi}-1$ ângulos distribuindo esses de maneira equidistante completando o intervalo $[0,2 \pi]$. Esses são os algoritmos mais simples e também os mais baratos computacionalmente.

O último algoritmo implementado sorteia os ângulos para tentativa de inserção com um viés, selecionando os mesmos à partir do seus pesos de Boltzmann. Isso é feito com utilizando um esquema de aceitação-rejeição ${ }^{[14]}$ que somente aceita o ângulo $\phi$ como um ângulo tentativa quando

$$
\tau \leq \exp \left[-\beta u_{\text {torsional }}^{i-i+1}(\phi)\right]
$$

onde $\tau$ representa um número pseudo-aleatório gerado uniformemente no intervalo $[0,1]$ e $u_{\text {torsional }}^{i-i+1}(\phi)$ a energia de diedro total da união entre os fragmentos $i$ e $i+1$. Com esse esquema, os ângulos obtidos dão energias que obedecem a distribuição de Boltzmann. Portanto, nesse esquema com viés, um ângulo é gerado aleatoriamente no intervalo $[0,2 \pi]$, a energia $u_{\text {torsional }}^{i-i+1}(\phi)$ é calculada, e através do sorteio de $\tau$ o ângulo é aceito ou não como um ângulo de tentativa de inserção. Esse processo é repetido até que os $\kappa_{\phi}$ ângulos sejam gerados. Quando esse último esquema de aceitação e rejeição é utilizado, a energia $u_{\text {torsional }}^{i-i+1}(\phi)$, que normalmente está incluída no termo $u\left(\left\{\phi_{i}^{n}\right\}\right)$ da equação 2.18 , é separada, o que modifica a equação 2.23 e consequentemente o critério de aceitação. O termo referente ao viés vindo dos $u_{\text {torsional }}^{i-i+1}(\phi)$ aparece explicitamente na equação 2.19, mas é igual nos movimentos de ida e volta, se cancelando no balanço detalhado. Apesar de alterado, o critério de aceitação continua com a mesma expressão da equação 2.48 , onde nesse caso somente o fator de Rosenbluth da equação 2.27 que é diferente. No esquema com viés na seleção dos $\phi$, o fator de Rosenbluth não deve levar em consideração $u_{\text {torsional }}^{i-i+1}(\phi)$, restando portanto somente os termos referentes a energia não ligada, de modo que

$$
P_{i-i+1}^{\text {união }}(\phi)=\frac{\exp \left[-\beta u_{\mathrm{nb}}(\phi)\right]}{\sum_{k=1}^{\kappa_{\phi}} \exp \left[-\beta u_{\mathrm{nb}}\left(\phi_{k}\right)\right]},
$$

com $u_{\mathrm{nb}}(\phi)$ sendo a energia não ligada de interação para a inserção do fragmento $i+1$ ao fragmento $i$ com os ângulos representados por $\phi$. No algoritmo com viés, portanto, um ângulo de inserção é selecionado com a probabilidade dada pela equação 2.56 .

De uma maneira geral, a forma como o método CBMC foi implementado no DICE é apresentada na figura 3. Quando uma molécula flexível é selecionada durante a simulação com - Metropolis MC convencional, um movimento CBMC pode ser iniciado com uma probabilidade $p_{\text {CBMC. }}$ Se o sorteio não selecionar o movimento CBMC, apenas uma translação de centro 
de massa e rotação da molécula são realizados. Contudo, se o movimento CBMC é iniciado, uma ligação entre fragmentos é selecionada, e todos os fragmentos ligados a um dos lados dessa ligação, ou ligados aos fragmentos que estavam ligados ao lado selecionado, ou assim sucessivamente, são removidos (deletados). Começa então a reconstrução da molécula para gerar uma conformação nova, que segue os passos detalhados nas seções anteriores. O passo "Reconstrução da configuração antiga" segue os mesmos passos anteriores da construção da conformação nova: seleção de fragmento da biblioteca, gerar os possíveis ângulos de inserção e seleção de ângulos de inserção, porém o fragmento selecionado é o mesmo que estava na configuração original antes do movimento CBMC, e o selecionado também é o mesmo, de modo que ao final da reconstrução, a conformação original é obtida. A aceitação ou rejeição da nova conformação depende então das posições possíveis geradas na inserção de cada fragmento, que dão origem aos fatores de Rosenbluth que por sua vez são utilizados na equação 2.48 .

\subsubsection{Ferramentas do DICEtools}

Para tornar a utilização do programa DICE mais amigável, facilitar a produção de arquivos de entrada e análise de resultados, uma série de scripts escritos em Python foram desenvolvidos e agrupados num conjunto de ferramentas que chamamos de DICEtools. Essas ferramentas auxiliam a fragmentação da molécula, a parametrização de ângulos de diedro cujo potencial com campos de força clássico não correspondem aos de mecânica quântica, análise de distribuições de ângulos e análise de clustering com algoritmos de aprendizado de máquina. Dentre essas ferramentas, algumas merecem ser destacados, pois o seu uso facilita em grande parte o trabalho do usuário, ou ainda por fornecer análises que podem ser fundamentais para o entendimento do problema físico.

O "fragGen" é um script utilizado para gerar a maior fragmentação possível de uma molécula fornecida em .xyz, .pdb ou qualquer formato padrão de arquivo para armazenagem de estruturas interpretado pelo OpenBabel. Isso é feito procurando por rotatable bonds com o padrão SMARTS [! \$(*\#*)\&!D1]-!@[! \$(*\#*)\&!D1] que encontra ligações que não sejam triplas, não sejam de anel e não estejam ligadas a átomos terminais. Dessa maneira, é possível separar a molécula no maior conjunto possível de fragmentos, definidos pelas rotatable bonds. O script também encontra e gera no formato do input do DICE (.dfr), todas as ligações e ângulos (inclusive de diedro e diedro impróprio), deixando a cargo do usuário somente preencher os valores referentes ao campo de forças utilizado. Esse conjunto de fragmentos deve ser utilizado apenas como uma sugestão, já que fragmentos podem ser unidos quando conveniente. No caso do usuário optar por utilizar alguns dos fragmentos como rígido, o script "clean_dof" pode ser utilizado para eliminar os graus de liberdade rígidos desnecessários do arquivo .dfr.

Outro script que pode ser destacado é o "gromacs2dice", que converte topologias do código de dinâmica molecular GROMACS para o formato do DICE, facilitando a utilização para 


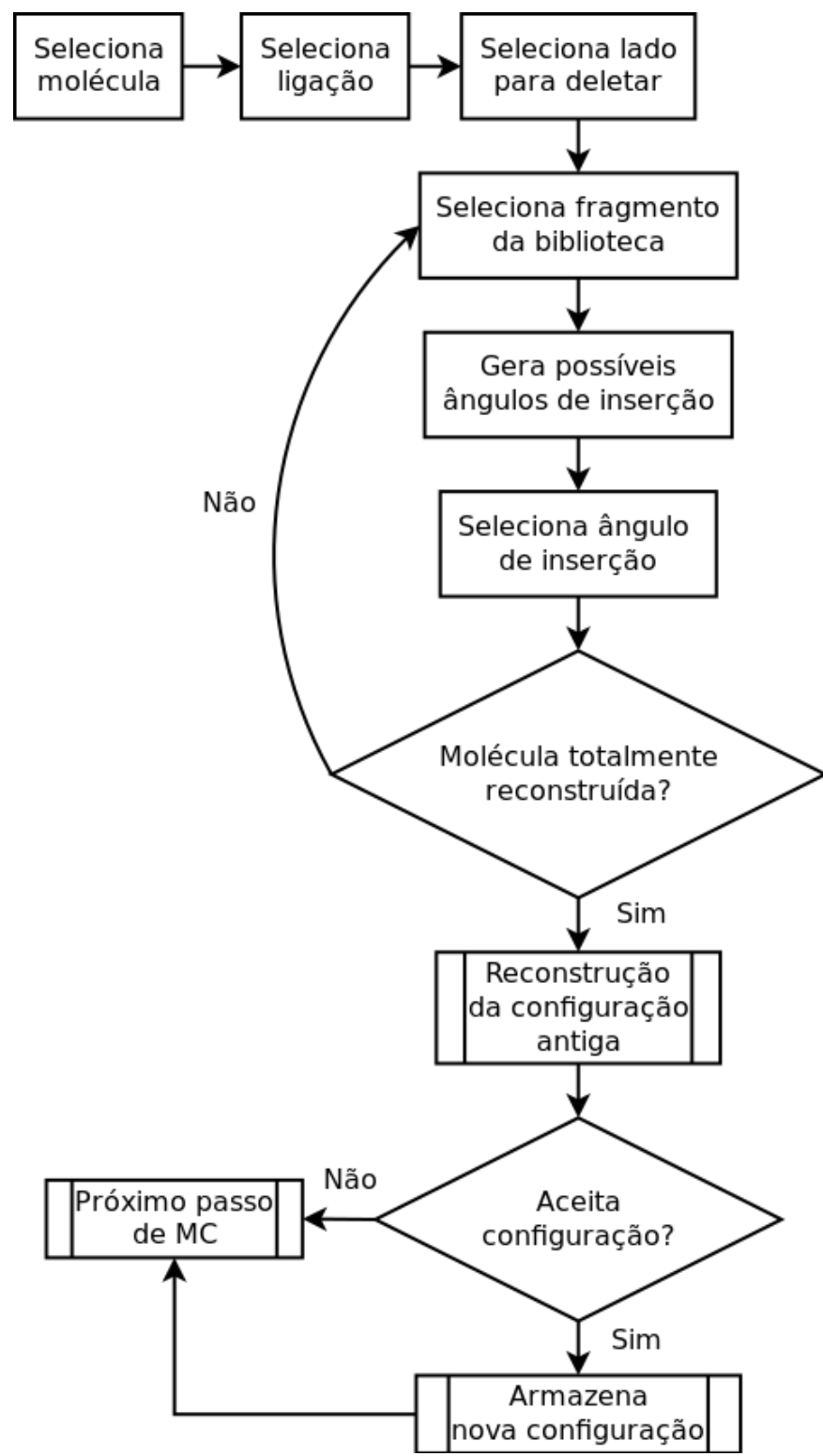

Figura 3 - Fluxograma mostrando a implementação do método CBMC no DICE. Detalhes de cada um dos passos são apresentados no texto.

quem já possui arquivos de entrada do GROMACS, ou ainda permitindo o uso das diversas ferramentas disponíveis para gerar a topologia com o GROMACS. Um procedimento muito conveniente para determinar parâmetros de simulação com o AMBER e OPLS-AA, que não deve ser utilizado cegamente, é utilizando o software MKTOP ${ }^{[80]}$ e o gromacs2dice. Utilizando o MKTOP, um conjunto de parâmetros e uma topologia do GROMACS é gerada. Conferindo os tipos dos átomos presentes nessa topologia com os tipos do arquivo atomtypes atp presente no diretório top do campo de força no diretório do GROMACS, e ajustando quando necessário, é possível utilizar o gromacs2dice para obter um arquivo de entrada para o CBMC do DICE de maneira relativamente simples. Contudo, mesmo utilizando a abordagem de conferir os tipos atômicos, ainda é necessário conferir os diedros das uniões dos fragmentos, que podem ter perfis de energia completamente diferentes dos encontrados com mecânica quântica. 
Para visualizar os diedros efetivos e auxilar a reparametrização do campo de força quando necessário, um outro script chamado "plot_eff_tors" pode ser utilizado. Com essa ferramenta, é possível encontrar o perfil de energia referente a rotação em torno de uma das rotatable bonds e comparar essa energia com a energia encontrada com cálculos de mecânica quântica. Para isso, o script também gera arquivos de entrada do Gaussian para um conjunto de rotações em torno de uma rotatable bond, baseado no método e base informado pelo usuário. Baseado nessas informações, a reparametrização de termos de energia de diedro é facilitada, e é possível garantir que o potencial se assemelha ao de mecânica quântica.

\subsection{Dinâmica Molecular}

Assim como o método de Monte Carlo para a amostragem de sistemas moleculares, a dinâmica molecular ${ }^{[13,14]}$ é um método extremamente popular para o cálculo de médias de propriedades em ensembles termodinâmicos e amostragem de estruturas. A ideia principal do método é tratar o sistema como sendo um conjunto de $N$ partículas clássicas interagentes, resolvendo as equações de Newton numericamente e fazendo a evolução temporal

$$
m_{i} \frac{\partial^{2} \mathbf{r}_{i}}{\partial t^{2}}=\mathbf{F}_{i}, \text { para } i=1,2,3, \ldots, N
$$

com $\mathbf{r}_{i}$ e $m_{i}$ sendo, respectivamente, a posição e massa da partícula $i$ e $\mathbf{F}_{i}$ sendo as forças, vindas do campo de força utilizado com a energia dada pelas funções descritas na seção 2.1 e forças dadas por

$$
\mathbf{F}_{i}=-\frac{\partial \mathcal{U}}{\partial \mathbf{r}_{i}}
$$

Para a solução das equações é feita uma discretização temporal em unidades $\Delta t$ (chamado timestep), que deve levar em consideração o compromisso de estabilidade numérica e desempenho computacional.

A solução numérica das equações de movimento é feito utilizando algum algoritmo de integração. Neste trabalho, o algoritmo leap-frog foi utilizado, mas outros algoritmos podem ser encontrados disponíveis na maioria das implementações, como por exemplo o algoritmo de Verlet velocidade. No algoritmo leap-frog, ${ }^{*}$ a integração da velocidade $\mathbf{v}$ é feita no tempo $t-\frac{1}{2} \Delta t$

$$
\mathbf{v}\left(t+\frac{1}{2} \Delta t\right)=\mathbf{v}\left(t-\frac{1}{2} \Delta t\right)+\frac{\mathbf{F}(t)}{m} \Delta t
$$

enquanto a integração da posição $\mathbf{r}$ é feita no tempo $t$

$$
\mathbf{r}(t+\Delta t)=\mathbf{r}(t)+\mathbf{v}\left(t+\frac{1}{2} \Delta t\right) \Delta t
$$

\footnotetext{
*O índice $i$ indicando a partícula será omitido para simplificar a notação.
} 
Essas são as equações básicas do método, que são modificadas com o uso de termostatos ou barostatos, introduzidos a seguir. Note que a velocidade no tempo $t$ também pode ser obtida

$$
\mathbf{v}(t)=\frac{\mathbf{v}\left(t+\frac{1}{2} \Delta t\right)-\mathbf{v}\left(t-\frac{1}{2} \Delta t\right)}{2}
$$

o que é necessário para reescalar as velocidades com os termostatos e obter a distribuição de velocidades da temperatura desejada.

Diferentemente dos métodos de Monte Carlo onde a temperatura é naturalmente um parâmetro da simulação vindo da distribuição de Boltzmann, na dinâmica molecular o ensemble que se obtém imediatamente da integração com as equações 2.59 e 2.60 é o $N V E$ onde o número de partículas, volume e energia são mantidos constantes. Contudo, a utilização de outros ensembles termodinâmicos é interessante principalmente para a comparação com dados experimentais, já que o ensemble microcanônico normalmente não reproduz as condições usuais dos experimentos. A introdução tanto de temperatura quanto pressão (para os ensembles NVT e NPT) é feita com o uso de termostatos e barostatos.

Os termostatos são introduzidos através de um novo "reservatório" que é mantido em contato com o da simulação de interesse, e fazendo o reescalonamento das velocidades das partículas. Dois termostatos foram usados nesse trabalho para a comparação de efeitos do termostato, especialmente no que se refere ao banho térmico de sistemas pequenos. Um dos termostatos utilizados foi o velocity rescaling de Bussi, Donadio e Parrinello ${ }^{[81]}$, um termostato de acoplamento fraco onde as velocidades são reescalonados, mas diferentemente dos termostatos usuais de reescalonamento de velocidades como o de Berendsen, ${ }^{[82]}$ o velocity rescaling reproduz de fato o ensemble canônico. Isso é feito evoluindo a energia cinética temporalmente a cada passo, com um termo estocástico*, para então fazer o reescalonamento das velocidades baseados nessa energia cinética alvo.

O outro termostato utilizado foi o termostato de Nosé-Hoover, ${ }^{[14,83]}$ onde temos são adicionado a lagrangeana do sistema, referente ao banho térmico. Dessa maneira, o reservatório introduzido tem associado a si um momento e equação de movimento, com um parâmetro chamado de "parâmetro de massa" do reservatório dando a forma que a temperatura de equilíbrio é atingida. Com esse termostato, diferentemente dos termostatos de acoplamento fraco onde a temperatura alvo é atingida com uma relaxação exponencial, a temperatura alvo é atingida de maneira oscilatória, o que torna o processo de relaxação tipicamente mais demorado. ${ }^{[21]}$ Por outro lado, diferentemente dos termostatos de acoplamento fraco comuns, onde não se garante a amostragem no ensemble canônico, o termostato de Nosé-Hoover garante a amostragem nesse ensemble, e por isso historicamente tem sido utilizado. Vale ressaltar no entanto que o termostato de Nosé-Hoover pode sofrer de problemas com a ergodicidade

* Esse termo estocástico que garante a amostragem no ensemble canônico, e se o mesmo é removido o termostato recai no termostato de Berendsen 
quando há forças externas ou o centro de massa da partícula não está fixo, e por isso pode ser importante a utilização de cadeias de termostatos de Nosé-Hoover nesses casos. ${ }^{[14]}$

Já os barostatos reescalam as coordenadas das moléculas e tamanho da caixa periodicamente, tendo como objetivo manter a caixa em uma pressão constante. Especificamente, nesse trabalho é utilizado o barostato de Berendsen, ${ }^{[82]}$ que tem o mesmo princípio do termostato de Berendsen e converge exponencialmente o tamanho da caixa para o tamanho de equilíbrio. Assim como no caso dos termostatos, a pressão varia durante a simulação, mas somente em torno da pressão alvo desejada.

\subsection{Métodos de mecânica quântica}

Na seção 4.5 o espectro de absorção da molécula de óxido mesityl é calculado. Para esse tipo de cálculo, o conhecimento dos níveis de energia eletrônicos da molécula é necessário, o que só é possível utilizando métodos de mecânica quântica. Por se tratar de um assunto com vasta literatura e não ser o método principal de estudo nessa tese, apenas uma breve introdução a esses métodos é apresentada. Uma visão mais completa sobre os métodos de teoria de funcional da densidade (DFT, do inglês density functional theory) pode ser encontrada em diversos livros texto, ${ }^{[84-86]}$ e a versão dependente do tempo da teoria (TD-DFT, do inglês time dependant $D F T$ ) é descrita em detalhes em livros texto e artigos de revisão. ${ }^{[87-89]}$

O problema a ser resolvido para encontrar os níveis de energia eletrônicos é a solução da equação de Schrödinger não relativística independente do tempo para $P$ elétrons e $N$ núcleos.

$$
\hat{H} \Psi\left(\mathbf{r}^{P}, \mathbf{R}^{N}\right)=E \Psi\left(\mathbf{r}^{P}, \mathbf{R}^{N}\right)
$$

onde $\hat{H}$ é o Hamiltoniano de muitos corpos, $\Psi\left(\mathbf{r}^{P}, \mathbf{R}^{N}\right)$ a função de onda em função, respectivamente, das coordenadas eletrônicas ( $\mathbf{r}$ ) e nucleares $(\mathbf{R})$, e $E$ é a energia do auto-estado $\Psi\left(\mathbf{r}^{P}, \mathbf{R}^{N}\right)$. Em unidades atômicas, o Hamiltoniano para esse problema de muitos corpos é dado por

$$
\hat{H}\left(\mathbf{r}^{P}, \mathbf{R}^{N}\right)=\hat{K}_{n}\left(\mathbf{R}^{N}\right)+\hat{K}_{e}\left(\mathbf{r}^{P}\right)+\hat{V}_{n e}\left(\mathbf{r}^{P}, \mathbf{R}^{N}\right)+\hat{V}_{e e}\left(\mathbf{r}^{P}, \mathbf{R}^{N}\right)+\hat{V}_{n n}\left(\mathbf{R}^{N}\right),
$$

sendo os dois primeiros termos referentes à energia cinética nuclear e eletrônica, e os termos restantes referentes aos potenciais eletrostáticos de interação núcleo-elétron, elétron-elétron e núcleo-núcleo.

Utilizando a aproximação de Born-Oppenheimer, os movimentos eletrônico e nuclear são separados na equação de Schrödinger, de modo que o movimento nuclear pode, tipicamente, ser tratado classicamente. A equação de Schrödinger para o problema eletrônico é então dada por

$$
\hat{H}_{e} \psi\left(\mathbf{r}^{P} ;\left\{\mathbf{R}^{N}\right\}\right)=E_{e} \psi\left(\mathbf{r}^{P} ;\left\{\mathbf{R}^{N}\right\}\right),
$$


onde $\left\{\mathbf{R}^{N}\right\}$ indica a dependência paramétrica da função de onda eletrônica com as posições nucleares. O Hamiltoniano eletrônico da equação 2.64 é composto dos termos

$$
\hat{H}_{e}=\hat{K}_{e}\left(\mathbf{r}^{P}\right)+\hat{V}_{n e}\left(\mathbf{r}^{P} ;\left\{\mathbf{R}^{N}\right\}\right)+\hat{V}_{e e}\left(\mathbf{r}^{P}\right)
$$

que por sua vez são dados por

$$
\begin{aligned}
& \hat{K}_{e}\left(\mathbf{r}^{P}\right)=-\sum_{i=1}^{P} \frac{1}{2} \nabla_{\mathbf{r}_{i}}^{2}, \\
& \hat{V}_{n e}\left(\mathbf{r}^{P},\left\{\mathbf{R}^{N}\right\}\right)=-\sum_{\alpha=1}^{N} \sum_{i=1}^{P} \frac{Z_{\alpha}}{\left|\mathbf{R}_{\alpha}-\mathbf{r}_{i}\right|}, \\
& \hat{V}_{e e}\left(\mathbf{r}^{P}\right)=\frac{1}{2} \sum_{\substack{i=1 \\
j \neq i}}^{P} \sum_{\substack{j=1 \\
j \neq i}}^{P} \frac{1}{\left|\mathbf{r}_{j}-\mathbf{r}_{i}\right|},
\end{aligned}
$$

onde $Z_{\alpha}$ são os números atômicos dos núcleos $\alpha$.

A solução da equação 2.64 é uma tarefa complicada para os casos onde $P \neq 1$. A DFT é uma teoria que tenta simplificar a solução da equação 2.64 ao utilizar ao invés da função de onda, que é descrita por $3 P$ variáveis, a densidade eletrônica, que pode ser descrita por apenas 3. Isso é possível graças aos teoremas de Hohenberg e Kohn, ${ }^{[90]}$ que mostram que qualquer observável pode ser descrito como um funcional da densidade eletrônica $n(\mathbf{r})$, e também que a energia do estado fundamental e densidade do estado fundamental podem ser obtidas com o princípio variacional. O caminho para a solução do problema eletrônico é então dada por Kohn e Sham (KS), ${ }^{[91]}$ que utilizam de um sistema de elétrons não interagentes que possui a mesma densidade eletrônica que o sistema real com os elétrons interagindo. A energia total do sistema de KS é escrita como

$$
E_{e}[n(\mathbf{r})]=K_{0}[n(\mathbf{r})]+V_{n e}[n(\mathbf{r})]+V_{e e}[n(\mathbf{r})]+E_{x c}[n(\mathbf{r})]
$$

sendo $K_{0}[n(\mathbf{r})]$ a energia cinética do sistema não interagente, e o termo $E_{x c}[n(\mathbf{r})]$ é a energia de troca e correlação, que além das energias de troca e correlação, inclui a correção da energia cinética e exclui a auto interação no termo $V_{e e}[n(\mathbf{r})]$.

A equação 2.69 mostra que se o termo de troca e correlação for conhecido exatamente, a energia obtida é exata e a mesma do problema da equação de Schrödinger. Contudo, a $E_{x c}[n(\mathbf{r})]$ não é conhecida exatamente, e diversos termos (chamados de funcionais de troca e correlação) foram e vem sendo propostos, sendo que cada um deles apresenta uma certa quantidade de esforço computacional para o seu cálculo, e é mais adequado a um tipo de sistema. Os funcionais de troca e correlação utilizados no capítulo 4 foram o B3LYP e o BHandHLYP. Ambos os funcionais são classificados como funcionais híbridos, por incluírem uma fração da energia de troca de Hartree-Fock. A escolha dos funcionais se deu baseada nos estudos realizados por Damasceno, Cabral e Coutinho ${ }^{[92]}$, que já haviam utilizado esses funcionais para o estudo da molécula de óxido mesityl. 
A densidade, necessária para o cálculo da energia com a equação 2.69 , é obtida através da solução auto consistente do problema de elétrons não interagentes de KS. Os orbitais de $\mathrm{KS}, \phi_{i}^{K S}(\mathbf{r})$, são encontrados através da equação

$$
\hat{h} \phi_{i}^{K S}(\mathbf{r})=\epsilon_{i}^{K S} \phi_{i}^{K S}(\mathbf{r})
$$

com

$$
\hat{h}=-\frac{1}{2} \nabla_{i}^{2}+V_{e f f}(\mathbf{r})
$$

e sendo

$$
V_{e f f}[n(\mathbf{r})]=V_{n e}[n(\mathbf{r})]+V_{e e}[n(\mathbf{r})]+\frac{\delta E_{x c}[n(\mathbf{r})]}{\delta n(\mathbf{r})} .
$$

Da dependência da equação 2.72 com a densidade que surge a necessidade da solução auto consistente das equaçãos 2.70 e 2.72. À partir dos $\phi_{i}^{K S}(\mathbf{r})$ a densidade é então calculada como $n(\mathbf{r})=\sum_{i}^{N}\left|\phi_{i}^{K S}(\mathbf{r})\right|^{2}$.

Os orbitais de KS por sua vez, são expandidos em um conjunto de funções base finito. Esse conjunto de funções base normalmente é composto de funções de onda plana, funções do tipo Slater, funções gaussianas ou ainda funções hidrogenóides. Para sistemas moleculares, um tipo de função base muito popular, e utilizado nesse trabalho, são as funções gaussianas. Em sistemas não periódicos, o uso de funções gaussianas como conjunto de funções base é interessante pois o cálculo de integrais dessa função tem um custo computacional muito menor do que o de funções do tipo Slater, por exemplo. As funções gaussianas utilizadas nos cálculos são na realidade compostas de uma combinação linear de funções gaussianas feita para representar um orbital molecular. Essa combinação linear das funções gera uma função que por sua vez é chamada de função gaussiana contraída, de modo que é possível obter o decaimento correto dos orbitais atômicos a curtas e longas distâncias.

Combinando funções gaussianas contraídas, as funções base do tipo split-valence (SV) são construídas. As funções SV atribuem aos orbitais de caroço uma base mínima, que é correspondente aos orbitais ocupados para cada espécie atômica, e bases duplas para orbitais de valência. No capítulo 4 o conjunto de funções base utilizado é um conjunto do tipo SV criado por John Pople, especificamente a base $6-311++G(d, p)$, que também conta com funções difusas e para a inclusão de polarização.

O cálculo das energias de transição eletrônica é realizado com a TD-DFT. A necessidade do uso da TD-DFT vem do fato de não haver uma expressão para as energias de transição eletrônicas em função da densidade. ${ }^{[88]}$ Utilizando o formalismo teoria de resposta linear, é possível mostrar que as energias de transição são os polos presentes na função resposta densidade-densidade. Partindo deste princípio, um conjunto de equações que relacionam os auto estados e auto valores solução do problema de KS, que é independente do tempo, é encontrado, o que simplifica o problema drasticamente. Esse conjunto de equações é conhecido como equações de Casida. 
As equações de Casida são um problema de autovalor do tipo

$$
\mathbb{C} \mathbf{Z}=\Omega^{2} \mathbf{Z}
$$

onde os $\Omega$ dão as energias de transição, e $\mathbb{C}$ e $\mathbf{Z}$ são matrizes construídas utilizando os orbitais e auto valores de KS obtidos com a solução da equação 2.70 e o kernel xc (de troca-correlação), que por sua vez é a derivada funcional com respeito a densidade do potencial de troca-correlação calculado na densidade do estado fundamental. A expressão para $\mathbb{C}$ e $\mathbf{Z}$ e uma abordagem completa de como o formalismo do TD-DFT e a teoria de resposta são utilizados para o cálculo de energia de excitações podem ser vistos no capítulo 7 da referência ${ }^{[87]}$. 



\section{Capítulo 3}

\section{Validação da implementação}

Neste capítulo, serão apresentados os resultados referentes a simulações com o método CBMC de octano em fase gasosa e 1,2-dicloroetano em fase gasosa e diferentes solventes. Os resultados serão comparados com simulações de dinâmica molecular e resultados experimentais, mostrando que a implementação do CBMC está correta, e possui algumas vantagens frente e dinâmica molecular no estudo dos sistemas mencionados.

\subsection{Octano em fase gasosa}

Após finalizada a implementação do método, foram iniciados os testes para verificar a consistência desta implementação e a robustez do método. Dois sistemas teste foram escolhidos: a molécula de octano em fase gasosa, e a molécula de 1,2-dicloroetano, que nesse caso foi estudada em fase gasosa e diferentes solventes, como será mostrado na seção 3.2. A escolha do octano se deu principalmente por se tratar de um sistema simples e com potencial bem estabelecido e bem comportado, que pode ser estudado tanto com o CBMC quanto com a dinâmica molecular sem grandes dificuldades.

O principal objetivo da simulação do octano foi investigar a população de diedros na configuração trans, e nas configurações gauche+ e gauche-. Essa análise foi feita através distribuição dos ângulos de diedro entre os carbonos centrais da cadeia (C6-C9-C12-C15, conforme a numeração da figura 4), do octano. Analisando a curva de potencial da figura 4 dada pelo campo de força OPLS-AA para o ângulo de diedro desejado, é possível observar que a estrutura de mais baixa energia se trata da estrutura trans. Contudo, a diferença de energia entre a estrutura trans e as estruturas gauche é de cerca de $1 \mathrm{kcal} / \mathrm{mol}$, com uma barreira de aproximadamente $3 \mathrm{kcal} / \mathrm{mol}$ que tipicamente é transposta com o auxílio da energia térmica. Isso faz com que haja uma coexistência dessas estruturas, com populações de equilíbrio que são a princípio bem definidas.

Através dessas informações, é possível ter uma ideia de como é a dinâmica da exploração da superfície de energia potencial durante a amostragem. O que se espera, é que as populações 

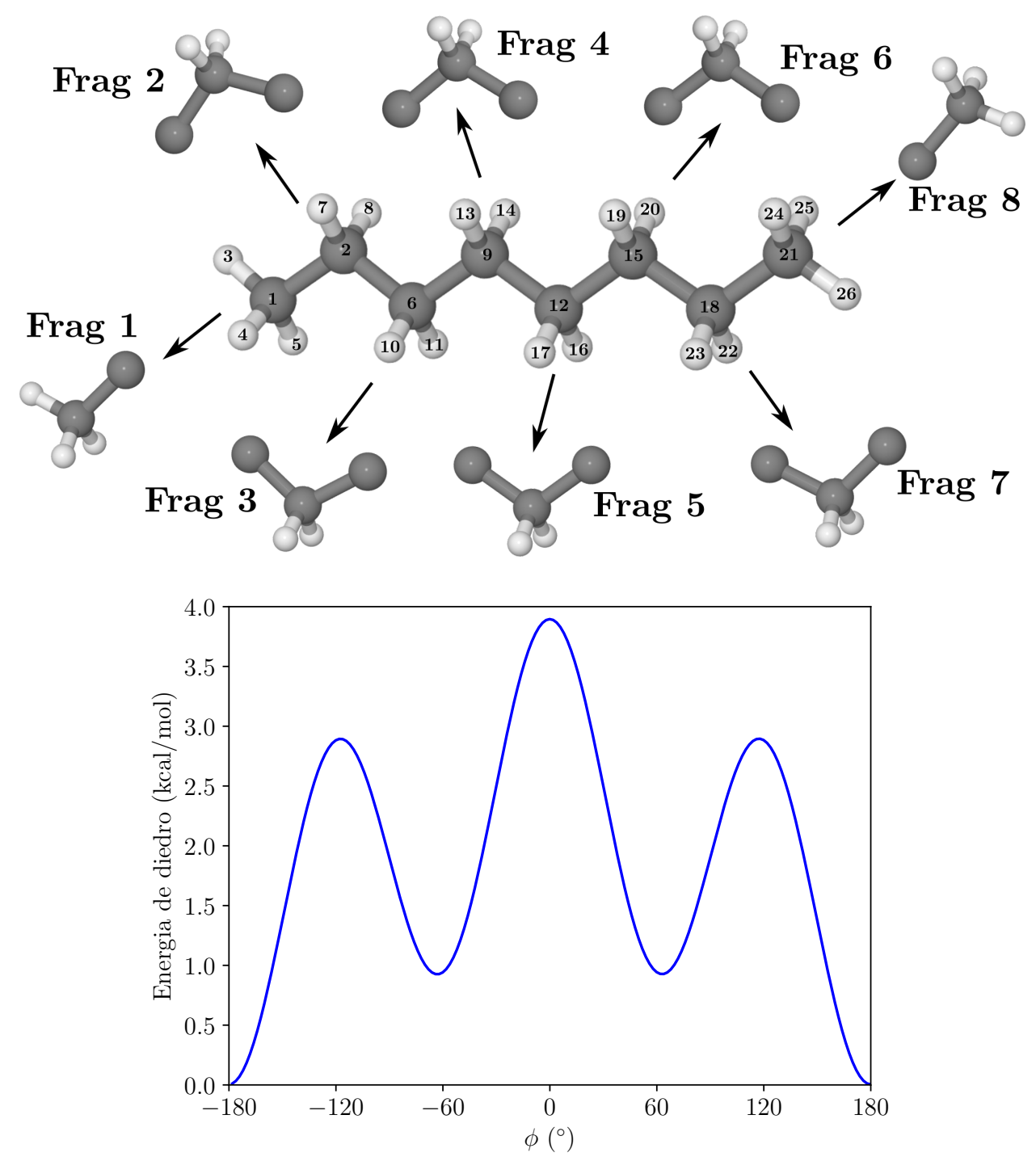

Figura 4 - Molécula de octano na configuração trans com átomos numerados e seus fragmentos, e energia potencial de diedro $u_{\text {torsional }}$ para a rotação dos grupos $\mathrm{CH}_{2}$ dos diedros internos da molécula. A curva foi obtida através da rotação em torno do diedro C6-C9-C12-C15 mantendo ambas as extremidades rígidas durante a rotação.

sejam consistentes com dados obtidos experimentalmente, ou ainda com estimativas teóricas, inferidas a partir da superfície de energia potencial. Também pelas características da superfície de energia potencial, se espera que algumas simetrias sejam obedecidas como, por exemplo, que as populações de configurações gauche+ e gauche- sejam iguais. Para checar esses fatos e realizar uma comparação entre os dois tipos de amostragem, simulações com o algoritmo CBMC e dinâmica molecular foram realizadas. Em ambos os casos, o campo de forças utilizado para as simulações foi o OPLS-AA, com os parâmetros usuais empregados para alcanos. ${ }^{[66]}$

No caso da simulação com o CBMC, a molécula de octano foi fragmentada em 8 fragmentos, sendo dois fragmentos compostos pelos átomos $\mathrm{C}_{2} \mathrm{H}_{3}$ (extremidades) e seis $\mathrm{C}_{3} \mathrm{H}_{2}$, conforme mostrado na figura 4. Vale ressaltar que os fragmentos são constituídos de 5 átomos, 
pois são formados pelo carbono central mais os 4 átomos ligados a ele, dando a coordenação 4 . A inclusão do segundo carbono no fragmento ocorre para definir a ligação que corresponde ao diedro do grau de liberdade maleável da união do fragmento ao fragmento vizinho. A amostragem dos graus de liberdade rígidos dos fragmentos é feita com o algoritmo de amostragem de branch-point descrito na subseção 2.3.2. A princípio, não é necessária a amostragem dos graus de liberdade rígidos para cada um dos 8 fragmentos já que, como mencionado, esses podem ser reduzidos a dois tipos de fragmentos, bastando então a amostragem de duas bibliotecas de fragmentos. Contudo, a amostragem de uma biblioteca para cada um dos fragmentos também está correta, já que a mesma distribuição é obtida. Por isso a estratégia de gerar uma biblioteca para cada um dos 8 fragmentos foi utilizada, evitando assim a necessidade de identificar fragmentos idênticos, que implicaria na implementação de mais uma etapa no algoritmo. Nas simulações do octano $10^{4}$ configurações foram utilizadas em cada biblioteca de fragmentos, cada uma dessas selecionadas a cada 500 passos de MC com a amostragem de branch-point.

As simulações com o CBMC foram realizadas no ensemble NVT, na temperatura de $298.15 \mathrm{~K}$ e com uma densidade de $0.001 \mathrm{~g} \mathrm{~cm}^{-3}$. Como já mencionado, o campo de forças utilizado foi o OPLS-AA, e os arquivos de entrada das simulações, contendo as constantes do campo de força, podem ser vistas no apêndice C. Foram utilizados 18 ângulos tentativas de inserção $\kappa_{\phi}$, distribuídos uniformemente no intervalo de $360^{\circ}$ (sendo o primeiro sorteado aleatoriamente). Esse valor de $\kappa_{\phi}$ foi escolhido para manter o compromisso entre custo computacional e taxa de aceitação. $O$ valor de $\kappa_{\phi}=18$ está de acordo com valores reportados na literatura, ${ }^{[1]}$ onde 12 ângulos tentativa de inserção foram utilizados na simulação de alcanos. As taxas de aceitação nessas simulações ficaram em torno de $35 \%$ e $65 \%$, sendo a taxa mais alta obtida na simulação onde somente o potencial de diedro foi considerado. Ao menos $10^{7}$ passos de CBMC foram realizados em cada simulação.

Para comparação, foram realizadas simulações de dinâmica molecular com o código GROMACS na versão 4.6.7. Assim como na simulação com o CBMC, o ensemble NVT foi utilizado, com uma densidade de $0.001 \mathrm{~g} \mathrm{~cm}^{-3}$ e a temperatura de $298.15 \mathrm{~K}$ mantida com o auxílio do termostato de Nosé-Hoover (com período $\tau_{T}=1.0$ ). O algoritmo Leap-Frog, descrito na seção 2.5 , foi utilizado para a integração das equações de movimento. O intervalo de integração foi definido como $d t=0.1 \mathrm{fs}$, e o tempo total simulado foi de 50 ns para cada simulação, totalizando $5 \times 10^{8}$ passos.

Como somente uma molécula foi utilizada na caixa, as únicas energia de interação presentes são as energia dos termos ligados, e não ligados (Lennard-Jones e Coulomb) intramoleculares. Com o objetivo de verificar a influência de cada uma das contribuições de energia, três tipos de simulação foram realizadas, sendo uma considerando todos os termos da energia, outra sem a parte eletrostática de Coulomb, e outra sem a contribuição de Coulomb e Lennard-Jones. Apesar de não refletirem necessariamente o sistema físico, as simulações 
que não levam em consideração alguns dos termos e energia são úteis pois apresentam uma superfície de energia potencial ainda mais simplificada, e fornecem alguma informação sobre a importância de cada contribuição nas populações configuracionais. A simulação sem a energia de Coulomb e Lennard-Jones é particularmente interessante, pois a única contribuição para as diferenças de energia vem da energia de diedro $u_{\text {torsional }}$, que pode ser vista na figura 4 , e que é independente da união entre quais fragmentos se olha a distribuição. Como a diferença de energia entre as configurações trans e gauche é conhecida, é possível estimar a população relativa de configurações gauche através da constante de equilíbrio. Consideramos uma configuração do octano como gauche quando o ângulo de diedro está no intervalo $\left[-120^{\circ}, 120^{\circ}\right]$, gauche + quando o diedro está em $\left[0^{\circ}, 120^{\circ}\right]$ e gauche- para diedros entre $\left[-120^{\circ}, 0^{\circ}\right]$.

Assumindo que somente três tipos de configuração são acessíveis ao sistema: trans $(t)$, gauche $+(g(+))$ e gauche- $(g(-))$, temos que a concentração total dessas conformações deve somar $100 \%$. Assim:

$$
[t]+[g(+)]+[g(-)]=1
$$

Além disso, levando em consideração o potencial da figura 4, vemos que há uma simetria com relação as configurações gauche+ e gauche-, de modo que suas concentrações são iguais:

$$
[g(+)]=[g(-)]
$$

Podemos portanto encontrar a constante de equilíbrio $K$ de mudança entre as conformações trans e gauche+

$$
K=\frac{[g(+)]}{[t]}=\frac{[g(+)]}{1-2[g(+)]},
$$

onde utilizamos a equação 3.1 e a equação 3.2, e a partir da qual podemos obter a população de configurações gauche+

$$
[g(+)]=\frac{K}{2 K+1}
$$

Finalmente, podemos calcular a concentração de configurações gauche + , pois sabemos que a constante de equilíbrio está relacionada com a variação da energia livre de Gibbs $\Delta G$ por

$$
K=e^{\frac{-\Delta G}{k T}}
$$

com $k$ sendo a constante de Boltzmann e $T=298.15 \mathrm{~K}$ a temperatura.

Como a molécula de octano é uma molécula pequena, com apenas 26 átomos, as simulações foram feitas no ensemble $N V T$, e podemos aproximar a variação de entropia e de pressão como sendo nulas, ou seja, $\Delta S \approx 0$ e $\Delta P \approx 0$. Desse modo, a variação da energia livre $\Delta G=\Delta U+V \Delta P-T \Delta S$ é dada, aproximadamente, pela variação da energia interna do sistema, $\Delta G \approx \Delta U$. Podemos então estimar $\Delta G \approx 0.922 \mathrm{kcal} / \mathrm{mol}$ à partir do $\Delta U$ da figura 4 , e finalmente encontramos a concentração $[g(+)]=14.8 \%$. Portanto, pela simetria esperada das populações, estimamos que o número total de configurações gauche é de $29.6 \%$. Essa população, que chamamos de população ideal, foi comparada com as populações obtidas pelas 
Tabela 1 - Populações relativas de configurações gauche obtidas com simulações de CBMC e dinâmica molecular. Os valores da MD foram calculados levando em consideração os últimos 20 ns da dinâmica. Essas populações foram calculadas com referência ao ângulo de diedro definido por C6-C9-C12-C15. O valor da população ideal é de $29.6 \%$ (ver texto) considerando somente $u_{\text {torsional, ou seja, a energia de rotação }}$ dos ângulos diedrais.

\begin{tabular}{lcccccc}
\hline \multirow{2}{*}{ Potencial } & \multicolumn{2}{c}{ \%gauche } & \multicolumn{2}{c}{ \%gauche+ } & \multicolumn{2}{c}{ \%gauche- } \\
\cline { 2 - 7 } & CBMC & MD & CBMC & MD & CBMC & MD \\
\hline Somente diedro & $27.30 \%$ & $33.41 \%$ & $13.63 \%$ & $17.39 \%$ & $13.67 \%$ & $16.02 \%$ \\
Diedro + LJ & $12.31 \%$ & $12.38 \%$ & $6.30 \%$ & $6.76 \%$ & $6.01 \%$ & $5.63 \%$ \\
OPLS-AA completo & $17.67 \%$ & $17.51 \%$ & $8.73 \%$ & $8.33 \%$ & $8.94 \%$ & $9.18 \%$ \\
\hline
\end{tabular}

simulações de dinâmica molecular e CBMC. Os valores obtidos para as populações gauche com as simulações podem ser vistos na tabela 1 . Na linha com o potencial identificado como somente diedro, os termos de LJ e Coulomb do potencial foram desligados, e portanto o potencial amostrado é somente o exibido na figura 4. Como nesse caso sabemos que a população ideal de configurações gauche é de $29.6 \%$, vemos que o valor obtido com as configurações geradas pelo CBMC (27.3\%) está em melhor acordo do que o valor obtido da simulação de dinâmica molecular $(33.41 \%)$.

A análise foi feita sobre um conjunto de $5 \times 10^{4}$ estruturas tanto para o CBMC quanto para a MD, sendo essas selecionadas a cada $10^{3}$ configurações no caso da simulação de CBMC e a cada $10^{4}$ configurações no caso da MD. Para estimar a incerteza da porcentagem relativa de configurações gauche, o conjunto de estruturas amostradas foi subdividido em 5 janelas, sendo cada janela composta de 200 valores de porcentagem de população gauche. Cada uma das 200 porcentagens, por sua vez, foi estimada baseada num conjunto de 50 diedros consecutivos vindos da simulação. O valor médio de cada janela foi calculado pela média aritmética simples das 200 porcentagens, enquanto que a barra de erro foi estimada através do desvio padrão obtido com os mesmos valores. Na figura 5 é mostrada a evolução das porcentagens de estruturas gauche com a evolução dos passos de simulação. Foi notado que mesmo com um intervalo maior entre a seleção de estruturas da dinâmica molecular, as barras de erro são severamente maiores na figura 5(b), devido a correlação entre as estruturas que faz com que o número de configurações gauche no subconjunto de 50 diedros tenha uma grande variância. Uma variância menor é obtida se mais configurações são consideradas no conjunto para estimar a porcentagem, e.g., se ao invés de 50 configurações como na figura 5(b), 3000 configurações forem utilizadas. Contudo, para atingir esse objetivo mais configurações devem ser salvas, exigindo uma simulação mais longa. Ainda assim, mesmo com mais configurações, o melhor valor da incerteza obtido foi de $17 \%$, uma melhora sobre os $33 \%$ da figura 5 (b), mas ainda maior que os $6 \%$ obtidos com o CBMC.

A maior correlação entre as estruturas na MD fica evidente quando se observa a 


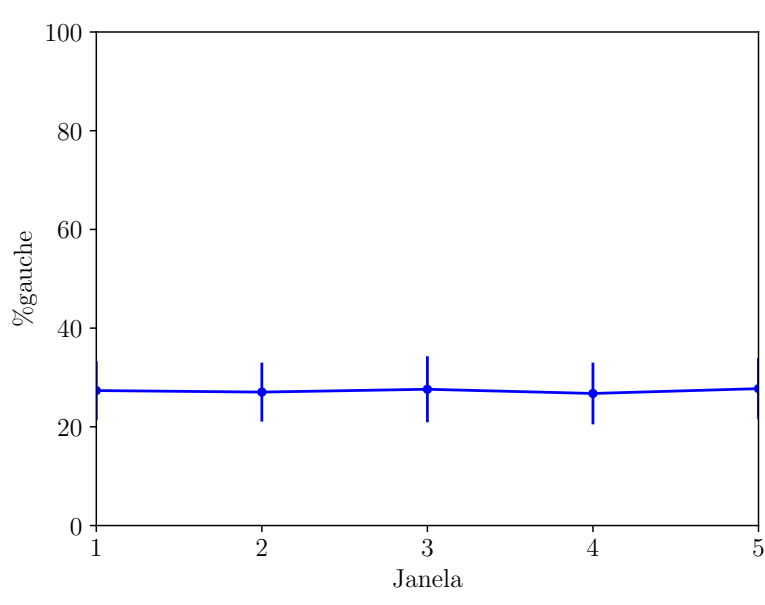

(a) CBMC

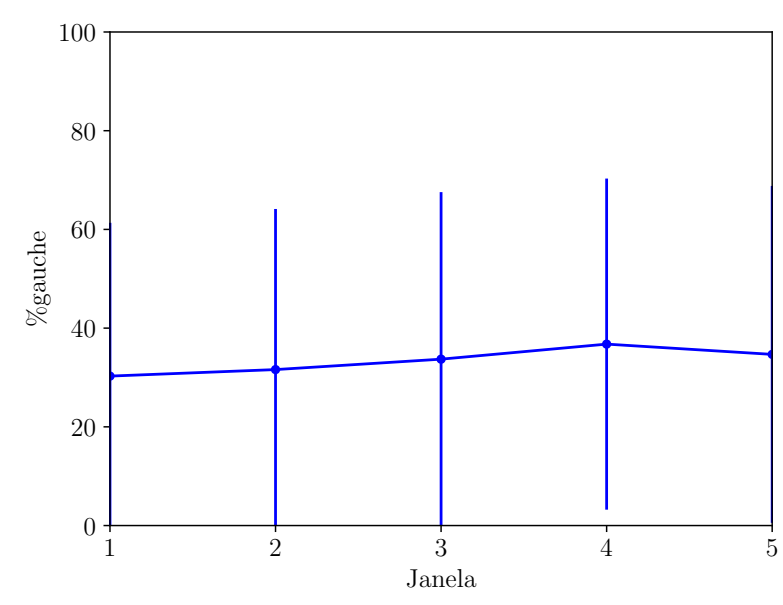

(b) MD

Figura 5 - Evolução da porcentagem relativa de configurações gauche durante as simulações. Detalhes de como os valores e barras de erro foram calculados estão no texto. $O$ erro médio percentual estimado para o caso do CBMC foi de $6 \%$, enquanto que para a MD ficou em $33 \%$, devido à correlação entre as estruturas mesmo com um intervalo maior entre as mesmas.

evolução do ângulo de diedro C6-C9-C12-C15 com os passos de simulação. Na figura 6 estão a evolução deste ângulo com os passos de simulação de CBMC e de MD, sendo nesse caso as configurações selecionadas a cada $10^{3}$ passos, e considerando somente os últimos $5 \times 10^{7}$ passos de cada uma das simulações. Notamos que a distribuição dos pontos no caso do CBMC é muito mais uniforme do que no caso da MD, onde é possível observar diversas linhas verticais próximas aos mínimos, indicando que são necessários diversos passos de simulação antes da dinâmica conseguir superar a barreira de energia. Isso também é verificado nas populações de gauche+ e gauche-, que de maneira geral, são menos simétricas no caso da MD. Essa diferença se dá justamente pelo fato da molécula ter de superar a barreira de energia antes de atingir outra configuração, fazendo com que a amostragem seja menos uniforme nesse sentido. Vale ressaltar no entanto que para simulações suficientemente longas, ambas as simulações devem obter as mesmas propriedades médias (como de fato se observa), já que ambas amostram o mesmo ensemble.

A discussão feita para o caso onde o potencial é constituído somente da energia de diedro, vale de maneira geral para os casos do potencial com os termos de Lennard-Jones e o potencial com a interação de Coulomb (OPLS-AA completo). O que se observa no entanto são diferentes populações de configurações gauche conforme exibido na tabela 1, o que é esperado, dado que a superfície de energia potencial explorada é diferente em cada caso e, portanto, as diferenças de energia entre as configurações trans e gauche são modificadas. Contudo, as porcentagens de configuração gauche calculadas a partir das simulações de CBMC e MD estão em acordo para os diferentes potenciais.

Esse conjunto de dados obtidos para as simulações de octano revela que a implementação 


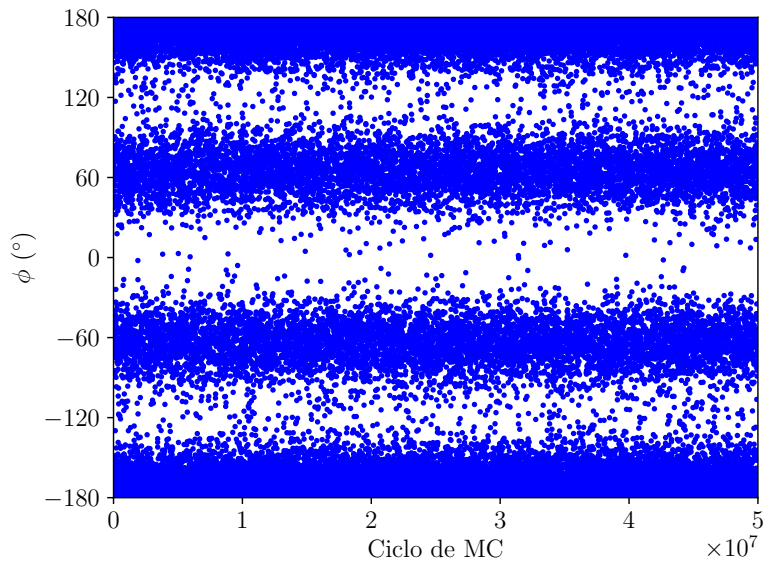

(a) CBMC

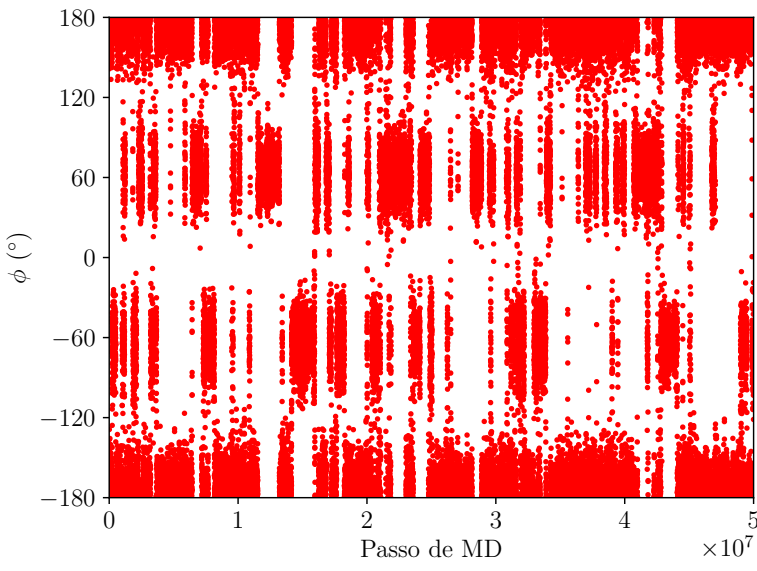

(b) MD

Figura 6 - Evolução do ângulo de diedro C6-C9-C12-C15 com os passos de simulação para a simulação com o CBMC e MD.

do método CBMC está consistente com o esperado. A concordância com os dados da MD obtidos com um software já bem estabelecido (GROMACS) trás confiabilidade aos resultados. No caso dá amostragem como potencial somente de diedro, onde há aparentemente uma pequena diferença entre os resultados das duas metodologias, observa-se na realidade uma melhor concordância do resultado da simulação CBMC com o resultado estimado pela constante de equilíbrio.

\subsection{1,2-Dicloroetano em fase gasosa e em meio solvente}

Com os resultados para a simulação de uma única molécula de octano mostrando valores compatíveis com os esperados, indicando uma implementação correta, foi então iniciada a simulação das moléculas em um líquido de 1,2-dicloroetano (DCE) e da molécula de DCE em diferentes solventes. A escolha do DCE se deu por existir na literatura um potencial bem definido para essa molécula, ${ }^{[93]}$ além de resultados de simulação e dados experimentais também estarem disponíveis. ${ }^{[93-96]}$ Outro fator importante é que se trata de uma molécula simples (composta de apenas 2 fragmentos para a simulação com o CBMC, conforme ilustrado na figura 7), o que permite avaliar como a implementação se comporta para a simulação de líquidos partindo de um caso simples. Assim como nas simulações do octano, para as simulações do DCE com o CBMC as bibliotecas de cada fragmento continham $10^{4}$ configurações cada uma, sendo essas selecionadas a cada 500 passos de MC.

Antes de iniciar as simulações com os líquidos, uma amostragem de uma molécula isolada de DCE foi realizada com o CBMC. Foram utilizados 16 possíveis ângulos de inserção $\left(\kappa_{\phi}\right)$ a cada passo, sorteados independentemente e aleatoriamente no intervalo de $360^{\circ}$. Esse valor de $\kappa_{\phi}$ está em acordo com os valores utilizados na literatura, e representa um bom 


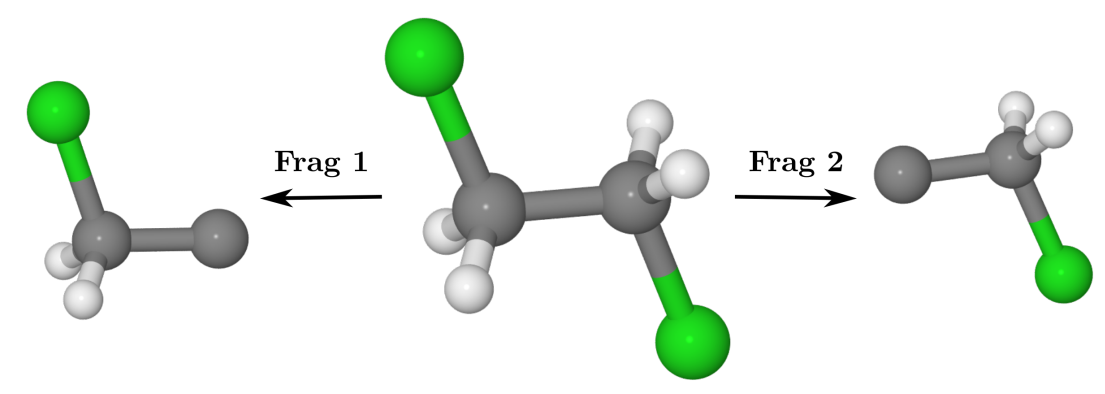

Figura 7 - Molécula de 1,2-dicloroetano (DCE) e seus fragmentos para a simulação com o CBMC.

compromisso entre custo computacional e taxa de aceitação, que nessa simulação se manteve em torno de $70 \%$. O campo de forças utilizado foi o OPLS-AA, com a parametrização específica para o DCE de Jorgensen et al. ${ }^{[93]}$, cujos parâmetros se encontram nos arquivos de entrada das simulações no apêndice D. Um total de $5 \times 10^{6}$ configurações foram selecionadas de uma simulação de $5 \times 10^{7}$ passos de MC. Com essas configurações o percentual de configurações trans foi estimado a partir das configurações com o diedro $\mathrm{Cl}-\mathrm{C}-\mathrm{C}-\mathrm{Cl}$ no intervalo $\left[120^{\circ}, 240^{\circ}\right]$, ou seja, $(180 \pm 60)^{\circ}$ (utilizando uma definição de diedro no intervalo $\left[0^{\circ}, 360^{\circ}\right]$ ).

Além do percentual de configurações trans, a distribuição de probabilidades $(f(\phi))$ para o ângulo de diedro exibida na figura 8 também foi calculada a partir das configurações da simulação com o CBMC. Na figura também está apresentada uma curva legendada como ideal, calculada partindo da energia de interação obtida com a rotação de um dos fragmentos (mantendo os ângulos de ligação fixos e variando apenas os diedros). Conhecendo a curva de energia em função da rotação a distribuição é calculada partindo da distribuição de Boltzmann, i.e., $f(\phi) \propto e^{-\beta \mathcal{U}\left(\mathbf{r}^{N}\right)} \operatorname{com} \mathcal{U}\left(\mathbf{r}^{N}\right)$ definido na seção 2.1. Vemos uma ótima concordância dos resultados, com os picos localizados na mesma posição e com amplitudes similares. A pequena diferença nas amplitudes da figura 8 pode ser entendida se levarmos em consideração que os grupos são mantidos rígidos durante o levantamento da curva de potencial da rotação dos fragmentos, e que a distribuição obtida com os dados da simulação de CBMC é obtida com um histograma e depende portanto do número de classes (caixas).

Na tabela 2 estão exibidos os valores obtidos para a porcentagem de configurações trans do DCE amostradas para diferentes condições de simulação. Os valores para os líquidos puro e DCE em meio solvente serão discutidos mais à frente no texto. Por hora, no atemos ao valor da porcentagem para o gás, assim como o valor experimental nessas mesmas condições, obtido através do espectro de absorção infra-vermelhor, ${ }^{[94]}$ e o obtido por outra simulação de MC. ${ }^{[93]}$ Observamos, dentro das margens de erro, uma ótima concordância entre os três valores. A incerteza foi estimada, assim como no caso do octano, a partir do desvio padrão médio calculado em diversas janelas de medidas. As janelas foram compostas de $10^{3}$ valores da porcentagem de configurações trans, que por sua vez foram calculadas partindo de 500 configurações. 


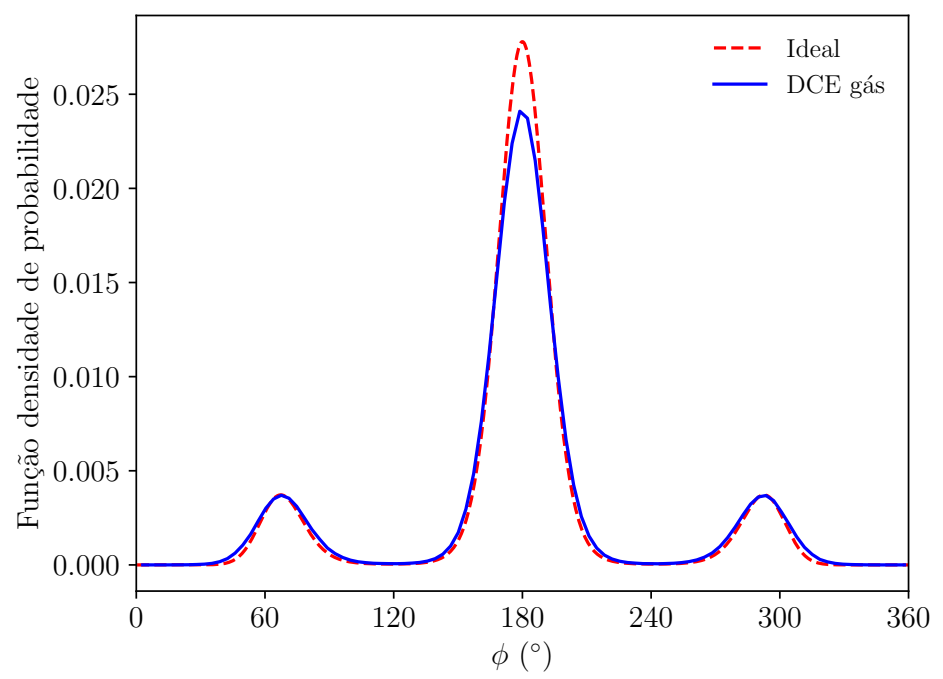

Figura 8 - Densidade de probabilidades da amostragem do ângulo de diedro $\mathrm{Cl}-\mathrm{C}-\mathrm{C}-\mathrm{Cl}$ calculada a partir da energia total de rotação de um dos fragmentos e a partir das configurações amostradas com o CBMC.

Tabela 2 - Porcentagem de configurações trans (com o diedro $\mathrm{Cl}-\mathrm{C}-\mathrm{C}-\mathrm{Cl}$ no intervalo $\left[120^{\circ}, 240^{\circ}\right]$ ) para o DCE em diferentes condições de simulação e solvente. Puro (rígido) indica uma simulação mantendo os ângulos internos dos fragmentos rígidos. Puro (viés no sorteio de $\phi$ ) é de uma simulação onde os ângulos possíveis de inserção são gerados com um viés antes mesmo da seleção com o CBMC, conforme descrito na seção 2.4. ${ }^{*}$ Valor obtido sem a polarização do ciclohexano. ${ }^{a}$ Tanabe ${ }^{[94]}$, ${ }^{b}$ Wiberg et al.; Jorgensen et al. ${ }^{[93,95]} \mathrm{e}^{c}$ Jorgensen et al. ${ }^{[93]}$. Os valores experimentais foram obtidos através do espectro de absorção infra-vermelho. Demais valores obtidos pelo autor.

\begin{tabular}{|c|c|c|c|c|}
\hline & $\%$ trans CBMC & $\%$ trans MD & \%trans Exp & $\%$ trans MC $c$ \\
\hline Gás & $77 \pm 3$ & $80 \pm 15$ & $77 \pm 2^{a}$ & 78.3 \\
\hline Ciclohexano & $77 \pm 3$ & $67 \pm 7$ & $62.0 \quad b$ & $75.3 *$ \\
\hline Puro & $30 \pm 3$ & $34 \pm 3$ & $35 \pm 4^{a}$ & 36.1 \\
\hline Puro (rígido) & $33 \pm 3$ & & & \\
\hline Puro (viés no sorteio de $\phi$ ) & $32 \pm 3$ & & & \\
\hline Acetonitrila & $21 \pm 3$ & & 25.6 & 22.2 \\
\hline
\end{tabular}

Uma análise adicional sob os ângulos amostrados internamente nos fragmentos com o algoritmo de branch-point pode ser vista nas figuras 9, 10 e 11. A distribuição ideal foi obtida utilizando a distribuição de Boltzmann com a energia obtida à partir dos parâmetros do campo de força e o potencial harmônico de interação $u_{\text {angle }}$ da equação 2.2. Como visto na figura 9 , a amostragem feita com o algoritmo branch-point, onde não há interações além daquelas descritas pelos termos dos ângulos, está de acordo com a distribuição esperada para esse caso. A distribuição exibida nesse caso, é somente a distribuição dos ângulos dentro da biblioteca de fragmentos, reproduzindo o ensemble que contém somente os átomos pertencentes ao 


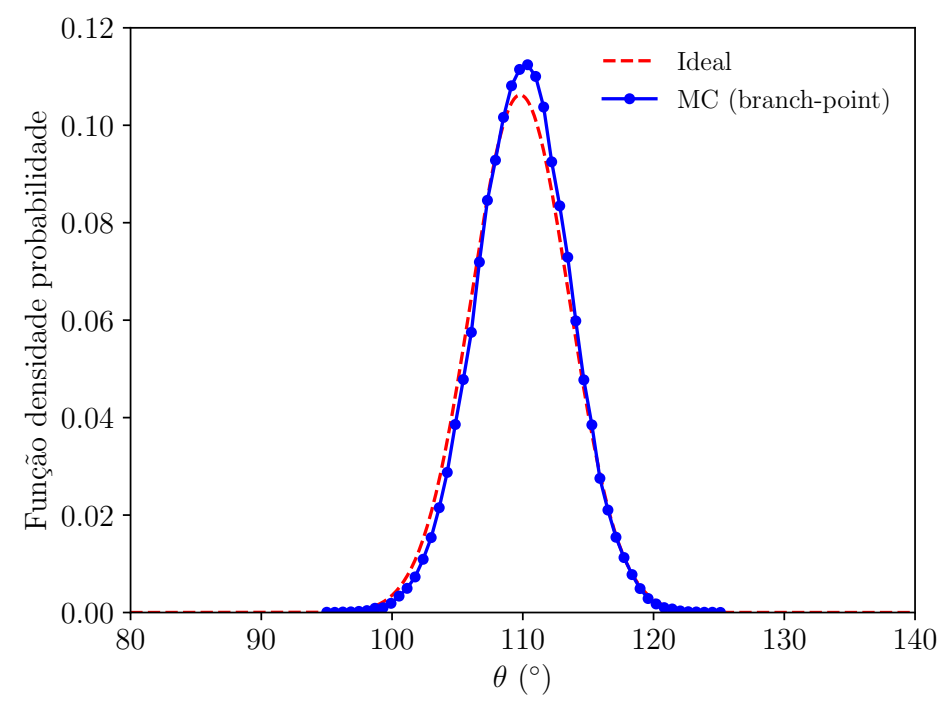

Figura 9 - Distribuição dos ângulos $\mathrm{Cl}-\mathrm{C}-\mathrm{C}$ amostrados com o algoritmo de amostragem de branch-point em comparação com a curva ideal, que representa a distribuição obtida à partir do potencial harmônico $u_{\text {angle }}$.

respectivo fragmento na temperatura desejada. Nesse caso não é levado em consideração quais os ângulos que são amostrados com o CBMC, i.e., quais são aceitos pelo critério do CBMC que dá a amostragem do ensemble que queremos de fato amostrar.

Já nas figuras 10 e 11, as distribuições de ângulo exibidas são as dos ângulos selecionados da biblioteca de fragmentos e aceitos com o critério do CBMC, sendo mantida a curva da distribuição ideal apenas como referência. No caso das simulações do gás, a diferença para a distribuição da biblioteca, exibida na figura 9 vem somente da interação com o outro fragmento, o que é o suficiente para estreitar a distribuição. As curvas referentes ao líquido de DCE foram obtidas com a simulação de líquido puro nas condições descritas nos próximos parágrafos. Notamos em ambas as curvas que os picos da densidade de probabilidade se encontram nas posições esperadas, contudo, a amplitude no caso do ângulo $\mathrm{H}-\mathrm{C}-\mathrm{H}$ da molécula isolada (gás) é ligeiramente diferente para a simulação com o CBMC. A justificativa para tal fato vem da interação eletrostática dos hidrogênios com o cloro oposto (pertencente ao outro fragmento) que é eletronegativo, e devido a carga positiva dos hidrogênios, configurações com os hidrogênios mais afastados são mais desfavoráveis energeticamente.

As simulações do líquido puro de DCE foram realizadas em uma caixa contendo 300 moléculas de DCE a $298.15 \mathrm{~K}$ e $1 \mathrm{~atm}$ no ensemble $N P T$. Um total de $6 \times 10^{8}$ passos de MC foram realizados na simulação de produção com o CBMC, das quais configurações foram armazenadas a cada $3 \times 10^{4}$ passos. Um raio de corte de $42 \%$ do lado da caixa foi adotado, e a correção de longo alcance para a energia de Lennard-Jones foi utilizada. A probabilidade utilizada para realizar um movimento de CBMC foi de $70 \%$, i.e., cada vez que uma das moléculas era sorteada aleatoriamente, ela tinha $70 \%$ de chance de ser reconstruída com o CBMC e $30 \%$ de sofrer apenas um movimento de rotação e translação. Foram utilizados 32 


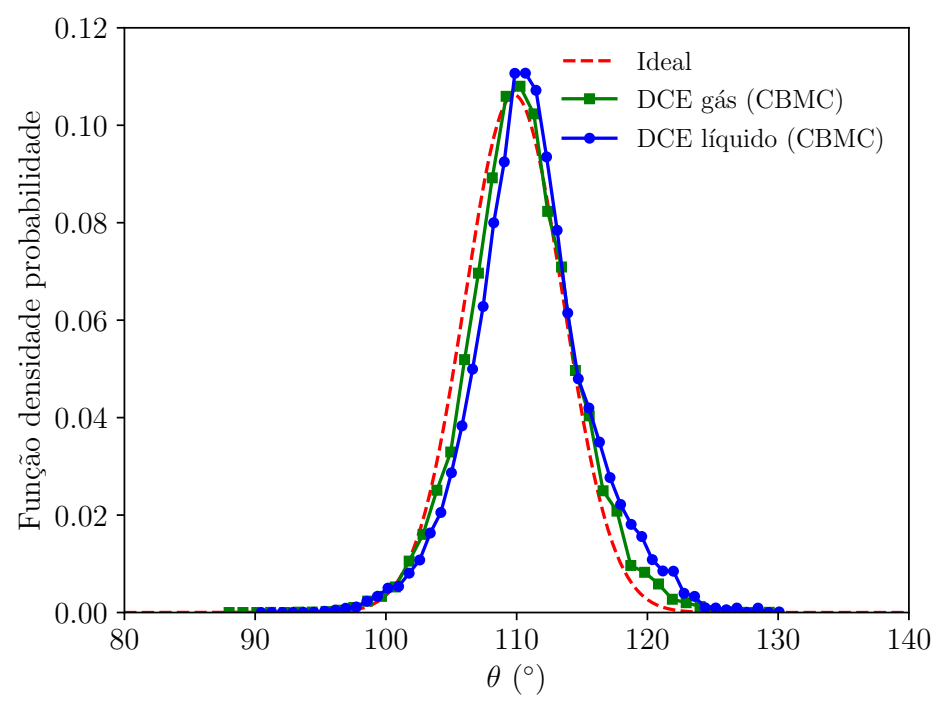

Figura 10 - Distribuição dos ângulos $\mathrm{Cl}-\mathrm{C}-\mathrm{C}$ amostrados com o algoritmo de amostragem de branch-point e então inseridos com o algoritmo CBMC na molécula. A curva ideal representa a distribuição obtida à partir do potencial harmônico $u_{\text {angle }}$.

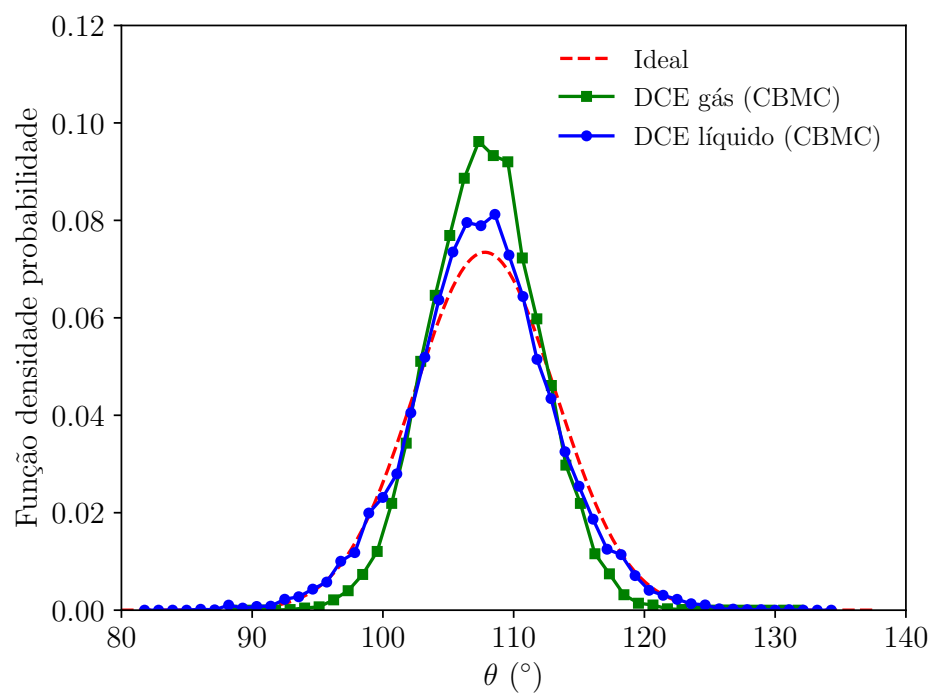

Figura 11 - Distribuição dos ângulos H-C-H amostrados com o algoritmo de amostragem de branch-point e então inseridos com o algoritmo CBMC na molécula. A curva ideal representa a distribuição obtida à partir do potencial harmônico $u_{\text {angle }}$.

ângulos de tentativa de inserção $\left(\kappa_{\phi}\right)$ no caso da simulação identificada somente como "Puro" na tabela 2, enquanto nas simulações com fragmentos rígidos foram utilizados 24 ângulos de inserção e a simulação com o viés no sorteio dos $\phi$ (veja seção 2.4) tiveram 16 ângulos a cada passo de CBMC. Esses valores de $\kappa_{\phi}$ foram escolhidos buscando compromisso entre uma maior taxa de aceitação e o custo computacional. As taxas de aceitação dos movimentos CBMC nas simulações dos líquidos ficaram entre $53 \%$ e $62 \%$.

A primeira propriedade observada nas simulações foi a densidade média do líquido, que 
no caso da simulação identificada apenas como "Puro" foi de $1.229 \mathrm{~g} \mathrm{~cm}^{-3}$, um valor que está em ótimo acordo com a densidade experimental de $1.246 \mathrm{~g} \mathrm{~cm}^{-3}$. ${ }^{[97]}$ Para verificar o efeito da flexibilidade sobre as moléculas, uma simulação considerando todas as moléculas rígidas e fixas na configuração trans também foi realizada com o método de Metropolis MC. Com as moléculas fixas na conformação trans, foi verificado que a densidade média do líquido foi de $1.194 \mathrm{~g} \mathrm{~cm}^{-3}$, indicando que a flexibilidade da molécula é essencial inclusive para reproduzir propriedades fundamentais como a densidade.

Outra propriedade calculada foi a entalpia de vaporização $\Delta H_{\text {vap }}$, que possui dados experimentais para comparação. A entalpia de vaporização é obtida através da diferença da entalpia do gás e do líquido

$$
\Delta H_{\text {vap }}=H_{\text {gás }}-H_{\text {liq }} .
$$

A entalpia do gás é calculada com a energia interna do gás e com a temperatura do sistema

$$
H_{\text {gás }}=E_{\text {gás }}+p V=E_{\text {gás }}+N_{\text {mol }} k T,
$$

onde $E_{\text {gás }}=\left\langle\mathcal{U}\left(\mathbf{r}^{N}\right)\right\rangle$ é a energia configuracional média obtida com a simulação CBMC, e $N_{\text {mol }}$ é o número de moléculas $\left(N_{\text {mol }}=1\right.$ nesse caso). Já e entalpia conformacional do líquido tem seu valor médio calculado com a expressão

$$
H_{\text {liq }}=\frac{1}{N_{\text {passos }}} \sum_{i=1}^{N_{\text {passos }}} \mathcal{U}\left(\mathbf{r}_{i}^{N}\right)+p V_{i}
$$

sendo $V_{i}$ o volume da caixa, $p=1 \mathrm{~atm}$ a pressão, e a soma sobre os valores acumulados em cada passo da simulação. Utilizando os dados obtidos com as simulações CBMC, o valor de $\Delta H_{\text {vap }}=8.46 \mathrm{kcal} / \mathrm{mol}$ foi obtido, o que também está em ótimo acordo com o valor experimental de $\Delta H_{\text {vap }}^{\text {exp }}=8.40 \mathrm{kcal} / \mathrm{mol}^{[98]}$

Sobre as propriedades estruturais, a característica que mais nos interessa para verificar a consistência da implementação é a distribuição dos ângulos e diedros. A distribuição dos ângulos da biblioteca de fragmentos selecionados pelo algoritmo CBMC para a simulação do líquido, é capaz de mostrar a sensibilidade da metodologia quanto a seleção dos ângulos internos dos fragmentos. Em comparação com a amostragem da molécula isolada de DCE, vemos na figura 11 que a distribuição de ângulos do líquido se aproxima mais da distribuição ideal que a distribuição do gás, devido a blindagem que as outras moléculas de DCE causam. As distribuições dos ângulos $\mathrm{Cl}-\mathrm{C}-\mathrm{H}$ e C-C-H também podem ser vistas na figuras figuras 12 e 13 respectivamente.

Os valores das porcentagens de configurações trans para os líquidos da tabela 2 foram calculados sobre o conjunto total de $2 \times 10^{4}$ configurações, armazenadas durante cada simulação. Como cada configuração contém 300 moléculas de DCE, no total foram utilizados $6 \times 10^{6}$ diedros para as análises. Conforme já mencionado, o líquido puro foi simulado em três condições diferentes com o CBMC: com os fragmentos flexíveis, com os fragmentos mantidos 


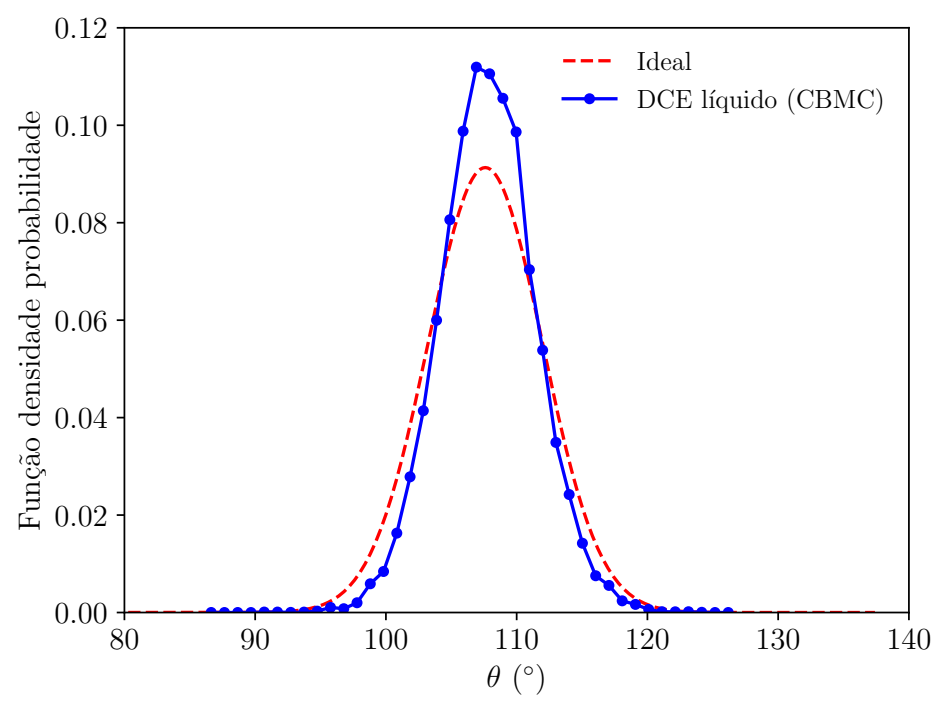

Figura 12 - Distribuição dos ângulos $\mathrm{Cl}-\mathrm{C}-\mathrm{H}$ amostrados com o algoritmo de amostragem de branch-point e então inseridos com o algoritmo CBMC na molécula. A curva ideal representa a distribuição obtida à partir do potencial harmônico $u_{\text {angle }}$.

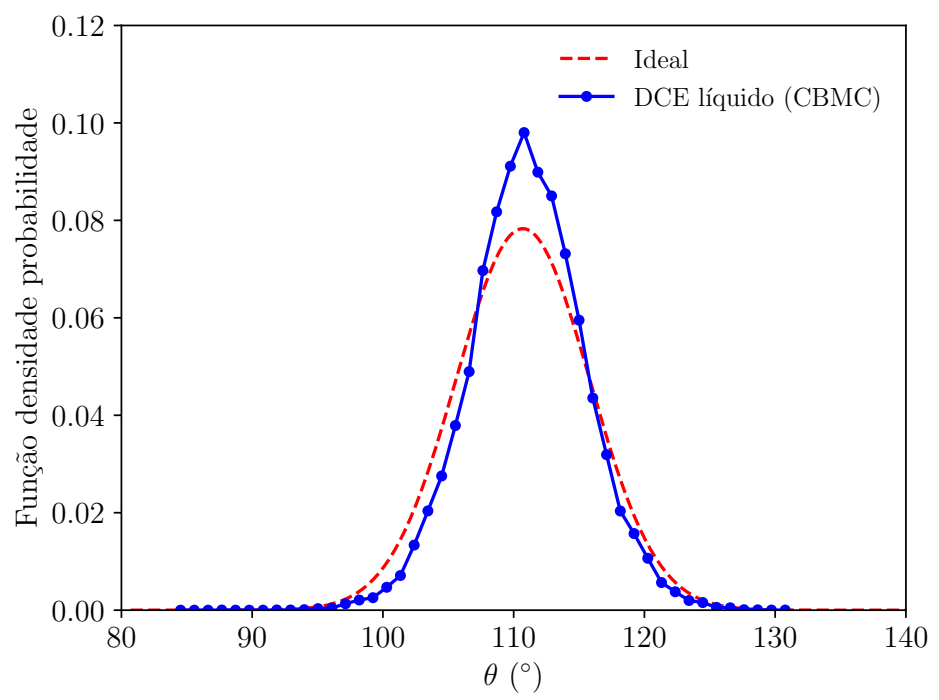

Figura 13 - Distribuição dos ângulos C-C-H amostrados com o algoritmo de amostragem de branch-point e então inseridos com o algoritmo CBMC na molécula. A curva ideal representa a distribuição obtida à partir do potencial harmônico $u_{\text {angle }}$.

rígidos e com fragmentos flexíveis fazendo a seleção dos $\kappa_{\phi}$ de maneira enviesada. Como vemos, tanto a forma dos fragmentos quanto a estratégia utilizada para a seleção dos ângulos de inserção não afetam de maneira drástica os resultados, que se mantém dentro do mesmo intervalo considerando-se a incerteza. Os três valores também estão de acordo com o valor experimental, ${ }^{[94]}$ e estão próximos do valor obtido com o método de MC da referência original do campo de forças, ${ }^{[93]}$ onde a incerteza da grandeza não é estimada.

As simulações de DCE em acetonitrila e em ciclohexano foram realizadas utilizando 


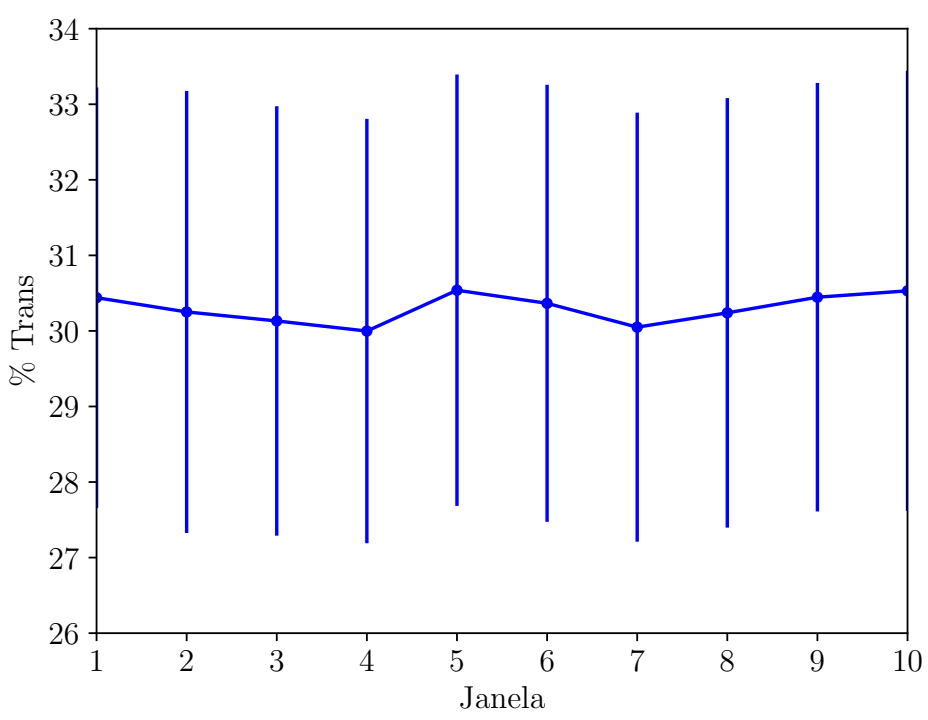

Figura 14 - Evolução do número de configurações trans amostradas com o CBMC durante diferentes intervalos da simulação. O método do cálculo da probabilidades e barras de erro foi apresentado no texto.

as parametrizações do campo de força OPLS-AA para os solventes. As caixas de simulações continham 300 moléculas, sendo uma única molécula de DCE e o restante das moléculas sendo do solvente. Foram utilizadas $2 \times 10^{4}$ configurações de DCE para estimar os valores das porcentagens de configurações trans em cada caso. Os valores encontrados podem ser vistos na tabela 2. Para a acetonitrila obtemos um bom acordo com o valor experimental, ${ }^{*}$ o que não acontece para o ciclohexano. Contudo, o não acordo com o valor experimental para o ciclohexano é justificado pelo modelo não polarizável do mesmo, conforme mostrado por Jorgensen et al. ${ }^{[93]}$ Por outro lado, a concordância com o resultado de $\mathrm{MC}^{[93]}$ também com um modelo não polarizável está boa, indicando que dado o campo de forças, as amostragens são compatíveis.

Simulações de dinâmica molecular do gás, do líquido puro e do DCE em ciclohexano também foram realizadas sob as mesmas condições das simulações de CBMC. O algoritmo de integração utilizado foi o leap-frog, a temperatura foi mantida em $298.15 \mathrm{~K}$ com o termostato velocity rescaling com o parâmetro $\tau_{T}=0.1$. Nas simulações dos líquidos o ensemble $N P T$ foi utilizado, e a pressão foi mantida em $1 \mathrm{~atm}$ com o barostato de Berendsen ( $\operatorname{com} \tau_{P}=0.5$ ), enquanto a simulação da molécula isolada foi realizada no ensemble $N V T$. Utilizando um passo de integração de $0.1 \mathrm{fs}$, foram simulados para produção um total de $10 \mathrm{~ns}$. Para as simulações dos líquidos, as interações eletrostáticas de longo alcance foram calculadas utilizando o Particle Mesh Ewald $(\mathrm{PME})^{[99]}$ com um raio de corte de $15 \AA$.

Assim como no resultado do octano apresentado na seção 3.1, para uma molécula isolada na fase gasosa, a incerteza sobre o valor da porcentagem de configurações trans é

\footnotetext{
${ }^{*}$ A incerteza da medida não é estimada pelo autor, ${ }^{[95]}$ que fornece somente as mudanças de energia livre.
} 


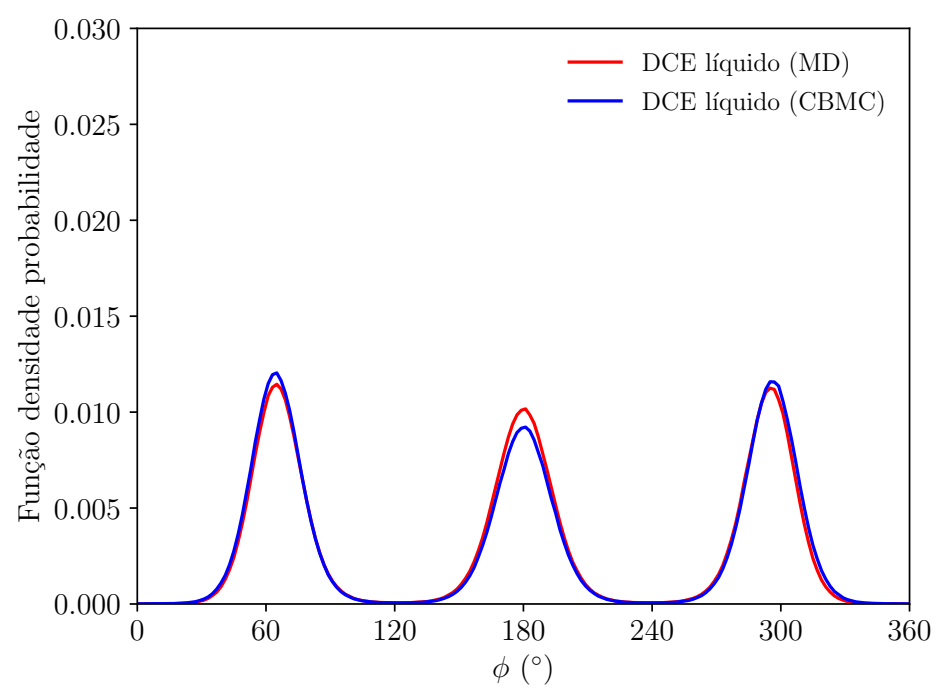

Figura 15 - Densidade de probabilidades da amostragem do ângulo de diedro $\mathrm{Cl}-\mathrm{C}-\mathrm{C}-\mathrm{Cl}$ para o líquido de DCE, calculada a partir das configurações amostradas com o CBMC e MD.

bem grande, conforme visto na tabela 2. Novamente a razão da incerteza ser tão grande é atribuída à correlação estatística entre as configurações, que faz com que os valores da porcentagem de configuração trans para os diferentes grupos que constroem as janelas tenham uma grande variância. Contudo, o valor médio ainda assim reflete de maneira razoável os valores experimentais e se compara à porcentagem obtida com o método de CBMC.

No caso do líquido puro, a distribuição dos ângulos de diedro $\mathrm{Cl}-\mathrm{C}-\mathrm{C}-\mathrm{Cl}$ calculadas a partir dos dados da simulação de CBMC e MD podem ser vistos na figura 15. Foram utilizados os ângulos de diedro provenientes das $2 \times 10^{4}$ configurações armazenadas durante a simulação, totalizando assim como no caso do CBMC $6 \times 10^{6}$ diedros. Vemos na comparação com a curva obtida com o método CBMC que ambas possuem apenas pequenas diferenças, tendo os seus máximos na mesma posição e amplitudes equivalentes. Partindo desses ângulos de diedro, a porcentagem de configurações trans também foi calculada conforme mostrado na tabela 2, onde vemos um ótimo acordo tanto com o valor experimental quanto com o valor das simulações de CBMC. Também foi realizada uma simulação de dinâmica molecular em ciclohexano utilizando as mesmas condições da simulação CBMC, i.e., com o campo de força não polarizável. Como pode ser visto na tabela 2 a porcentagem de configurações trans encontrada continua sendo maior do que a experimental, porém, está mais próxima do valor que a simulação com CBMC. Essa diferença pode ser atribuída a forma do cálculo da energia eletrostática, que é truncada na simulação com CBMC e feita com o PME na dinâmica. De fato, ao realizar uma simulação de MD com o reaction-field para as correções de longo alcance no termo de Coulomb, o valor obtido para a porcentagem de configurações trans é $(75 \pm 8) \%$, que está de acordo com os valores obtidos pelas simulações de CBMC e MC.

De maneira similar a distribuição dos diedros calculados para o líquido puro, comparamos 


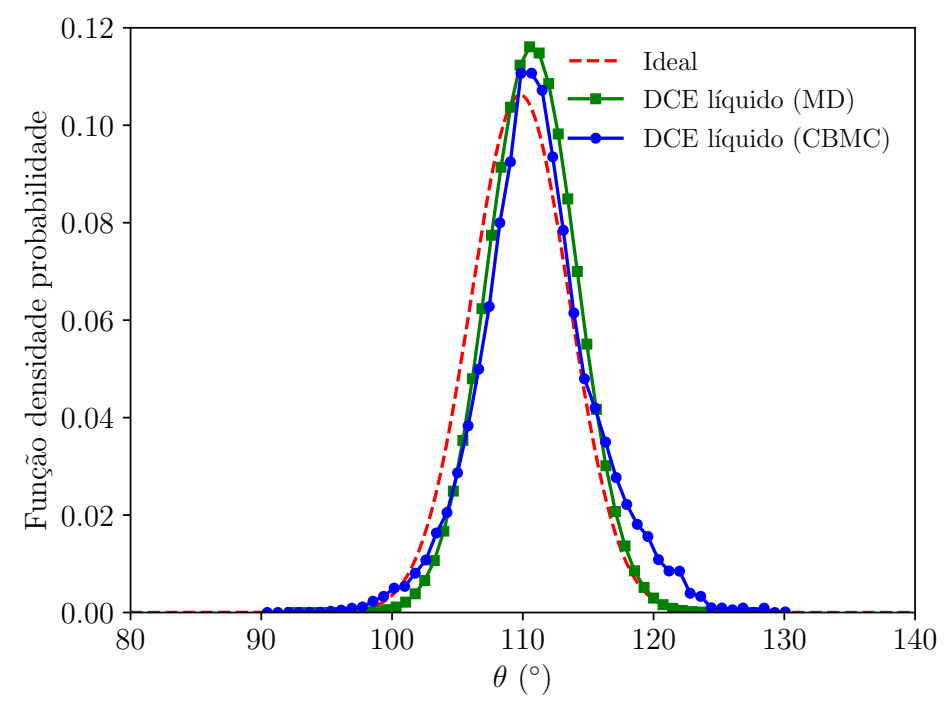

Figura 16 - Distribuição dos ângulos $\mathrm{Cl}-\mathrm{C}-\mathrm{C}$ amostrados com o algoritmo de amostragem de branch-point e então inseridos com o algoritmo CBMC na molécula e também dos ângulos amostrados com MD. A curva ideal representa a distribuição obtida à partir do potencial harmônico $u_{\text {angle }}$.

os ângulos $\mathrm{Cl}-\mathrm{C}-\mathrm{C}$ amostrados com as duas metodologias na figura 16. Vemos que ambas as distribuições possuem o seu máximo ligeiramente deslocado para a direita, quando comparadas a distribuição ideal. No entanto, a distribuição encontrada pela dinâmica molecular é ligeiramente mais estreita que a distribuição do CBMC, provavelmente devido à correção de longo alcance nas interações Coulombianas, presentes na dinâmica e não no CBMC, ou ainda a flutuações estatísticas. Essa ligeira diferença nas distribuições não afeta no entanto os resultados das propriedades termodinâmicas e estruturais estudadas, já que como foi mostrado nos parágrafos anteriores, os resultados obtidos com o CBMC estão em acordo com os valores observados experimentalmente.

De uma maneira geral, podemos concluir que a proposta de implementação do método CBMC está correta e sua execução está livre de erros grosseiros que afetam propriedades físicas. Vemos que a metodologia dá resultados consistentes não somente com os experimentais, mas também com os resultados de simulações de dinâmica molecular obtidos com a implementação estável do GROMACS. No caso do octano, e nas simulações em fase gasosa de maneira geral, o CBMC mostrou uma melhor amostragem, com tempos de autocorrelação menores. A metodologia, no entanto, ainda precisa ser estabelecida através da aplicação em diferentes sistemas com diferentes características, para que então as limitações da mesma sejam evidenciadas. $O$ que vemos em um primeiro momento, com as aplicações no octano e 1,2-dicloroetano, é que a mesma é capaz de realizar uma boa amostragem em sistemas com até poucas dezenas de átomos e com superfície de energia potencial relativamente simples. 


\section{Capítulo 4}

\section{Óxido mesityl}

Neste capítulo é realizado um estudo sobre o efeito solvente na molécula de óxido mesityl (MOx). Mostramos que o uso de MD não é adequado para a amostragem das populações conformacionais do MOx, enquanto que o uso do CBMC se mostrou eficiente. Após encontrar o equilíbrio conformacional das populações syn e anti em fase gasosa, acetonitrila, metanol e água, um estudo do espectro de absorção e solvatocromismo da molécula foi realizado.

\subsection{Motivação}

Um dos interesses no estudo do efeito solvente é equilíbrio populacional das diferentes conformações, que pode resultar em propriedades espectroscópicas diferentes. Esse é justamente o caso da molécula de óxido mesityl (MOx) $\left[\left(\mathrm{CH}_{3}\right)_{2} \mathrm{C}=\mathrm{CHC}(=\mathrm{O}) \mathrm{CH}_{3}\right]$, que tem o equilíbrio das conformações syn e anti dependente do solvente, resultando num espectro de absorção ligeiramente diferente em cada caso. ${ }^{[92,100,101]}$ O MOx é uma molécula de 17 átomos utilizada como modelo para o estudo de $\alpha, \beta$-cetonas não saturadas, um grupo de cetonas da forma $\mathrm{R}_{1} \mathrm{C}-\mathrm{C}(=\mathrm{O})-\mathrm{CR}_{2}$, caracterizados pela presença de uma cadeia $\mathrm{C}=\mathrm{C}-\mathrm{C}=\mathrm{O}$ que dá origem as conformações syn e anti exibidas na seção 4.1. De uma maneira geral, as conformações são classificadas de acordo com o ângulo de diedro $\mathrm{C}=\mathrm{C}-\mathrm{C}=\mathrm{O}$ que é $(0 \pm 30)^{\circ}$ para a conformação syn, $( \pm 60 \pm 30)^{\circ}$ ou $( \pm 120 \pm 30)^{\circ}$ para as conformações gauche e $(180 \pm 30)^{\circ}$ para a conformação anti.

Através de espectroscopia UV-vis, foi verificada a dependência do espectro de absorção da molécula com o solvente. ${ }^{[100,101]}$ Segundo Kosower ${ }^{[101]}$, foi levantada a hipótese em comunicação privada do Dr. M. C. Whiting de Oxford, que o equilíbrio das conformações syn e anti do MOx era dependente do solvente. Contudo, as populações exatas em cada solvente não podem ser determinadas experimentalmente devido à presença da molécula de iso-óxido mesityl (IMOx) $\left[\mathrm{CH}_{3}-\mathrm{C}\left(=\mathrm{CH}_{2}\right) \mathrm{CH}_{2} \mathrm{C}(=\mathrm{O}) \mathrm{CH}_{3}\right]$, que compõe cerca de $9 \%$ das amostras. ${ }^{\text {[103] }}$ Por esse motivo, cálculos teóricos com simulações $M C$ de moléculas rígidas e ciclos de energia livre foram utilizados para determinar as populações dos confôrmeros em gás e em água. ${ }^{[92]} \mathrm{O}$ 
<smiles>CC(=O)C=C(C)C</smiles>

(a) syn $\mathrm{MOx}$

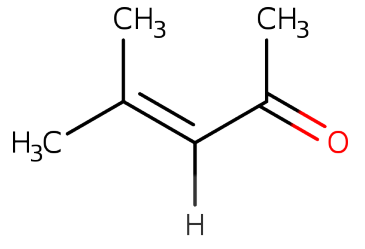

(b) anti $\mathrm{MOx}$

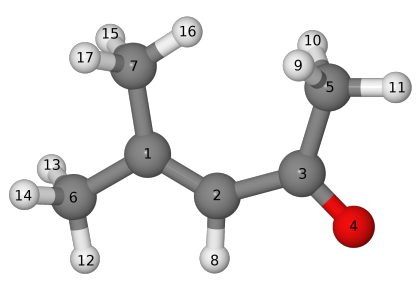

(c) rótulos dos átomos

Figura 17 - Configurações (a) syn e (b) anti do óxido mesityl (MOx). Uma representação $3 \mathrm{D}$ da molécula contendo os rótulos atômicos é exibida na figura (c). Os diedros 1-2-3-4, 1-2-3-5, 8-2-3-4 e 8-2-3-5 compõe o torsional $\mathrm{C}=\mathrm{C}-\mathrm{C}=\mathrm{O}$ mencionado durante o texto. Figura adaptada de Cezar, Canuto e Coutinho[102].

que foi encontrado nesses casos é uma inversão das populações nos dois extremos de polaridade, sendo a conformação syn dominante em gás, e a conformação anti dominante em água.

O objetivo das simulações apresentadas nesse capítulo é a verificação de que o equilíbrio conformacional syn/anti é dependente do solvente, e além disso, que a espectroscopia em diferentes solventes é alterada justamente pelas diferentes populações conformacionais. Para isso utilizamos o método de CBMC apresentado na seção 2.3, já que, como será mostrado na seção 4.3, o uso da técnica de MD tradicional não é capaz de realizar a amostragem conformacional, devido à barreira de energia de cerca de $10 \mathrm{kcal} / \mathrm{mol}$ entre os confôrmeros.

\subsection{Parametrização}

Cálculos DFT da molécula MOx em fase gasosa realizados por Damasceno, Cabral e Coutinho ${ }^{[92]}$, utilizando diferentes funcionais e bases, indicam uma barreira entre 3-7 kcal/mol entre a configuração syn e o estado de transição TS. Além disso, a diferença de energia livre entre as conformações syn e anti foi de $1.34 \mathrm{kcal} / \mathrm{mol}$ no nível de cálculo MP2/aug-cc-pVDZ na fase gasosa. A parametrização da molécula com potenciais clássicos deve reproduzir esses valores, especialmente a diferença de energia syn $\rightarrow a n t i$, que é responsável pelas populações dos confôrmeros. A barreira de energia entre os estados, por sua vez, não deveria influenciar nas populações, a menos que o método de amostragem fique preso em um mínimo e a hipótese da ergodicidade não seja satisfeita.

Utilizando um conjunto de cargas polarizadas em água médio e arredondado das configurações syn e anti de Damasceno, Cabral e Coutinho ${ }^{[92]}$ o potencial de rotação através da ligação C2-C3 foi calculado com os parâmetros de diedro do OPLS-AA. Para esse cálculo a molécula é dividida em duas partes, que são mantidas rígidas durante a rotação dos grupos. Esse potencial é mostrado na figura $18(\mathrm{a})$, onde se observa mínimos locais em $\pm 180^{\circ}, \pm 119.5^{\circ}$ e $\pm 34^{\circ}$. O potencial OPLS-AA apresenta e uma diferença entre a energia das conformações syn e anti de cerca de $2.4 \mathrm{kcal} / \mathrm{mol}$ que não reflete o potencial calculado com o MP2 na base 
Tabela 3 - Parâmetros de Fourier para os diedros de rotação em torno da ligação entre $\mathrm{C}=\mathrm{C}-\mathrm{C}=\mathrm{O}$ do $\mathrm{MOx}$, ajustados para obter as diferenças de energia em fase gasosa. A expressão para o diedro é dado na equação 2.5. Os parâmetros estão em $\mathrm{kcal} / \mathrm{mol}$. Tabela adaptada de Cezar, Canuto e Coutinho ${ }^{[102]}$.

\begin{tabular}{lrrrrrl}
\hline & $V_{1}$ & $V_{2}$ & $V_{3}$ & $f_{1}$ & $f_{2}$ & $f_{3}$ \\
\hline $\mathrm{C} 1=\mathrm{C} 2-\mathrm{C} 3-\mathrm{C} 5$ & 1.4 & 5.2 & -4.7 & 0.0 & 0.0 & 0.0 \\
$\mathrm{H} 8-\mathrm{C} 2-\mathrm{C} 3-\mathrm{C} 5$ & 0.0 & 0.0 & 0.7 & 0.0 & 0.0 & 0.0 \\
$\mathrm{C} 1=\mathrm{C} 2-\mathrm{C} 3=\mathrm{O} 4$ & -1.8 & 4.3 & -1.9 & 0.0 & 0.0 & 0.0 \\
$\mathrm{H} 8-\mathrm{C} 2-\mathrm{C} 3=\mathrm{O} 4$ & 0.0 & 0.0 & 0.0 & 0.0 & 0.0 & 0.0 \\
\hline
\end{tabular}

já citada. Por esse motivo, os parâmetros $V_{1}^{i}, V_{2}^{i}$ e $V_{3}^{i}$ (veja equação 2.5) foram ajustados, assumindo os valores apresentados na tabela 3 . As fases $f_{1}^{i}, f_{2}^{i}$ e $f_{3}^{i}$ foram definidas como zero, como usual para o OPLS-AA. Os outros parâmetros do campo de força podem ser vistos no apêndice $E$.

Esse conjunto de parâmetros para os diedros foram utilizados para todas as simulações apresentadas nesse capítulo. O potencial resultante, gerado pelo mesmo método descrito anteriormente é apresentado na figura 18(b), onde as estruturas referência a cada ponto de inflexão e as diferenças de energia são indicadas. O potencial da figura 18(b) possui a diferença de energia de $1.34 \mathrm{kcal} / \mathrm{mol}$ entre as conformações syn e anti, conforme reportado para o cálculo MP2/aug-cc-pVDZ. Devido ao conjunto de parâmetros selecionados para reproduzir a diferença de energia entre as conformações, a barreira de energia ficou em torno de $10 \mathrm{kcal} / \mathrm{mol}$, maior que o valor estimado de até $7 \mathrm{kcal} / \mathrm{mol}$. Essa diferença de $3 \mathrm{kcal} / \mathrm{mol}$, no entanto, não é importante para a amostragem com $\mathrm{MC}$, já que com $\mathrm{MC}$ o tempo do processo cinético não é importante e somente a diferença de energia entre as conformações é importante. Para a MD, no entanto, essa diferença pode ser importante, e portanto, os resultados de MD apresentados nesse capítulo, devem ser vistos como um teste metodológico sobre a amostragem do potencial da figura 18 , e não como a amostragem do potencial real do MOx.

Com esse conjunto de cargas, os dipolos das conformações syn e anti são 5.2 D e 7.2 D, respectivamente, em concordância com os valores dos momentos obtidos com os cálculos MP2/aug-cc-pVDZ, onde a conformação syn possui 5.0 D e a anti 7.0 D. ${ }^{[92]}$

\subsection{Equilíbrio conformacional em gás e água}

Para verificar a hipótese de que o equilíbrio de configurações syn:anti é dependente do solvente, foram realizadas simulações da molécula de MOx inicialmente em fase gasosa e água, utilizando o potencial intramolecular modificado apresentado na seção 4.2. Através de cálculos de energia livre feitos com teoria de perturbação termodinâmica ${ }^{[104,105]}$ estimou-se na literatura ${ }^{[92]}$ que a população syn:anti em fase gasosa é de $91: 9 \%$, enquanto que a população 


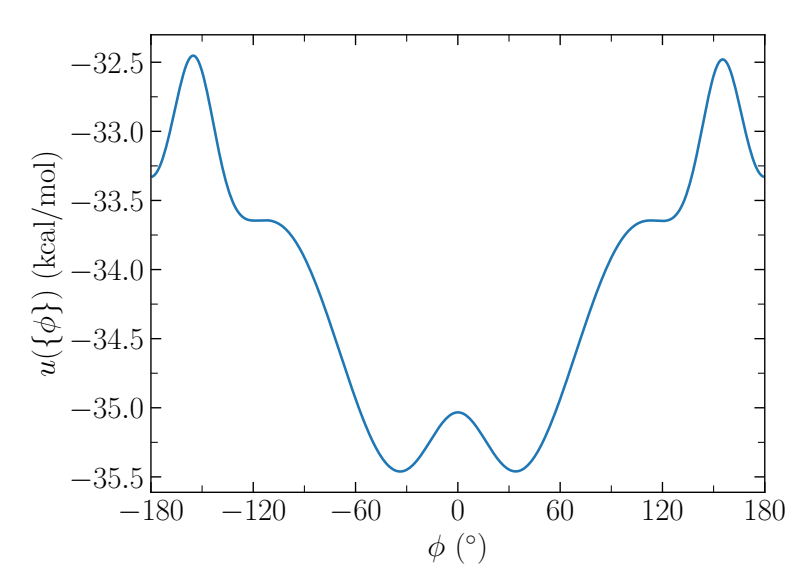

(a) Potencial OPLS-AA

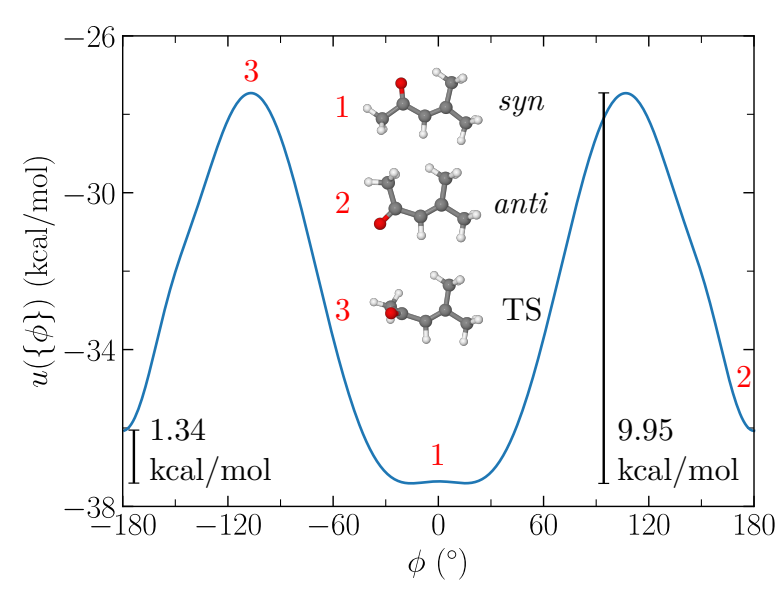

(b) Potencial modificado

Figura 18 - Potencial da rotação do grupo $\mathrm{C}=\mathrm{C}-\mathrm{C}=\mathrm{O}$. Em (a) é exibido o potencial utilizando os parâmetros do OPLS-AA e em (b) o potencial modificado utilizado nas simulações. As cargas utilizadas são uma média das cargas CHELPG MP2/aug-cc-pVDZ das configurações syn e anti de Damasceno, Cabral e Coutinho ${ }^{[92]}$. Os dois lados da molécula, separados pela ligação sobre a qual a rotação é feita, são mantidos rígidos durante a rotação. Figura adaptada de Cezar, Canuto e Coutinho ${ }^{[102]}$.

em água, foi estimada como sendo 1:99 \%. Ou seja, o confôrmero dominante é diferente em cada um dos extremos de polaridade. Com essa informação, também é possível levantar a hipótese de que a porcentagem que conformações anti aumenta conforme a polaridade do solvente, hipótese que será estudada na seção 4.4. As simulações em fase gasosa e em água foram realizadas com o CBMC e MD, com o objetivo de verificar se as populações amostradas vêm de distribuições semelhantes. Os resultados apresentados nessa seção estão publicados na revista International Journal of Quantum Chemistry. ${ }^{[102]}$

Para as simulações CBMC, a molécula de MOx foi fragmentada em 5 fragmentos, ilustrados na figura 19. Com a exceção dos fragmentos 1 e 2 que foram amostrados com deslocamentos Cartesianos e o critério de Metropolis, os outros fragmentos foram amostrados com o esquema de branch-point. O fragmento 2 foi amostrado com deslocamentos Cartesianos, pois havia o interesse de se observar o comportamento do comprimento da ligação $C 3=04$. A opção de não fragmentar o fragmento 1 em duas partes ocorreu devido ao potencial torsional em torno da ligação $\mathrm{C} 1=\mathrm{C} 2$. Conforme exibido na figura 20 , o mínimo mais estável em $\pm 180^{\circ}$ tem uma energia $\sim 15 \mathrm{kcal} / \mathrm{mol}$ menor que a energia do mínimo em $0^{\circ}$. Por esse motivo, é esperado que toda a população de configurações do fragmento esteja ao redor de $\pm 180^{\circ}$. Como o fragmento é relativamente rígido, a aceitação do movimento CBMC como um todo poderia ser prejudicada caso fosse dividido em dois, e por esse motivo, utilizar o fragmento conforme definido na figura 19 é justificado. Além disso, a amostragem do fragmento com deslocamentos Cartesianos e o algoritmo de Metropolis é suficiente para amostrar uma distribuição de ângulos similar a da MD, como será mostrado. 


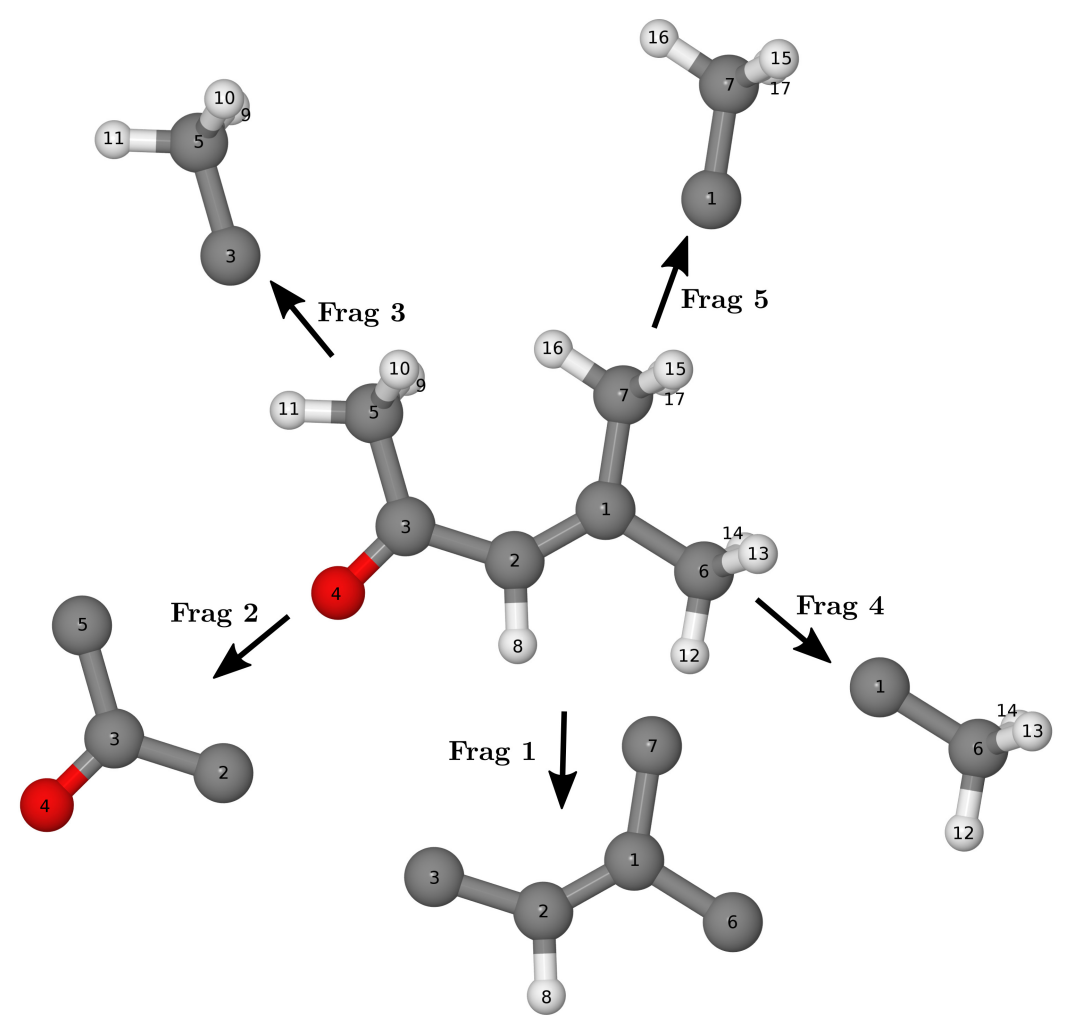

Figura 19 - Fragmentos do MOx utilizados para as simulações CBMC. Figura de Cezar, Canuto e Coutinho ${ }^{[102]}$.

Para a simulação em fase gasosa, uma simulação no ensemble $N V T$ de uma única molécula de $\mathrm{MOx}$ foi realizada. Com exceção das cargas e dos torsionais reparametrizados, todos os outros parâmetros de termos ligados e não ligados foram do campo de força OPLS-AA. ${ }^{[66]}$ A temperatura foi de $300 \mathrm{~K}$ e a cada passo de simulação a molécula era reconstruída com o CBMC. Foram utilizados $\kappa_{\phi}=32$ ângulos tentativas de inserção, distribuídos uniformemente no intervalo $2 \pi$. Assim como nas simulações apresentadas no capítulo 3 , as bibliotecas de fragmentos eram compostas de $10^{4}$ configurações independentes, obtidas de simulações prévias de $10^{8}$ passos. Um total de $10^{6}$ passos de MC foram simulados, e $10^{4}$ configurações foram utilizadas para o cálculo das porcentagens das populações conformacionais.

Já a simulação em água foi realizada no ensemble $N P T$, em uma caixa com 1200 moléculas de água e 1 molécula de MOx. Os parâmetros para o MOx foram os mesmos utilizados para a simulação em fase gasosa e a água foi descrita pelo modelo SPC/E. ${ }^{[106]} \mathrm{A}$ temperatura foi também de $300 \mathrm{~K}$ e a pressão foi mantida em $1 \mathrm{~atm}$. Condições periódicas de contorno na caixa cúbica com lado inicialmente com $L=33.04 \AA$ foram aplicadas. O raio de corte utilizado foi de $r_{c}=0.8 \times L / 2 \approx 15 \AA$. Para garantir uma amostragem conformacional mais eficiente do soluto e seus arredores, um esquema de amostragem preferencial (com $n=2$ ) 


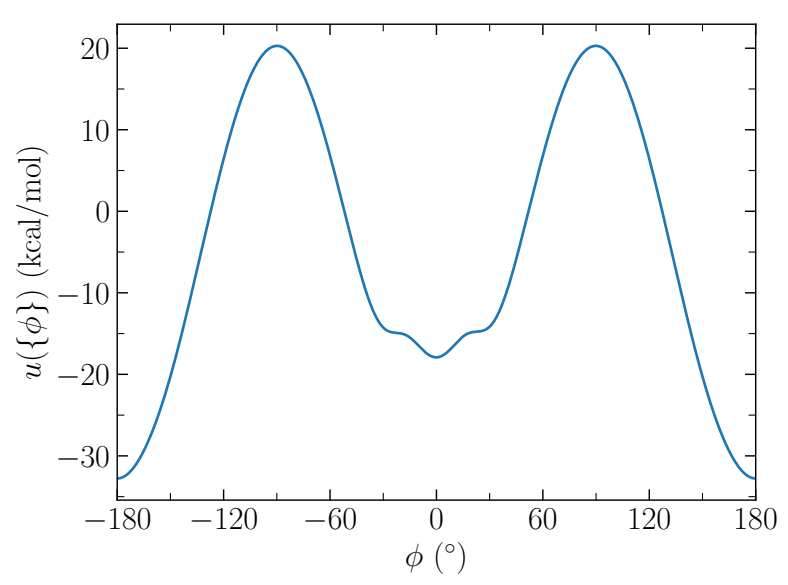

Figura 20 - Potencial torsional ao redor da ligação dupla $\mathrm{C} 6-\mathrm{C} 1=\mathrm{C} 2-\mathrm{C} 3$. Figura de Cezar, Canuto e Coutinho ${ }^{[102]}$.

foi aplicado. ${ }^{[77,78]}$ Quando o soluto era selecionado, o tipo de movimento de MC era sorteado com a probabilidade de $80 \%$ de realizar o movimento CBMC e $20 \%$ de realizar um movimento de rotação e translação apenas. Nessas simulações, $3 \times 10^{8}$ passos de $\mathrm{MC}$ foram realizados para termalizar a caixa, com a configuração inicial syn ou anti. Após a termalização $48 \times 10^{8}$ passos de MC foram realizados, dos quais somente os últimos $36 \times 10^{8}$ foram utilizados para calcular a população de cada confôrmero.

As simulações de MD em fase gasosa e em água foram feitas utilizando o software GROMACS na versão 5.1.4. ${ }^{[20]}$ O mesmo número de moléculas e condições termodinâmicas das simulações CBMC foram utilizados. Para a integração das equações de movimento foi utilizado o algoritmo leap frog com um passo de integração de $2 \mathrm{fs}$, o que é possível devido a restrição imposta aos comprimentos de ligação dos hidrogênios, que foram mantidos fixos utilizando o algoritmo LINCS. ${ }^{[107]}$ A temperatura foi mantida constante em $300 \mathrm{~K}$ com o auxílio do termostato velocity rescale, ${ }^{[81]}$ utilizado com uma constante de acoplamento de 0.1 ps. Para manter a pressão em $1 \mathrm{~atm}$, foi utilizado o barostato de Berendsen, ${ }^{[82]}$ com compressibilidade de $4.5 \times 10^{-5}$ bar $^{-1}$ e uma constante de acoplamento de $0.1 \mathrm{ps}$. As simulações tanto em fase gasosa quanto em água foram simuladas por 400 ns para cada conformação inicial (syn e anti). Adicionalmente, duas outras simulações em água foram realizadas para confirmar o tempo estimado para a mudança conformacional na MD.

Assim como no capítulo 3, as simulações de MD foram inicialmente utilizadas para a validação da implementação e do modelo. Parâmetros geométricos como valores médios de comprimentos de ligação e ângulos, comuns e de diedro, assim como seus desvios, foram utilizados para verificar que a amostragem de fato corresponde à dos valores esperados. Esses resultados são apresentados na tabela 4, onde é feita a comparação dos valores em fase gasosa e em água. Verificamos que todos os valores para comprimentos de ligação e ângulos das simulações CBMC estão em acordo com os valores da simulação MD, como esperado. Comparando os valores médios para as simulações em fase gasosa e em água, não 
Tabela 4 - Médias dos parâmetros geométricos do MOx analisados nas simulações CBMC e MD em fase gasosa e água. As distâncias $r$ são dadas em $\AA$ e ângulos em ${ }^{\circ}$. Os valores em parênteses indicam dados de simulações iniciadas na conformação anti, enquanto os outros valores são de simulações iniciadas na conformação syn. A linha $\phi_{\mathrm{C} 1=\mathrm{C} 2-\mathrm{C} 3=\mathrm{O} 4}$ é dividida em syn e anti por se tratar de uma distribuição bimodal. * indica que somente uma conformação foi amostrada. Tabela adaptada de Cezar, Canuto e Coutinho ${ }^{[102]}$.

\begin{tabular}{|c|c|c|c|c|}
\hline & \multicolumn{2}{|c|}{ Fase gasosa } & \multicolumn{2}{|c|}{ Água } \\
\hline & CBMC & MD & CBMC & MD \\
\hline$r_{\mathrm{C} 1}=\mathrm{C} 2$ & $1.356 \pm 0.016$ & $1.360 \pm 0.024$ & $1.356 \pm 0.016$ & $1.359 \pm 0.023$ \\
\hline$r_{\mathrm{C} 2-\mathrm{C} 3}$ & $1.486 \pm 0.019$ & $1.488 \pm 0.028$ & $1.486 \pm 0.012$ & $1.485 \pm 0.027$ \\
\hline$r_{\mathrm{C} 3}=\mathrm{O} 4$ & $1.227 \pm 0.016$ & $1.225 \pm 0.024$ & $1.235 \pm 0.016$ & $1.237 \pm 0.023$ \\
\hline$\theta_{\mathrm{C} 1}=\mathrm{C} 2-\mathrm{C} 3$ & $133.9 \pm 2.0$ & $134.7 \pm 2.8$ & $134.8 \pm 2.0$ & $135.7 \pm 2.8$ \\
\hline$\theta_{\mathrm{C} 2-\mathrm{C} 3-\mathrm{O} 4}$ & $117.7 \pm 2.0$ & $117.6 \pm 2.8$ & $116.7 \pm 2.0$ & $117.2 \pm 2.9$ \\
\hline$\theta_{\mathrm{C} 6-\mathrm{C} 1-\mathrm{C} 7}$ & $112.5 \pm 2.1$ & $112.2 \pm 2.8$ & $112.4 \pm 2.0$ & $112.0 \pm 2.8$ \\
\hline$\theta_{\mathrm{H} 12-\mathrm{C} 6-\mathrm{C} 1}$ & $112.5 \pm 3.3$ & $112.7 \pm 4.7$ & $112.6 \pm 3.3$ & $112.8 \pm 4.6$ \\
\hline$\phi_{\mathrm{C} 6-\mathrm{C} 1=\mathrm{C} 2-\mathrm{C} 3}$ & $180.0 \pm 4.0$ & $180.0 \pm 5.9$ & $180.0 \pm 4.1$ & $180.0 \pm 5.8$ \\
\hline \multicolumn{5}{|l|}{$\phi_{\mathrm{C} 1}=\mathrm{C} 2-\mathrm{C} 3=\mathrm{O} 4$} \\
\hline syn & $\begin{array}{l}0.3 \pm 19.8 \\
(0.1 \pm 19.9)\end{array}$ & $\begin{array}{l}0.0 \pm 19.0 \\
(0.1 \pm 19.9)\end{array}$ & $\begin{array}{l}0.2 \pm 25.3 \\
(2.0 \pm 25.4)\end{array}$ & $\begin{array}{l}0.0 \pm 23.1 \\
(*)\end{array}$ \\
\hline anti & $\begin{array}{l}179.8 \pm 9.5 \\
(179.7 \pm 9.7)\end{array}$ & $\begin{array}{l}* \\
(179.7 \pm 9.7)\end{array}$ & $\begin{array}{l}179.7 \pm 10.1 \\
(179.7 \pm 10.2)\end{array}$ & $\begin{array}{l}180.0 \pm 11.6 \\
(180 \pm 11.5)\end{array}$ \\
\hline
\end{tabular}

são observadas grandes mudanças nos valores médios causados pelo efeito solvente. Para o comprimento de ligação $\mathrm{C} 3=04$, no entanto, um pequeno estiramento de $\sim 0.01 \AA$ foi observado para a simulação em água, quando comparado com a simulação em fase gasosa, tanto para a MD quanto para a simulação CBMC. Esse estiramento, ainda que muito pequeno, é esperado devido às ligações de hidrogênio formadas com o solvente. ${ }^{[108,109]}$ O número médio de ligações de hidrogênio $\left\langle N_{\mathrm{HB}}\right\rangle$, assim como valores médios de outras grandezas associadas a formação destas ligações, são exibidos na tabela 5. Os critérios geométricos e energéticos utilizados para a formação de ligações de hidrogênios foram: distância entre o 0 do $\mathrm{MOx}$ e $\mathrm{O}$ da água $R\left(\mathrm{O}_{\mathrm{M}} \cdots \mathrm{O}_{\mathrm{W}}\right) \leq 3.25 \AA$, ângulo entre $\mathrm{O}$ do $\mathrm{MOx}$, da água e $\mathrm{H}$ da água $\theta\left(\mathrm{O}_{\mathrm{M}} \cdots \mathrm{O}_{\mathrm{W}} \mathrm{H}\right) \leq 40^{\circ}$ e energia de ligação $E_{i j} \leq-0.01 \mathrm{kcal} / \mathrm{mol}$. Observamos que o número médio de ligações de hidrogênio é dependente da conformação da molécula de $\mathrm{MOx}$, sendo de 2.4 para a conformação syn e 2.8 para a conformação anti. Na simulação CBMC, $\left\langle N_{\mathrm{HB}}\right\rangle=2.7$ independe da configuração inicial, e assume um valor mais próximo da conformação anti, o que é consistente com o esperado de uma população majoritariamente anti em água.

A comparação entre os ângulos médios de diedro amostrados com a MD e o CBMC, também exibidos na tabela 4 , trás alguns resultados interessantes. Para o diedro $\phi_{\mathrm{C} 6-\mathrm{C} 1}={ }_{\mathrm{C} 2}-\mathrm{C} 3$, cujo potencial é exibido na figura 20, a concordância entre os dois métodos de amostragem é excelente, com valores médios e desvios muito próximos tanto em fase gasosa quanto em 
Tabela 5 - Dados sobre as ligações de hidrogênio entre a molécula de MOx (rígida e flexível) e as moléculas de água partindo das conformações iniciais syn e anti. As unidades de $E, R$ e $\theta$ são $\mathrm{kcal} / \mathrm{mol}$, Å e graus respectivamente. Tabela adaptada de Cezar, Canuto e Coutinho ${ }^{[102]}$.

\begin{tabular}{lcccc}
\hline Soluto & $\left\langle N_{\mathrm{HB}}\right\rangle$ & $\left\langle E_{i j}\right\rangle$ & $\left\langle R\left(\mathrm{O}_{\mathrm{M}} \cdots \mathrm{O}_{\mathrm{W}}\right)\right\rangle$ & $\left\langle\theta\left(\mathrm{O}_{\mathrm{M}} \cdots \mathrm{O}_{\mathrm{W}} \mathrm{H}\right)\right\rangle$ \\
\hline rígido - syn & $2.4 \pm 0.5$ & $-7.7 \pm 1.7$ & $2.75 \pm 0.16$ & $12 \pm 7$ \\
rígido - anti & $2.8 \pm 0.5$ & $-7.9 \pm 1.8$ & $2.76 \pm 0.16$ & $12 \pm 7$ \\
flexível - início syn & $2.7 \pm 0.5$ & $-8.0 \pm 1.8$ & $2.76 \pm 0.16$ & $12 \pm 7$ \\
flexível - início anti & $2.7 \pm 0.5$ & $-7.9 \pm 1.7$ & $2.76 \pm 0.16$ & $12 \pm 7$ \\
\hline
\end{tabular}

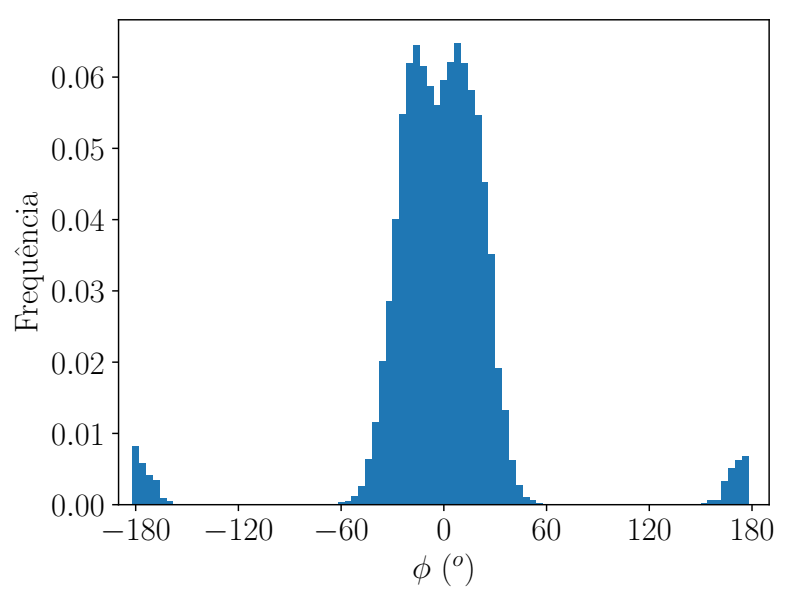

Figura 21 - Histograma normalizado da frequência de amostragem do ângulo de diedro $\mathrm{C} 1=\mathrm{C} 2-\mathrm{C} 3=\mathrm{O} 4$ do $\mathrm{MOx}$ em fase gasosa com o CBMC.

água. Isso é um indicativo de que, para potenciais rígidos como o dos diedros entre $\mathrm{C} 1=\mathrm{C} 2$, a amostragem proposta com deslocamentos Cartesianos e aceitação com critério de Metropolis é suficiente para uma correta amostragem do espaço configuracional. Os valores médios da distribuição bimodal, devido às conformações syn e anti, do ângulo $\phi_{\mathrm{C} 1=\mathrm{C} 2-\mathrm{C} 3=\mathrm{O} 4}$ no entanto mostram um resultado interessante no caso das simulações MD. Para a MD em fase gasosa partindo da configuração syn e MD em água partindo da conformação anti, temos que não foram amostrados ângulos de diedro referente a configuração anti e syn, respectivamente. Portanto, durante a amostragem dessas simulações a conformação não foi alterada, o que indica uma amostragem ineficiente por parte da MD. Isso fica evidente observando a evolução do ângulo de diedro $\phi_{\mathrm{C} 1=\mathrm{C} 2-\mathrm{C} 3=\mathrm{O} 4}$ com os passos de simulação.

Na figura 22, a evolução do ângulo $\mathrm{C} 1=\mathrm{C} 2-\mathrm{C} 3=\mathrm{O} 4$ com os passos de simulação CBMC e MD para a simulação em fase gasosa são mostradas. As figuras com rótulo (a) são referentes a simulações iniciadas com o MOx na conformação anti, enquanto que as com rótulo (b) são de simulações iniciadas na conformação syn. Vemos que duas regiões são principalmente amostradas: uma em torno de $0^{\circ}$ correspondente a conformação syn e outra em torno de $180^{\circ}$ relativa a conformação anti, como pode ser visto também na figura 21 de outra maneira. Como 

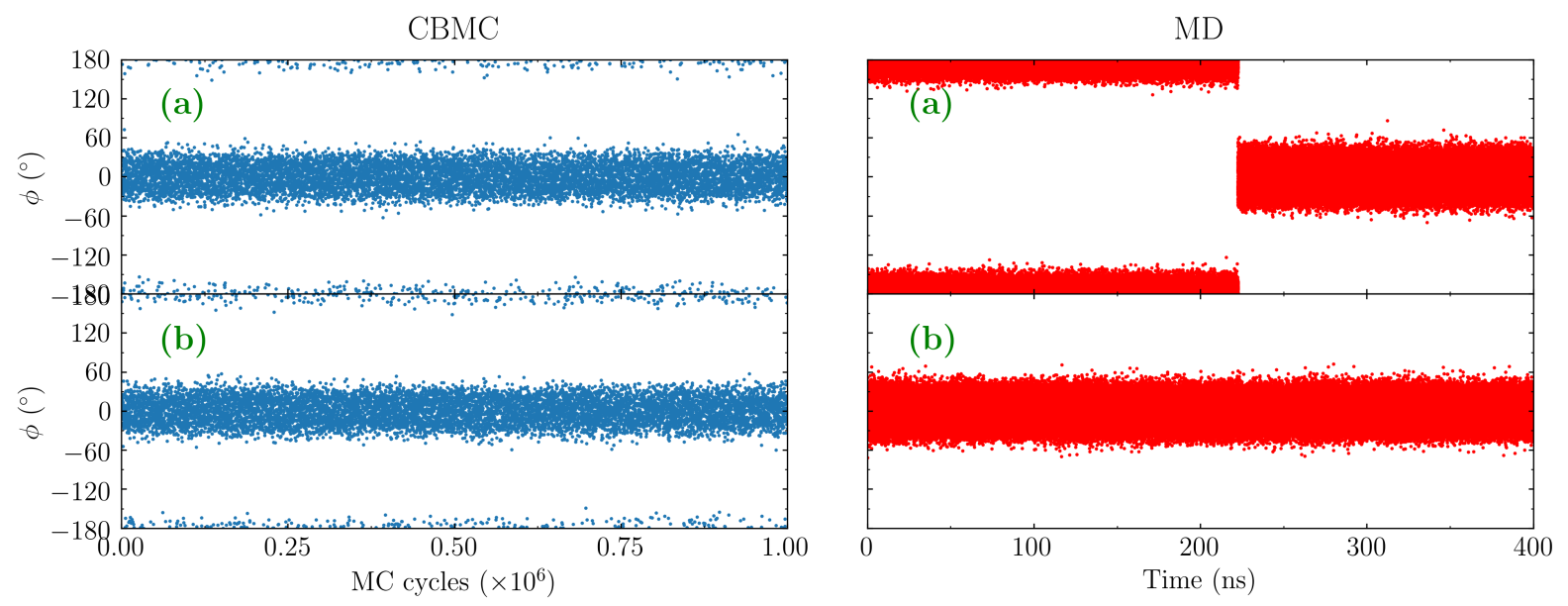

Figura 22 - Evolução do ângulo de diedro $\mathrm{C}=\mathrm{C}-\mathrm{C}=\mathrm{O}$ do $\mathrm{MOx}$ em fase gasosa com os passos de simulação. Os gráficos do topo, identificados com (a), são de simulações iniciadas com o MOx na configuração anti (com a simulação CBMC na esquerda e MD na direita). Os gráficos rotulados com (b) são correspondentes a simulações inciadas da conformação syn. Figura de Cezar, Canuto e Coutinho ${ }^{[102]}$.

as conformações que estão fora do limite de definição dos ângulos syn e anti são pertencentes ao mesmo pico do histograma na figura 21 , definimos neste trabalho conformações syn como tendo o diedro $(0 \pm 60)^{\circ}$ e anti com o diedro $(180 \pm 60)^{\circ}$. De acordo com o potencial utilizado para os diedros, exibido na figura 18(b), é esperado uma população syn:anti de (91:9)\% em fase gasosa. ${ }^{[92]}$ A simulação CBMC, independente da conformação inicial produz uma amostragem uniforme, principalmente em torno da região de $0^{\circ}$, o que não acontece na MD. A população amostrada foi de $95: 5 \%$ (96:4 \%) com erro de $1 \%$ para a simulação iniciada na conformação syn (conformação anti em parênteses).

Já na MD observamos na figura 22 que a simulação iniciada na conformação anti precisa de ao menos 200 ns para mudar a conformação e para a syn e então nela permanecer. Simulações de MD iniciadas com condições iniciais diferentes obtiveram resultado similar, indicando que a dificuldade de superar a barreira entre as duas conformações é uma característica do conjunto da metodologia e algoritmos empregados. Essa dificuldade da MD é diretamente refletida nas populações syn:anti. Para a simulação iniciada na configuração anti uma população de 44:56 $\%$ foi obtida, enquanto que para a simulação partindo da configuração syn foram amostradas somente configurações syn, ou seja, 100:0 \%. Como a MD tem dificuldade em ultrapassar a barreira energética entre as conformações, o tempo gasto durante a amostragem em torno de cada uma pode não refletir exatamente a diferença de energia entre os mínimos. Se esse é o caso, a hipótese ergódica falha, e o tempo gasto amostrando em cada um dos funis do potencial (diretamente relacionado às populações) não corresponde ao potencial da figura $18(\mathrm{~b})$. A solução para esse problema seriam simulações proibitivamente longas, ou ainda a utilização de métodos de ensemble estendido que poderiam melhorar a visitação do espaço configuracional, como por exemplo o replica-exchange. 

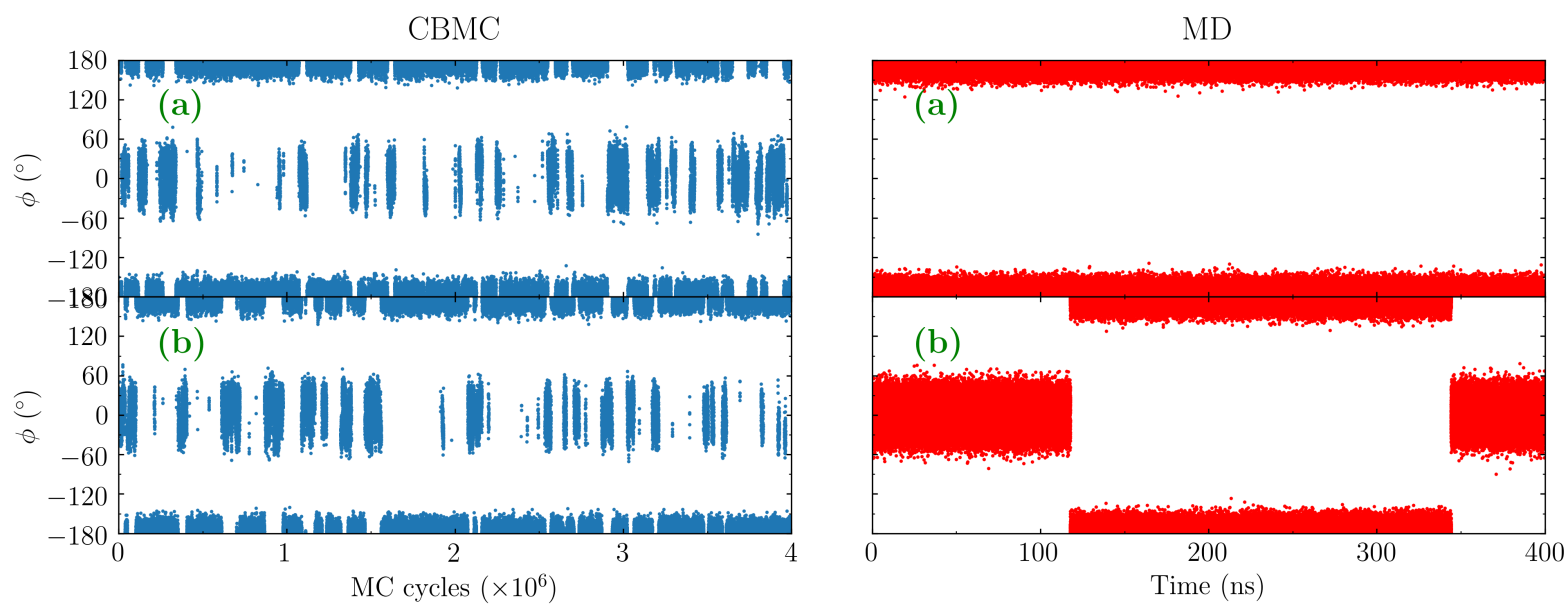

Figura 23 - Evolução do ângulo de diedro $\mathrm{C}=\mathrm{C}-\mathrm{C}=\mathrm{O}$ do $\mathrm{MOx}$ em água com os passos de simulação. Os gráficos do topo, identificados com (a), são de simulações iniciadas com o MOx na configuração anti (com a simulação CBMC na esquerda e MD na direita). Os gráficos rotulados com (b) são correspondentes a simulações inciadas da conformação syn. Figura de Cezar, Canuto e Coutinho ${ }^{[102]}$.

A situação é similar para a amostragem feita em água, que tem a evolução do diedro $\mathrm{C}=\mathrm{C}-\mathrm{C}=\mathrm{O}$ exibida na figura 23. Nesse caso, as simulações CBMC amostram em torno de um dos mínimos antes de conseguir mudar para o próximo, mas ainda conseguem superar as barreiras de energia e fazer uma amostragem uniforme, com diversas mudanças conformacionais. As populações syn:anti (em \%) obtidas para a simulação CBMC foram de 22:78 \pm 7 e 27:73 \pm 10 para as simulações iniciadas das conformações syn e anti respectivamente. Essas populações estão em acordo com a tendência esperada pelos cálculos de energia livre de Damasceno, Cabral e Coutinho ${ }^{[92]}$, que sugerem que a conformação anti se torna a dominante com uma população de $99 \%$. A diferença entre a população obtida e a esperada é justificada pelo potencial, que mesmo que ajustado para refletir em fase gasosa os cálculos de mecânica quântica, não necessariamente reflete o potencial em solução sentido pela molécula em água. Isso juntamente a pequenas diferenças no cálculo realizado anteriormente como o modelo utilizado para as moléculas de água (SPC na referência ${ }^{[92]}$ e SPC/E neste trabalho), e o conjunto de cargas diferente em cada conformação contribuem para essa diferença na população total.

Já a MD, como visto na figura 23, novamente fica presa em torno de um mínimo e necessita de um longo período antes de mudar de conformação. Nessas simulações as populações de conformação syn:anti foram de 35:65 \% e 0:100 \% para as simulações iniciadas nas conformações syn e anti, respectivamente. Os problemas relacionados a essa dificuldade de superar a barreira de energia, que gera menos mudanças conformacionais na MD, são os mesmos da simulação em gás, o que novamente indica que os valores das populações na tabela 6 não refletem a diferença de energia entre as conformações syn e anti também em água. Duas outras simulações independentes realizadas por 150 ns mostram a mesma dificuldade em superar a barreira de energia, indicando que esse comportamento é geral para as simulações 
MD.

A diferença da amostragem CBMC em fase gasosa e em água é ilustrada pelo "tempo de vida" de cada conformação, medido em ciclos de $\mathrm{MC}$, ou seja, o número de ciclos que em média a simulação passa em cada conformação antes de mudar para a próxima. Na simulação em fase gasosa, o tempo de vida médio da conformação anti é de $\sim 110$ ciclos de $\mathrm{MC}$, enquanto que a conformação syn tem um tempo de vida médio de $\sim 2300$ ciclos. Já para a simulação em água, a conformação anti possui um tempo de vida médio de $\sim 44250$ ciclos de MC, e a conformação syn $\sim 14400$ ciclos. Esses números indicam uma estabilização de ambas conformações em água, porém em maior proporção para a conformação anti, que se torna dominante nesse caso. $A$ estabilização ocorre não devido ao número de ligações de hidrogênio, como poderia se esperar, já que o número de ligações de hidrogênio em ambas as conformações é similar, como mostra a 5. Portanto, a estabilização da conformação anti em água pode se dar devido à interação eletrostática, já que o dipolo da conformação anti, de 7.20 D, é maior que o da conformação syn, de 5.22 D. Os valores médios do dipolo para a simulação em fase gasosa e em água são, respectivamente, $(5.3 \pm 0.4) \mathrm{D}$ e $(6.7 \pm 0.8) \mathrm{D}$. Esses valores refletem a população dominante em cada caso, e indicam que a conformação anti é favorecida devido a interação dipolo-dipolo do soluto com o solvente.

\subsection{Efeito da polarização do soluto pelo solvente}

Para investigar o efeito de outros solventes sob o equilíbrio das conformações do MOx, simulações em acetonitrila e metanol foram realizadas. Como esses solventes são menos polares que a água, se as populações tiverem uma dependência com a polaridade do solvente é esperado que a porcentagem que conformações anti seja maior na água, seguido pelo metanol e então a acetonitrila. Esse comportamento é de fato verificado, contudo, para uma abordagem mais completa, é necessário levar em consideração a polarização do soluto nos diferentes solventes. Dois conjuntos de simulações foram realizados, um com o conjunto de cargas do MOx polarizadas em água da seção 4.3, e outro com cargas polarizadas em acetonitrila e metanol.

Para a polarização, um procedimento similar ao realizado para a polarização em água foi adotado. ${ }^{[92]}$ Inicialmente, uma polarização com o modelo contínuo $\mathrm{PCM}^{[6,7]}$ foi realizada no software Gaussian 09 ${ }^{[110]}$ para ambas conformações e nos dois solventes, no nível MP2/augcc-pVDZ e utilizando um ajuste do potencial eletrostático com o método CHELPG. ${ }^{[11]}$ Então, simulações com o MOx rígida nas conformações syn e anti foram realizadas utilizando as cargas já polarizadas com o modelo contínuo, sendo realizados 100000 ciclos de MC para termalização e 75000 ciclos de MC para produção. As foram realizadas com 1 molécula de MOx e 800 moléculas de acetonitrila ou metanol. 75 configurações descorrelacionadas dessas simulações foram selecionadas para gerar um fundo eletrostático com cargas pontuais utilizando 


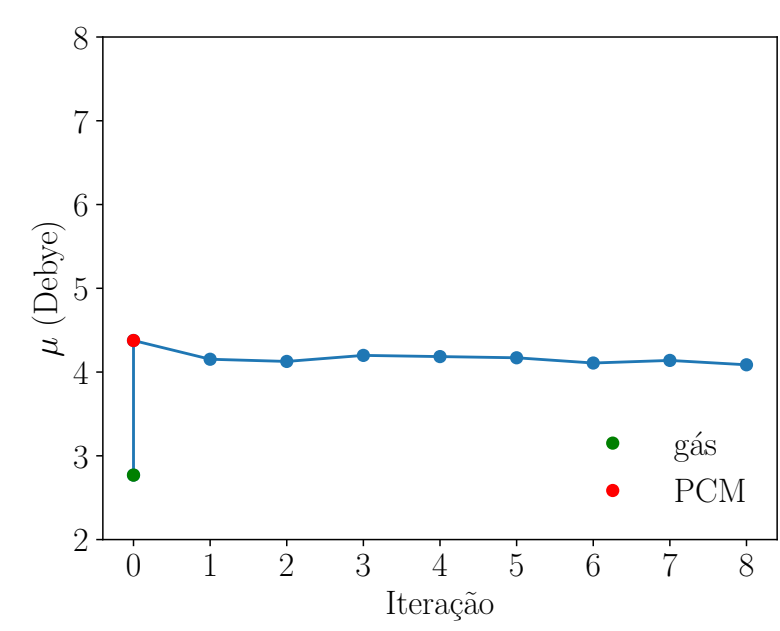

(a) syn

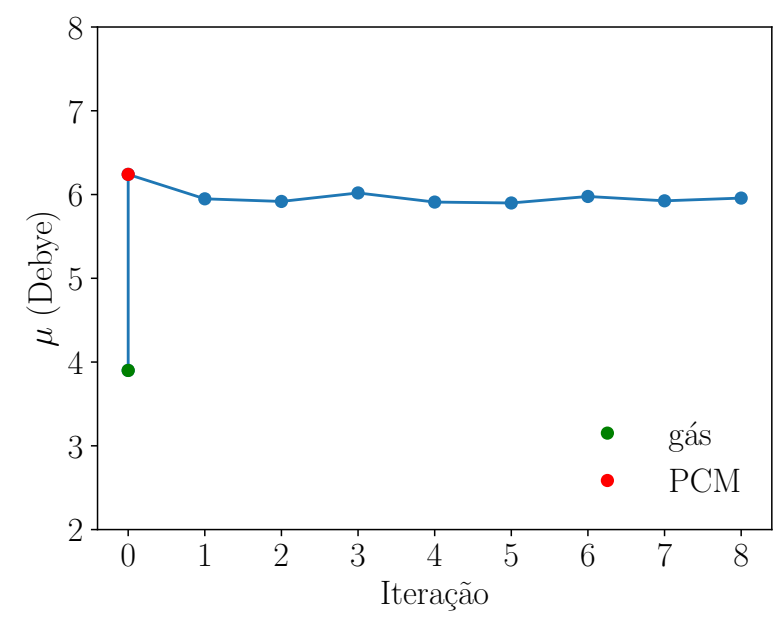

(b) anti

Figura 24 - Convergência do momento de dipolo do MOx em acetonitrila com o processo iterativo de polarização com simulações e ASEC. Mais detalhes do processo utilizado podem ser encontrados no texto.

o método ASEC. ${ }^{[112]}$ Com esse fundo eletrostático, novos cálculos foram realizados para obter um novo conjunto de cargas com o CHELPG, utilizando o mesmo nível de cálculo. Esse processo foi repetido iterativamente 8 vezes para cada um dos solventes, acetonitrila e metanol, e para as conformações syn e anti, até a convergência dos momentos de dipolo das moléculas, como ilustrado nas figuras 24 e 25, onde o ponto verde representa o momento de dipolo com cargas da fase gasosa, o ponto vermelho com as cargas polarizadas com PCM, e cada um dos outros pontos, referente ao cálculo de MQ com o fundo de cargas do ASEC, selecionado das configurações das simulações. À partir do conjunto de cargas polarizado em cada conformação, um conjunto de cargas composto da média das cargas nas conformações syn e anti para cada átomo, arredondada, foi escolhido para a simulação. $O$ conjunto de cargas final pode ser visto no apêndice $E$ nos arquivos . txt na sexta coluna, logo após o conjunto de coordenadas cartesianas dos átomos.

Contudo, ao alterar as cargas do soluto, o potencial de rotação do diedro $\mathrm{C}=\mathrm{C}-\mathrm{C}=\mathrm{O}$ também é alterado, e o potencial parametrizado na seção 4.2 já não possui as mesmas diferenças de energia da figura 18. Verificamos então que as mudanças entre a diferença de energia das configurações syn e anti não são drásticas, e portanto, o mesmo conjunto de parâmetros $V_{1}$, $V_{2}$ e $V_{3}$ para os torsionais envolvidos na rotação podem ser utilizados. Isso é ilustrado na figura 4.4. A diferença de energia syn $\rightarrow$ anti com o conjunto de cargas polarizado para a acetonitrila é de $1.32 \mathrm{kcal} / \mathrm{mol}$ e para o metanol de $1.81 \mathrm{kcal} / \mathrm{mol}$. Essas diferenças de energia seriam correspondentes à uma população anti de $10 \%$ e $5 \%$, respectivamente. É interessante notar que apesar de ser um solvente mais polar que a acetonitrila, o metanol aumenta a diferença de energia entre as conformações syn e anti, estabilizando em fase gasosa ainda mais a conformação syn. À princípio, isso é inesperado, pois em solução, espera-se que a população 


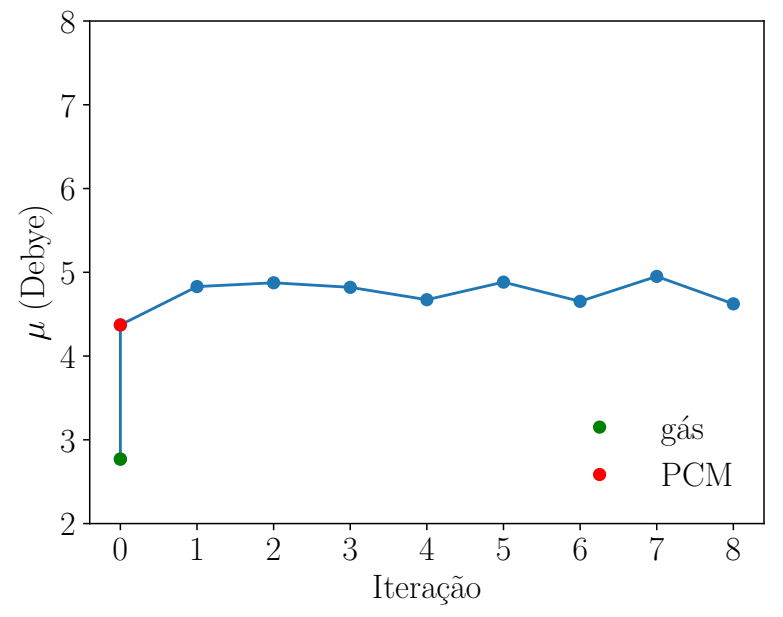

(a) syn

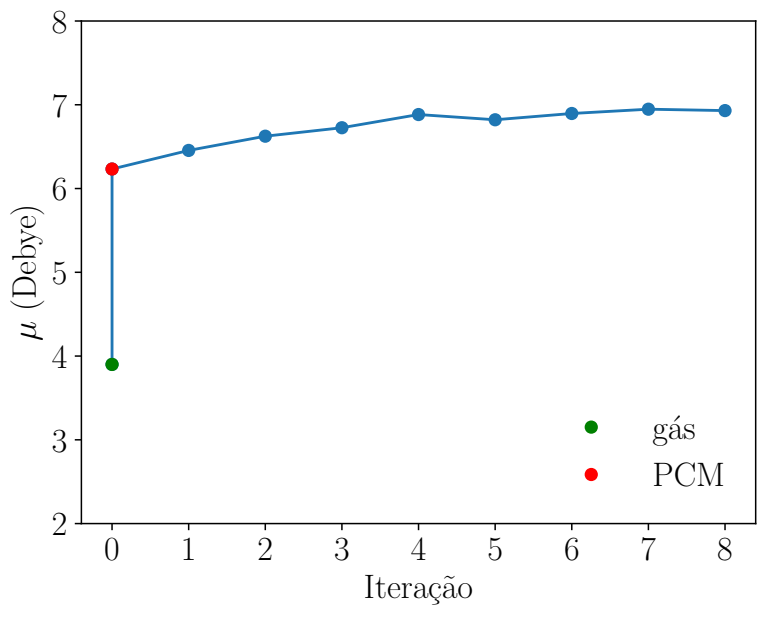

(b) anti

Figura 25 - Convergência do momento de dipolo do MOx em metanol com o processo iterativo de polarização com simulações e ASEC. Mais detalhes do processo utilizado podem ser encontrados no texto.

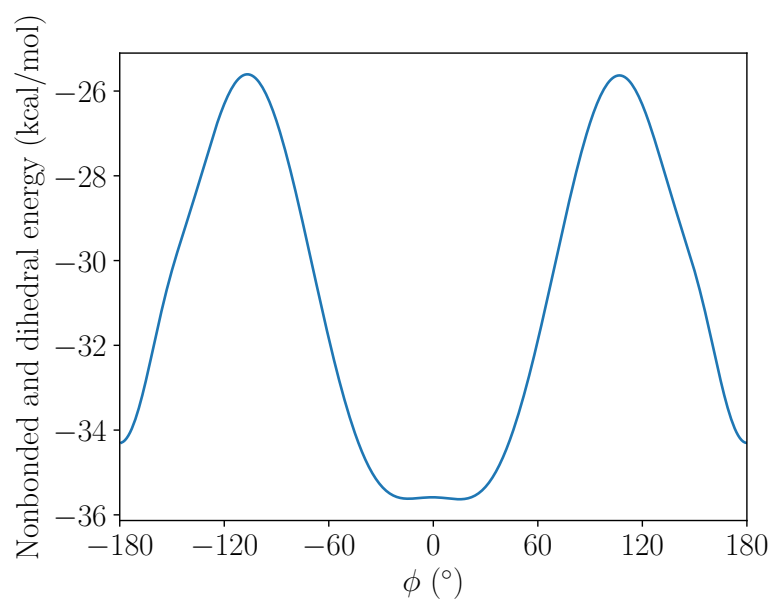

(a) acetonitrila

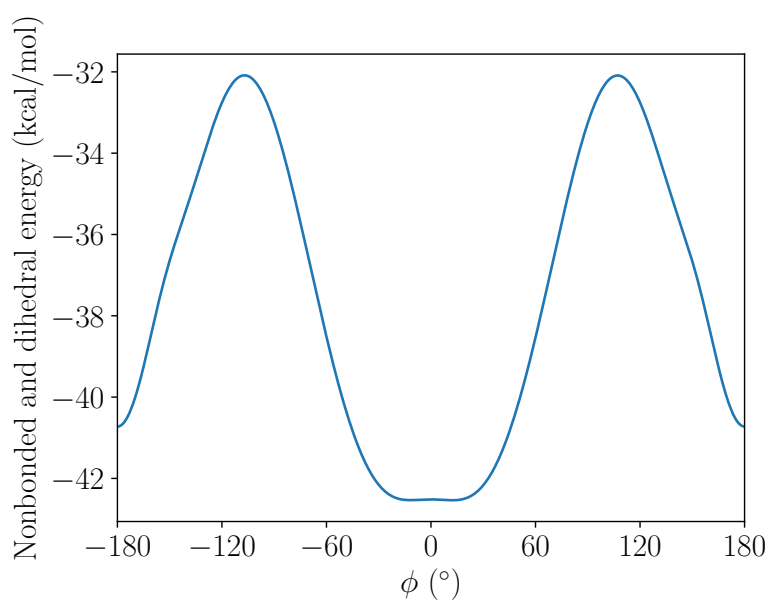

(b) metanol

Figura 26 - Potencial da rotação do grupo $\mathrm{C}=\mathrm{C}-\mathrm{C}=\mathrm{O}$ utilizando as cargas polarizadas nos solventes acetonitrila e metanol. Os parâmetros de diedro são os mesmos encontrados na figura 18.

de conformações anti em metanol seja maior que a da acetonitrila, e esse parece um passo na direção contrária. Devemos então verificar a população das conformações em solução para ver se esse é de fato o caso.

As simulações em metanol e acetonitrila foram realizadas nas mesmas condições termodinâmicas das simulações em água, i.e., $P=1 \mathrm{~atm}$ e $T=300 \mathrm{~K}$. Para esses solventes foram utilizadas 800 moléculas de solvente e 1 molécula de $\mathrm{MOx}$, todos os outros parâmetros de simulação foram mantidos. Os modelos utilizados para a acetonitrila ${ }^{[113]}$ e metanol ${ }^{[66]}$ são compatíveis com o OPLS-AA. A caixa de simulação foi termalizada por $2 \times 10^{8}$ passos de 
Tabela 6 - População syn:anti (em \%) do MOx amostrada em fase gasosa e em diferentes solventes utilizando CBMC, e em fase gasosa e água também utilizando MD. Os valores entre parênteses indicam os valores obtidos para simulações iniciadas da configuração anti enquanto os outros valores são correspondentes a simulações iniciadas na configuração syn. Para as simulações em acetonitrila e metanol, as populações com os dois conjuntos de cargas simulados são exibidos. * indica simulações onde somente uma conformação foi amostrada.

\begin{tabular}{lcc}
\hline Solvente & $\begin{array}{c}\text { syn:anti } \\
\text { CBMC }\end{array}$ & $\begin{array}{c}\text { syn:anti } \\
\text { MD }\end{array}$ \\
\hline fase gasosa & $95: 5 \pm 1$ & $100: 0^{*}$ \\
& $(96: 4 \pm 1)$ & $(44: 56)$ \\
água & $22: 78 \pm 7$ & $35: 65$ \\
& $(27: 73 \pm 10)$ & $(0: 100)^{*}$ \\
acetonitrila (carga água) & $51: 49 \pm 6$ & \\
acetonitrila (carga polarizada) & $56: 44 \pm 5$ & \\
metanol (carga água) & $51: 49 \pm 13$ & \\
metanol (carga polarizada) & $50: 50 \pm 15$ & \\
\hline
\end{tabular}

MC, enquanto $12 \times 10^{8}$ passos de MC foram utilizado para a simulação de produção. Duas simulações foram realizadas para cada solvente, uma delas utilizando o conjunto de cargas do MOx polarizado em água, e outra utilizando o conjunto de cargas polarizado obtido no solvente.

Um sumário das populações encontradas em fase gasosa e em cada solvente, com cada conjunto de cargas pode ser visto na tabela 6. Por completeza, os resultados obtidos com a MD para as populações em água e fase gasosa também são exibidos. Vemos que com o conjunto de cargas polarizado na água, as populações das conformações em acetonitrila e metanol são basicamente idênticas, diferindo apenas no desvio encontrado, que é maior no caso do metanol. Por outro lado, ao utilizar o conjunto de cargas polarizado em cada solvente, a tendência esperada de encontrar uma população de conformações anti maior em metanol do que em acetonitrila é obtida. Ainda que a diferença não seja grande, obter a tendência correta das populações é importante para o espectro de absorção, que tem uma contribuição conformacional relevante, como será mostrado na seção 4.5.

O resultado das populações concorda com a polaridade do solvente descrito pela escala $E_{T}^{N}(30)$, uma escala que dá a polaridade dos solventes segundo o solvatocromismo da betaína 30. Apesar da constante dielétrica da acetonitrila ser maior que a do metanol, e também a acetonitrila ter um momento de dipolo maior que o do metanol, a acetonitrila é um solvente menos polar na escala $E_{T}^{N}(30)$ que o metanol. Isso ocorre pois as escalas de polaridade levam em conta não somente as forças eletrostáticas, mas também a capacidade de polarização da molécula, se a molécula é ou não doadora de ligações de hidrogênio, entre outras interações específicas e não específicas. ${ }^{[114]} \mathrm{Na} E_{T}^{N}(30)$, apesar das constantes dielétricas de acetonitrila e metanol serem muito parecidas: 35.7 e 32.6 , respectivamente, os valores da polaridade são 
diferentes, sendo $E_{T}^{N}(30)=0.46$ para a acetonitrila e $E_{T}^{N}(30)=0.76$ para o metanol. ${ }^{[14]}$ Por esse motivo, com as cargas polarizadas nos respectivos solventes, os valores das populações da tabela 6 são consistentes com a polaridade do solvente.

\subsection{Espectro de absorção e solvatocromismo}

Dados experimentais de Kosower ${ }^{[101]}$ apontam que o máximo da banda de absorção $\pi-\pi^{*}$ é dependente da polaridade do solvente, tendo uma dependência linear na escala de Reichardt conforme já reportado na literatura. ${ }^{[92]}$ A origem dessa dependência pode ser conformacional, ou ao menos ter uma contribuição conformacional, já que como mostrado, - MOx tem a população syn:anti dependente da polaridade do solvente. Para investigar essa hipótese o espectro de absorção do MOx foram calculados em fase gasosa, em dois solventes próticos: metanol e água, e um solvente aprótico: acetonitrila. Esses solventes foram escolhidos buscando diversidade, por serem os extremos de polaridade e incluírem solventes com polaridade intermediária mas prótico e aprótico, e também por terem o seu máximo e absorção experimental reportados. ${ }^{[101]}$

Os cálculos do espectro utilizaram o conjunto de base e método escolhidos por Damasceno, Cabral e Coutinho ${ }^{[92]}$, sendo utilizados dois funcionais, B3LYP e BHandHLYP, e a base $6-311++G(d, p)$. Inicialmente, 200 configurações estatisticamente independentes provenientes das simulações CBMC em gás e em água foram utilizadas. $A$ análise da convergência da energia média de transição da banda $\pi-\pi^{*}$ para os casos onde o efeito do solvente é incluído através de 250 cargas pontuais (CP), e utilizando além das $250 \mathrm{CP}$ as moléculas de água que formam ligação de hidrogênio (HB, com os critérios apresentados na seção 4.3) com o MOx, é exibido na figura 27. Como pode ser observado, a utilização de 100 configurações para o cálculo da energia de transição é o suficiente para obter uma média da posição da banda convergida. Por esse motivo, os cálculos em acetonitrila e metanol foram feitos utilizando somente 100 configurações estatisticamente independentes.

A fim de observar a contribuição de cada termo na energia de transição, seja conformacional ou referente a inclusão do efeito solvente, diversos cálculos em cada solvente foram realizados. A contribuição conformacional pode ser encontrada comparando a energia de transição média em fase gasosa e a energia de transição média sob as configurações provenientes das simulações em cada um dos solventes. O efeito solvente pode ser incluído como cargas pontuais em cada configuração e com a adição de moléculas explícitas. Essas possibilidades são consideradas, e os valores da energia dos máximos da energia de transição, referente a banda $\pi-\pi^{*}$, são exibidos na tabela 7 . A coluna $S$ é referente a utilização em fase gasosa das estruturas amostradas em solução com o CBMC, enquanto as outras linhas incluem além da molécula de MOx em cada configuração, os efeitos do solvente com a utilização de cargas pontuais $(C P)$, moléculas que formam ligações de hidrogênio $(H B)$ e moléculas explícitas 


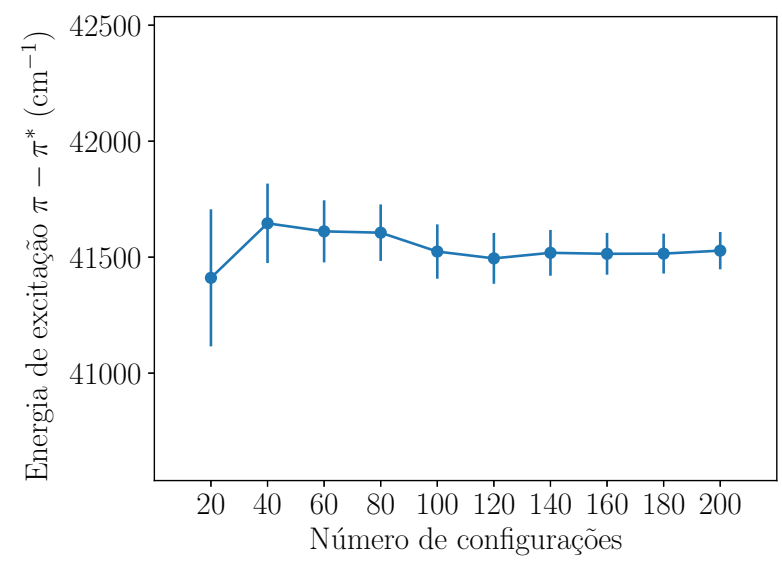

(a) $250 \mathrm{CP}$

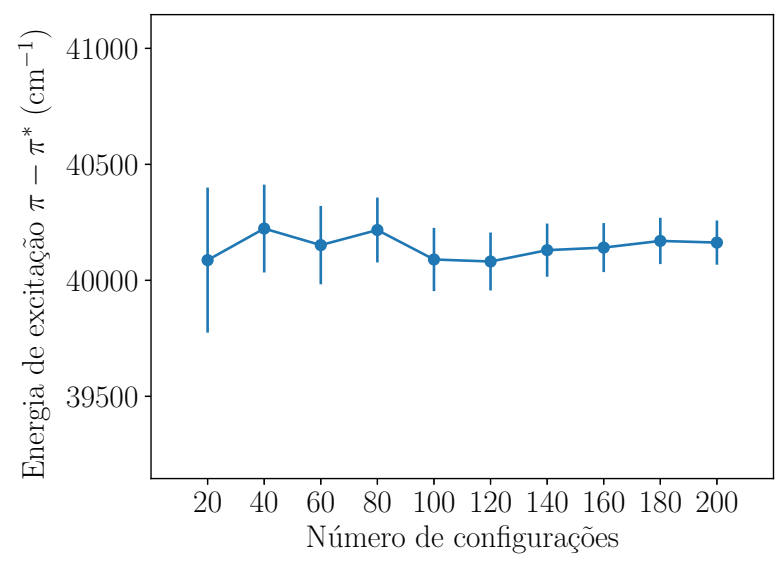

(b) $\mathrm{HB}+250 \mathrm{CP}$

Figura 27 - Convergência da energia de transição média da banda $\pi-\pi^{*}\left(\mathrm{em} \mathrm{cm}^{-1}\right)$ com o número de configurações da simulação CBMC utilizadas para o cálculo do espectro de absorção.

do solvente $(\mathrm{MOL})$. Os números em frente ao $\mathrm{CP}$ ou $\mathrm{MOL}$ indicam o número de moléculas representadas como carga pontual e explicitamente, respectivamente.

Como os cálculos utilizados para preencher a tabela 7 são realizados apenas sob um conjunto reduzido de 100 ou 200 configurações, os percentuais de configuração syn:anti não são exatamente os exibidos na tabela 6 . Os percentuais encontrados para as simulações em fase gasosa, acetonitrila, metanol e água, foram, respectivamente, 92:8 \%, 61:39 \%, 50:50\% e 20:80 \%. As diferenças entre esses valores e os da tabela 6 não são significativas pois os valores são próximos, e a tendência do aumento da população de configurações anti com a polaridade do solvente é mantida.

Para a coluna $S$ da tabela 7 a variação do máximo de absorção da média sob as várias configurações em cada um dos solventes e na fase gasosa, é originada somente pelo efeito conformacional introduzido pela simulação CBMC. Contudo, não é possível atribuir todo o efeito à variação da população syn:anti, já que outras diferenças conformacionais podem ser responsáveis pelo deslocamento do máximo no espectro. De fato, é possível observar que apesar do aumento sistemático do número de conformações anti com a polaridade do solvente, a contribuição conformacional dada por $\delta E_{\text {conf }}=E_{\mathrm{S}}-E_{\text {Gás }}$ não segue a mesma tendência. Considerando o funcional B3LYP, o deslocamento para o azul de $\delta E_{\text {conf }}^{\text {acetonitrila }}=$ $1169 \mathrm{~cm}^{-1}$ é menor do que o da água de $\delta E_{\text {conf }}^{\text {água }}=1653 \mathrm{~cm}^{-1}$, mas maior do que o do metanol de $\delta E_{\text {conf }}^{\text {metanol }}=967 \mathrm{~cm}^{-1}$. Se apenas a população de configurações syn:anti fosse a única responsável pelo deslocamento para o azul, seria esperado que o deslocamento no metanol fosse maior do que o na acetonitrila. A explicação para essa diferença vem do efeito conhecido de deslocamento para vermelho causado pelo estiramento $C=O$, que por sua vez é provocado pelas ligações de hidrogênio formadas no metanol. ${ }^{[108]}$ Considerando este efeito, mesmo que o deslocamento para o azul seja maior no metanol, essa contribuição é reduzida pelo estiramento 
Tabela 7 - Energia de transição $\pi-\pi^{*}\left(E\right.$, em $\left.\mathrm{cm}^{-1}\right)$ do $\mathrm{MOx}$ em fase gasosa e nos solventes água, metanol e acetonitrila. $\delta E_{\text {conf }}$ indica a contribuição conformacional à energia de transição nos diferentes solventes comparadas à simulação em fase gasosa, dada por $\delta E_{\text {conf }}=E_{\mathrm{S}}-E_{\mathrm{Gás}} . \delta E_{\mathrm{CP}}, \delta E_{\mathrm{HB}}$ e $\delta E_{\text {solv }}$ representa a contribuição do solvente à energia de transição para cada modelo, e é dada por $\delta E_{\text {solv }}=E-E_{S}$. $\mathrm{S}$ representa o soluto (MOx) e MOL moléculas do solvente. Para água temos que $n=14$ e $m=236$, enquanto que para o metanol e acetonitrila, $n=4$ e $m=246$. As energias foram calculadas com TD-DFT utilizando os funcionais B3LYP e BHandHLYP, na base $6-311++G(d, p)$. Os cálculos foram feitos sob configurações obtidas das simulações CBMC em cada um dos solventes e em gás. $O$ valor exibido é referente ao máximo de intensidade na região da transição, encontrado após a convolução de lorentzianas para a construção da curva do espectro de absorção. Os valores experimentais são de Kosower ${ }^{[101]}$. * o valor se refere a medida da energia de transição em iso-octano.

\begin{tabular}{rllllllll}
\hline & \multicolumn{2}{c}{$\mathrm{S}$} & \multicolumn{2}{c}{$\mathrm{S}+250 \mathrm{CP}$} & \multicolumn{2}{c}{$\mathrm{S}+\mathrm{HB}+250 \mathrm{CP}$} & \multicolumn{2}{c}{$\mathrm{S}+n \mathrm{MOL}+m \mathrm{CP}$} \\
\cline { 2 - 9 } & $E$ & $\delta E_{\text {conf }}$ & $E$ & $\delta E_{\mathrm{CP}}$ & $E$ & $\delta E_{\mathrm{HB}}$ & $E$ & $\delta E_{\text {solv }}$ \\
\hline Gás & & & & & & & & \\
B3LYP & 42506 & & & & & & & \\
BHandHLYP & 45248 & & & & & & & \\
Exp. & 43365 & & & & & & & \\
Acetonitrila & & & & & & & 42385 & -1290 \\
B3LYP & 43675 & 1169 & 42667 & -1008 & & & 45329 & -1451 \\
BHandHLYP & 46780 & 1532 & 45450 & -1330 & & & 42753 & \\
Exp. & & & & & & & & \\
Metanol & & & & & & & 41094 & -2379 \\
B3LYP & 43473 & 967 & 41820 & -1653 & & & 44038 & -2379 \\
BHandHLYP & 46417 & 1169 & 44724 & -1693 & & & 42230 & \\
Exp. & & & & & & & & \\
Água & & & & & & & & \\
B3LYP & 44159 & 1653 & 41618 & -2541 & 40570 & -3589 & 40005 & -4154 \\
BHandHLYP & 47305 & 2057 & 44642 & -2663 & 43635 & -3670 & 43272 & -4033 \\
Exp. & & & & & & & 41220 & \\
\hline
\end{tabular}

da ligação dupla, que desloca o espectro para o vermelho, o que no total, resulta em uma maior contribuição conformacional total para o azul no caso da acetonitrila. $O$ estiramento $\mathrm{C}=\mathrm{O}$ é de fato observado quando olhamos para o valor médio do comprimento de ligação sob as configurações amostradas com o $\mathrm{CBMC}$, que dá um valor de $r_{\mathrm{C}=\mathrm{O}}^{\text {acetonitrila }}=(1.229 \pm 0.016) \AA$ e $r_{\mathrm{C}=\mathrm{O}}^{\text {metanol }}=(1.232 \pm 0.016) \AA$.

A inclusão do efeito solvente vai na contramão do efeito conformacional e desloca o máximo do espectro de absorção para o vermelho. Isso pode ser visto na tabela 7 através dos valores entre chaves, que mostram um deslocamento para o vermelho mais notável conforme o modelo é melhorado (moléculas explícitas de solvente são incluídas). A maior contribuição, já pode ser encontrada com a adição somente de CP, que introduzem um 
deslocamento $\delta E_{\mathrm{CP}}=E_{\mathrm{S}+250 \mathrm{CP}}-E_{\mathrm{S}}$ de $\delta E_{\mathrm{CP}}^{\text {água }}=-2541 \mathrm{~cm}^{-1}, \delta E_{\mathrm{CP}}^{\text {metanol }}=-1653 \mathrm{~cm}^{-1} \mathrm{e}$ $\delta E_{\mathrm{CP}}^{\text {acetonitrila }}=-1008 \mathrm{~cm}^{-1}$ considerando o funcional B3LYP. Quando moléculas explicitas são incluídas, o deslocamento para o vermelho é ainda maior, chegando a um deslocamento total referente as energias incluindo apenas a contribuição conformacional de $-4154 \mathrm{~cm}^{-1}$ para água, $-2379 \mathrm{~cm}^{-1}$ para metanol e $-1290 \mathrm{~cm}^{-1}$ para acetonitrila. Diferentemente da contribuição conformacional, a contribuição para o máximo de absorção originada do efeito solvente é maior conforme a polaridade do solvente.

Através da extrapolação da energia do máximo de absorção experimental do $\mathrm{MOx}$ para diferentes solventes, foi encontrado um valor para a energia de transição em gás de $43630 \mathrm{~cm}^{-1}$. ${ }^{[92]}$ Esse valor é ligeiramente diferente do valor experimental da medida em iso-octano, apresentado na tabela 7 , e foi considerado como referência para encontrar os deslocamentos solvatocrômicos. Utilizando esse valor para a transição eletrônica em gás e o valor experimental para cada solvente, ${ }^{[101]}$ encontramos o deslocamento da energia de transição da banda $\pi-\pi^{*}, \Delta E=E$ (solvente) $-E$ (Gás), de $-2410 \mathrm{~cm}^{-1}$ para água, $-1400 \mathrm{~cm}^{-1}$ para metanol e $-877 \mathrm{~cm}^{-1}$ para acetonitrila. Considerando o funcional B3LYP e o efeito solvente incluído com moléculas explícitas + cargas pontuais, além da contribuição conformacional, o deslocamento obtido (calculado à partir dos valores da tabela 7) em água, metanol e acetonitrila foi, respectivamente, de $-2501 \mathrm{~cm}^{-1},-1412 \mathrm{~cm}^{-1}$ e $-121 \mathrm{~cm}^{-1}$. Como pode ser observado, esses valores estão em excelente acordo com os valores experimentais. Mesmo para o caso onde parece haver uma maior diferença entre o valor experimental e o calculado, para o $\mathrm{MOx}$ em acetonitrila, a diferença em comprimento de onda é de apenas $4 \mathrm{~nm}$, já que o deslocamento experimental é de $4.7 \mathrm{~nm}$ e o calculado de $0.67 \mathrm{~nm}$. Partindo desse resultado, concluímos que a inclusão da contribuição conformacional com o CBMC é fundamental para a correta descrição do espectro de absorção nos solventes, já que efeitos como o estiramento $\mathrm{C}=\mathrm{O}$ e das populações syn:anti das conformações variam com cada solvente.

Apesar de não haverem medidas experimentais para o espectro de absorção do MOx, é possível calculá-lo utilizando as energias de transição obtidas com os cálculos TD-DFT. Na figura 28 alguns dos espectros de absorção obtidos no nível B3LYP/6-311++G(d,p) são exibidos. Esses espectros são da molécula de MOx isolada na conformação syn, e do espectro médio de $N=200$ configurações obtidas da amostragem em fase gasosa e água, e $N=100$ configurações em metanol. A curva do espectro de absorção foi obtida através da convolução de lorentzianas da forma

$$
L(f)=\frac{1}{N} \sum_{i=1}^{n \cdot N} \frac{I_{i} \delta f^{2}}{\left[(\delta f)^{2}+\left(f_{i}-f\right)^{2}\right]},
$$

onde $n$ é o número de transições eletrônicas $f_{i}$ em eV e $I_{i}$ são suas respectivas forças de oscilador. $N$ é o número de configurações utilizadas e $\delta f$ é a largura de linha. Como nesse caso não há espectro experimental de referência, o valor arbitrário de $\delta f=0.1$ foi utilizado. Na figura 28 foram utilizadas $n=6$ transições eletrônicas para cada configuração. 

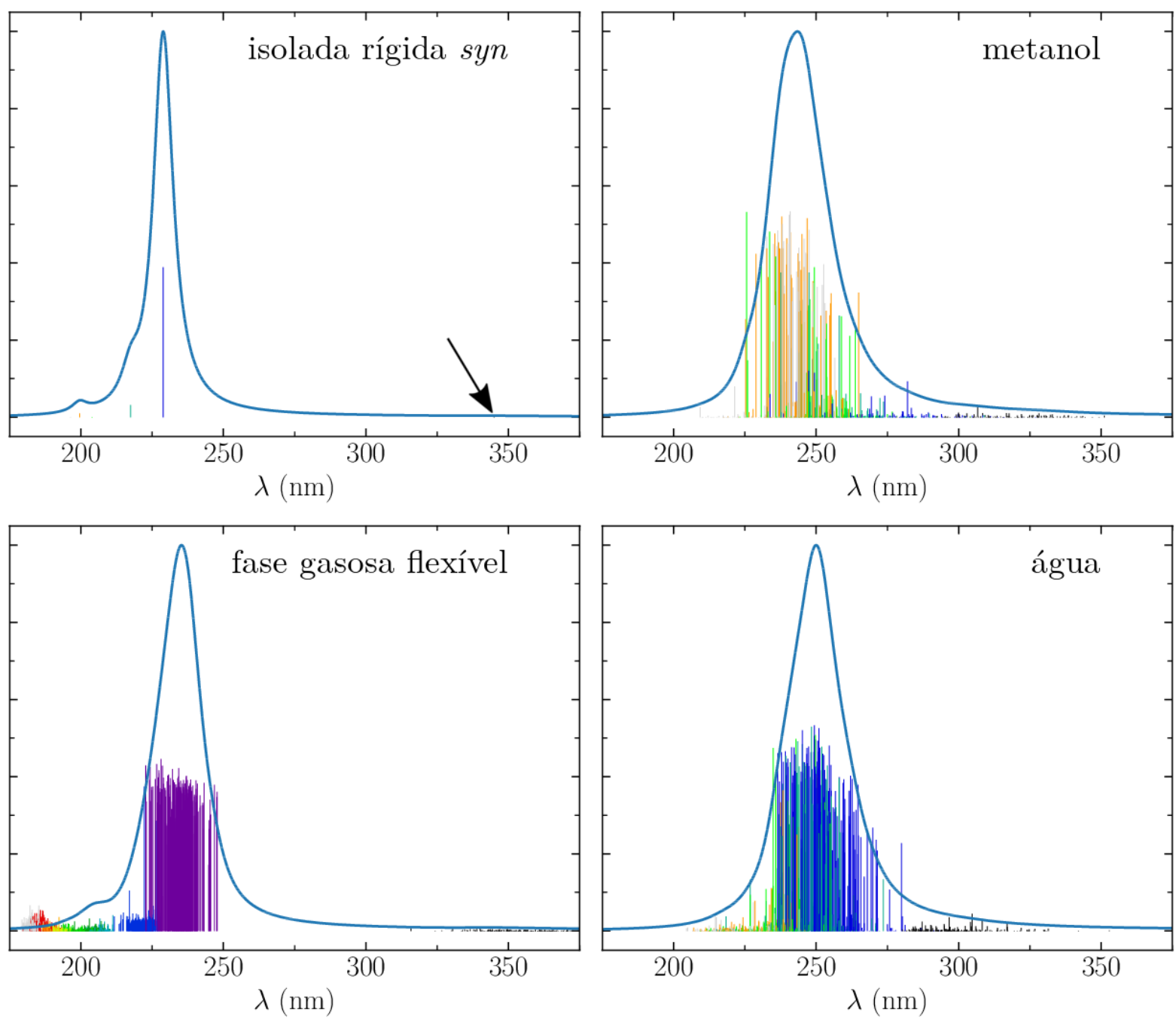

Figura 28 - Espectros de absorção do MOx nos ambientes: molécula isolada na conformação syn, em fase gasosa, em metanol e em água. Os dados se referem a convolução de lorentzianas das energias de transição obtidas com TD-DFT no nível B3LYP/6$311++\mathrm{G}(\mathrm{d}, \mathrm{p})$. As linhas coloridas representam as transições, sendo cada cor referente a uma transição diferente. A seta indica a transição $n-\pi^{*}$ que tem força de oscilador quase nula.

Os dados da tabela 7 são originados dos máximos dos picos das convoluções das energias de transição com a equação 4.1. Como é possível ver na figura 28, em meio solvente, o máximo do espectro convoluído é resultante de mais de uma transição. Esse máximo é atribuído a uma transição do tipo $\pi-\pi^{*}$. Por ser proveniente de mais de uma transição, uma investigação dos tipos de transição envolvidas podem abrir caminho para uma compreensão maior da fenomenologia da absorção do sistema. 



\section{Capítulo 5}

\section{Conclusão}

Neste capítulo as conclusões do trabalho são apresentadas, sumarizando as contribuições trazidas por essa tese de doutoramento.

Nesse trabalho, um método de CBMC para a amostragem dos graus de liberdade internos de moléculas em meio solvente foi apresentado e implementado no código DICE. $O$ método é baseado no algoritmo de Shah e Maginn, ${ }^{[1,27]}$ e tem as moléculas fragmentadas nos graus de liberdade maleáveis, formando fragmentos compostos dos graus de liberdade rígidos. A extensão do método proposta, permite a utilização do algoritmo com qualquer tipo de fragmento, diferente do algoritmo original, que é restrito a fragmentos com átomos central e anéis simples. Essa generalização permite, à princípio, o estudo de qualquer tipo de molécula com o método CBMC. O método é estendido utilizando deslocamentos Cartesianos e o algoritmo de Metropolis para a amostragem dos fragmentos, ou ainda mantendo os fragmentos rígidos durante a simulação. Através da utilização dos deslocamentos Cartesianos para a amostragem dos fragmentos, também é possível fazer a amostragem de comprimentos de ligação, o que pode ser importante, como no caso estudado do MOx. Manter os fragmentos rígidos introduz também a simplificação do arquivo de entrada de topologia da molécula, já que menos parâmetros do campo de força são necessários para a simulação. Um arquivo de entrada mais simples pode ser importante para a usabilidade do código, e também é útil por tornar necessária a parametrização apenas dos graus de liberdade estritamente necessários.

Além disso, o critério de aceitação do movimento CBMC foi simplificado e escrito de maneira diferente da apresentada pelos autores do método original. ${ }^{[27,63]}$ Através da separação dos termos de energia, foi possível escrever o critério de aceitação do método como uma razão de dois fatores de Rosenbluth, como usual para métodos de CBMC em geral. A instabilidade numérica aparentemente introduzida por escrever o critério de aceitação dessa maneira, foi resolvida escrevendo o critério como um logaritmo, como mostrado na seção 2.4 . O resultado é um critério de aceitação que se parece com os critérios tipicamente utilizados para os métodos CBMC, e que depende das energias de interação somente da parte reconstruída da molécula.

Outros detalhes de implementação também foram apresentados, junto com variações do método. Por exemplo, foi introduzida a ideia do CBMC com um viés eletrostático, que 
permite a divisão da contribuição eletrostática em uma parte que é incluída no momento que a configuração é gerada, e outra incluída somente no momento da aceitação ou rejeição da configuração total. Essa ideia é interessante especialmente para moléculas que têm sua superfície de energia potencial dominada pela contribuição eletrostática, pois fragmentos internos de uma cadeia podem sentir um campo durante a reconstrução que é diferente do campo final. Também foi mostrada a correção da amostragem preferencial, necessária devido a mudança no balanço detalhado com os termos do CBMC.

A validade e estabilidade da implementação foi testada no capítulo 3 através da simulação de dois sistemas: o octano e o DCE. Essas moléculas foram escolhidas por se tratarem de sistemas simples, e por permitirem a comparação imediata com outras simulações ou dados experimentais. Para o octano, as comparações com as simulações de MD e a análise populacional partindo da constante de equilíbrio mostram que o algoritmo é capaz de realizar uma amostragem ergódica, ao menos em sistemas com uma superfície de energia potencial simples nesse caso. No caso do DCE, foram realizadas simulações em líquidos, incluindo um liquido puro de DCE, que introduz a dificuldade de lidar com uma caixa cheia de moléculas flexíveis. Os resultados obtidos para as populações de configurações trans a partir das simulações do DCE com o CBMC estão em ótimo acordo com os valores experimentais, valores de $\mathrm{MC}$ reportados na literatura e com as simulações de MD realizadas pelo autor. A única exceção se dá para o resultado de DCE em ciclohexano, onde devido a falta de polarização do solvente, a população obtida é diferente da experimental, porém, consistente com o reportado para uma simulação de MC nas mesmas condições. Destes resultados destaca-se o desempenho do método CBMC frente a MD no caso de moléculas em fase gasosa, onde se observa uma correlação estatística entre conformações muito maior no caso da MD, mostrando que a memória do caminho que as conformações foram geradas é muito maior com a MD quando comparado ao CBMC. Assim, podemos afirmar que nesses casos a amostragem CBMC foi mais eficiente que a amostragem com a MD.

As comparações com a MD seguiram no capítulo 4 onde resultados de simulações do MOx foram apresentadas. Foi mostrado que a amostragem da MD não é ergódica para esse sistema, devido a barreira de energia de cerca de $10 \mathrm{kcal} / \mathrm{mol}$ entre as conformações syn e anti. A simulação MD tende a amostrar a região do mínimo por uma duração muito maior do que o CBMC, o que pode ser visto pelo número de mudanças conformacionais nos dois casos. Tanto em gás quanto em água, a amostragem da MD apresentou, no melhor dos casos, 3 mudanças conformacionais nos 400 ns de simulação, correspondentes a $2 \times 10^{8}$ passos. Já o CBMC teve uma amostragem e resultados de populações condizentes com o esperado em $4 \times 10^{6}$ ciclos.

Os resultados das simulações CBMC para o MOx indicam uma inversão da população dominante nos extremos de polaridade estudados (fase gasosa e água). Em fase gasosa, a população syn:anti do MOx (em \%) encontrada foi de $95: 5 \pm 1$, enquanto que em água a população foi $22: 78 \pm 7$. Esses resultados estão em acordo, ao menos em tendência, 
com os valores esperados por cálculos de energia livre feitos com teoria da perturbação termodinâmica. ${ }^{[92]}$ Nos solventes de polaridade intermediária, foram encontras populações de 56:44 \pm 5 e 50:50 \pm 15 para a acetonitrila e metanol, respectivamente. A maior estabilidade das configurações anti em solventes de maior polaridade foi atribuída a interação dipolo-dipolo do $\mathrm{MOx}$ com o solvente. Essa conclusão é reforçada pelo resultado obtido para o número médio de ligações de hidrogênio formado pelo MOx com a água nas formas syn e anti, é que muito similar $(2.4 \pm 0.5$ e $2.8 \pm 0.5$, respectivamente $)$.

Cálculos do espectro de absorção do MOx em fase gasosa e nos solventes anteriormente citados também foram realizados. Analisando a banda referente a transição $\pi-\pi^{*}$ nos diferente solventes foi possível identificar a contribuição conformacional e do solvente na energia de absorção. O aumento do número de conformações anti desloca o máximo da banda de absorção para o azul, ou seja, para maiores energias. Contudo, efeitos adicionais como o estiramento da ligação $\mathrm{C}=\mathrm{O}$ do $\mathrm{MOx}$, deslocam o espectro para o vermelho, isto é, para menores energias, o que faz com que a contribuição conformacional ao espectro, não siga estritamente a polaridade, indicando uma contribuição maior para o azul para a acetonitrila do que para o metanol. A inclusão do efeito solvente, por outro lado, desloca o máximo de absorção para o vermelho. A energia de absorção obtida nos cálculos que incluem a contribuição conformacional com a configurações do CBMC, assim como moléculas explícitas de solvente e cargas pontuais gerando um fundo eletrostático, está em ótimo acordo com os valores experimentais, sendo o maior desvio de apenas $4 \mathrm{~nm}$ no máximo de absorção para o caso do MOx em acetonitrila.

De uma maneira geral, é possível concluir que a implementação está estável e que o método CBMC desenvolvido é capaz de prover ótimos resultados para a amostragem conformacional, amostrando de maneira eficiente casos que mesmo a MD tradicional (sem técnicas de melhoramento de amostragem) tem dificuldades. Apesar de não exibidos no texto, testes realizados indicam que a implementação da amostragem de anéis simples e a utilização do viés eletrostático também funcionam de acordo com o esperado. Contudo, mais testes ainda são necessários para verificar como o viés eletrostático pode ser utilizado de sua melhor maneira e a limitação quanto ao tamanho da molécula e fragmento ainda não foi definida. As melhorias quanto ao desempenho do código devido à modernização e paralelização do mesmo também podem ser apontadas como um avanço importante do projeto, pois beneficiam não somente o autor, mas toda a base de usuários do programa DICE, que é utilizado pelo Grupo de Física Molecular e Modelagem do IFUSP e em cerca de outros 20 grupos de pesquisa no país e 18 grupos no exterior. ${ }^{[115]}$

Embora os testes indiquem que a metodologia implementada funciona muito bem em alguns casos, sabe-se no entanto que a mesma também pode apresentar limitações. Uma delas, é a dificuldade da simulação de moléculas com um grande número de fragmentos. Isso se dá devido à característica dos fatores de Rosenbluth presentes no critério de aceitação, que são construídos a partir de um produtório com o número de fragmentos, e com isso 
podem produzir uma probabilidade de aceitação proibitivamente baixa. Esse problema pode ser abordado através de como os fragmentos são definidos, onde ideias que mantém o balanço detalhado mas flexibilizam o algoritmo podem ser implementadas. 


\section{Referências}

1 SHAH, J. K.; MAGINN, E. J. A general and efficient Monte Carlo method for sampling intramolecular degrees of freedom of branched and cyclic molecules. The Journal of Chemical Physics, v. 135, n. 13, p. 134121, 2011.

2 REICHARDT, C.; WELTON, T. Solvents and Solvent Effects in Organic Chemistry. Weinheim: Wiley-VCH, 2011.

3 BORN, M. Volumes and hydration warmth of ions. Zeitschrift Fur Physik, v. 1, p. 45, 1920.

4 ONSAGER, L. Electric moments of molecules in liquids. Journal of the American Chemical Society, v. 58, n. 8, p. 1486-1493, 1936.

5 KIRKWOOD, J. G. On the theory of dielectric polarization. The Journal of Chemical Physics, v. 4, n. 9, p. 592-601, 1936.

6 MIERTUŠ, S.; SCROCCO, E.; TOMASI, J. Electrostatic interaction of a solute with a continuum. a direct utilizaion of ab initio molecular potentials for the prevision of solvent effects. Chemical Physics, v. 55, n. 1, p. 117-129, 1981.

7 TOMASI, J.; MENNUCCI, B.; CAMMI, R. Quantum mechanical continuum solvation models. Chemical Reviews, v. 105, n. 8, p. 2999-3094, 2005.

8 MARX, D.; HUTTER, J. Ab initio molecular dynamics: Basic theory and advanced methods. 1st. ed. New York: Cambridge University Press, 2009.

9 KUO, I. F. W.; MUNDY, C. J.; MCGRATH, M. J.; SIEPMANN, J. I.; VANDEVONDELE, J.; SPRIK, M.; HUTTER, J.; CHEN, B.; KLEIN, M. L.; MOHAMED, F.; KRACK, M.; PARRINELLO, M. Liquid water from first principles: Investigation of different sampling approaches. Journal of Physical Chemistry B, v. 108, n. 34, p. 12990-12998, 2004.

10 MCGRATH, M. J.; SIEPMANN, J. I.; KUO, I. F. W.; MUNDY, C. J.; VANDEVONDELE, J.; HUTTER, J.; MOHAMED, F.; KRACK, M. Isobaric-isothermal monte carlo simulations from first principles: Application to liquid water at ambient conditions. ChemPhysChem, v. 6, n. 9, p. 1894-1901, 2005.

11 DEL BEN, M.; SCHÖNHERR, M.; HUTTER, J.; VANDEVONDELE, J. Bulk liquid water at ambient temperature and pressure from mp2 theory. The Journal of Physical Chemistry Letters, v. 4, n. 21, p. 3753-3759, 2013. 
12 GOEL, H.; WINDOM, Z. W.; JACKSON, A. A.; RAI, N. Performance of density functionals for modeling vapor liquid equilibria of $\mathrm{co} 2$ and so2. Journal of Computational Chemistry, v. 39, n. 8, p. 397-406, 2017.

13 ALLEN, M. P.; TILDESLEY, D. J. Computer Simulation of Liquids. Oxford: Oxford University Press, 1989.

14 FRENKEL, D.; SMIT, B. Understanding molecular simulation: from algorithms to applications. 2nd. ed. San Diego: Academic Press, 2002.

15 METROPOlis, N.; ROSEnBluth, A. W.; ROSENBluth, M. N.; TELLER, A. H.; TELLER, E. Equation of state calculations by fast computing machines. Journal of Chemical Physics, v. 21, n. 6, p. 1087-1092, 1953.

16 KARPLUS, M.; MCCAMMON, J. A. Molecular dynamics simulations of biomolecules. Nature Structural Biology, v. 9, n. 9, p. 646-652, 2002.

17 MONTICELLI, L.; SALONEN, E. (Ed.). Biomolecular Simulations. 1st. ed. Totowa, NJ: Humana Press, 2013.

18 FELLER, S. E. Molecular dynamics simulations of lipid bilayers. Current Opinion in Colloid \& Interface Science, v. 5, n. 3-4, p. 217-223, 2000.

19 BRESME, F.; OETTEL, M. Nanoparticles at fluid interfaces. Journal of Physics: Condensed Matter, v. 19, n. 41, p. 413101, 2007.

20 PRONK, S.; PÁLL, S.; SCHULZ, R.; LARSSON, P.; BJELKMAR, P.; APOSTOLOV, R.; SHIRTS, M. R.; SMITH, J. C.; KASSON, P. M.; VAN DER SPOEL, D.; HESS, B.; LINDAHL, E. Gromacs 4.5: a high-throughput and highly parallel open source molecular simulation toolkit. Bioinformatics, v. 29, n. 7, p. 845-854, 2013.

21 VAN DER SPOEL, D.; LINDAHL, E.; HESS, B.; GROMACS development team. Gromacs user manual version 4.6.7, www.gromacs.org. 2014.

22 SALOMON-FERRER, R.; CASE, D. A.; WALKER, R. C. An overview of the amber biomolecular simulation package. Wiley Interdisciplinary Reviews: Computational Molecular Science, v. 3, n. 2, p. 198-210, 2013.

23 PHILLIPS, J. C.; BRAUN, R.; WANG, W.; GUMBART, J.; TAJKHORSHID, E.; VILLA, E.; CHIPOT, C.; SKEEL, R. D.; KALÉ, L.; SCHULTEN, K. Scalable molecular dynamics with namd. Journal of Computational Chemistry, v. 26, n. 16, p. 1781-1802, 2005.

24 PLIMPTON, S. Fast parallel algorithms for short-range molecular dynamics. Journal of Computational Physics, v. 117, n. 1, p. 1-19, 1995.

25 CANUTO, S. Solvation Effects on Molecules and Biomolecules: Computational methods and applications. Netherlands: Springer, 2008.

26 JORGENSEN, W. L.; TIRADO-RIVES, J. Molecular modeling of organic and biomolecular systems using BOSS and MCPRO. Journal of Computational Chemistry, v. 26, n. 16, p. 1689-1700, 2005. 
27 SHAH, J. K.; MARIN-RIMOLDI, E.; MULLEN, R. G.; KEENE, B. P.; KHAN, S.; PALUCH, A. S.; RAI, N.; ROMANIELO, L. L.; ROSCH, T. W.; YOO, B.; MAGINN, E. J. Cassandra: An open source Monte Carlo package for molecular simulation. Journal of Computational Chemistry, v. 38, n. 19, p. 1727-1739, 2017.

28 MARTIN, M. G. MCCCS Towhee: a tool for Monte Carlo molecular simulation. Molecular Simulation, v. 39, n. 14-15, p. 1212-1222, 2013.

29 CEZAR, H. M.; CANUTO, S.; COUTINHO, K. DICE v3.0. São Paulo: Universidade de São Paulo, 2018. A Monte Carlo program for molecular liquid simulation.

30 FREITAS, L. C. G. DIADORIM: a Monte Carlo program for liquid simulations including quantum mechanics and molecular mechanics ( $\mathrm{QM} / \mathrm{MM})$ facilities: applications to liquid ethanol. Journal of the Brazilian Chemical Society, v. 20, p. $1541-1548,2009$.

31 JORGENSEN, W. L.; TIRADO-RIVES, J. Monte Carlo vs molecular dynamics for conformational sampling. Journal of Physical Chemistry, v. 100, n. 34, p. 14508-14513, 1996.

32 ULMSCHNEIDER, J. P.; ULMSCHNEIDER, M. B.; NOLA, A. D. Monte Carlo vs molecular dynamics for all-atom polypeptide folding simulations. Journal of Physical Chemistry B, v. 110, p. 16733-16742, 2006.

33 HERNANDES, M. Z.; LONGO, R.; COUTINHO, K.; CANUTO, S. Solute relaxation on the solvatochromism of ortho-betaine dyes. a sequential monte carlo/quantum mechanics study. Physical Chemistry Chemical Physics, v. 6, p. 2088-2092, 2004.

34 OLIVEIRA, L. B.; FONSECA, T. L.; COUTINHO, K.; CANUTO, S. A sequential $\mathrm{mc} / \mathrm{td}$-dft study of the solvatochromic shift of the pyridinium-n-phenoxide betaine dye in water using standard and long-range corrected functionals. Chemical Physics Letters, v. 514, p. 251-256, 2011.

35 MURUGAN, N. A.; ÅGREN, H. Role of dynamic flexibility in computing solvatochromic properties of dye-solvent systems: o-betaine in water. Journal Physical Chemistry A, v. 113, n. 11, p. 2572-7, 2009.

36 TAUSCHER, L.; GHISLA, S.; HEMMERICH, P. NMR study of nitrogen inversion and conformation of 1,5-dihydro-isoalloxazines("reduced flavin"). Helvetica Chimica Acta, v. 56, n. 2, p. 630-644, 1973.

37 ENGEL, J. D.; HIPPEL, P. H. V. Effects of methylation on the stability of nucleic acid conformations. monomer level. Biochemistry, v. 13, n. 20, p. 4143-4158, 1974.

38 KATAGIRI, H.; HATTORI, T.; MOROHASHI, N.; IKI, N.; MIYANO, S. Conformational behaviors of tetra-o-methylsulfinylcalix[4]arenesan approach to control the conformation of thiacalix[4]arenes by oxidizing sulfur bridges. The Journal of Organic Chemistry, v. 72, n. 22, p. 8327-8331, 2007.

39 NEWMAN, M. E. J.; BARKEMA, G. T. Monte Carlo methods in statistical physics. 1st. ed. Oxford: Clarendon Press, 1999. 
40 CEZAR, H. M.; RONDINA, G. G.; DA SILVA, J. L. F. Parallel tempering Monte Carlo combined with clustering Euclidean metric analysis to study the thermodynamic stability of Lennard-Jones nanoclusters. The Journal of Chemical Physics, v. 146, n. 6, p. 064114, 2017.

41 EARL, D. J.; DEEM, M. W. Parallel tempering: Theory, applications, and new perspectives. Physical Chemistry Chemical Physics, v. 7, p. 3910-3916, 2005.

42 KREMER, K.; BINDER, K. Monte carlo simulation of lattice models for macromolecules. Computer Physics Reports, v. 7, n. 6, p. 259-310, 1988.

43 THEODOROU, D. N. Progress and outlook in monte carlo simulations. Industrial \& Engineering Chemistry Research, v. 49, n. 7, p. 3047-3058, 2010.

44 VACATELLO, M.; AVITABILE, G.; CORRADINI, P.; TUZI, A. A computer model of molecular arrangement in a n-paraffinic liquid. The Journal of Chemical Physics, v. 73, n. 1, p. 548,1980 .

45 MAVRANTZAS, V. G.; BOONE, T. D.; ZERVOPOULOU, E.; THEODOROU, D. N. End-bridging monte carlo: A fast algorithm for atomistic simulation of condensed phases of long polymer chains. Macromolecules, v. 32, n. 15, p. 5072-5096, 1999.

46 KARAYIANNIS, N. C.; MAVRANTZAS, V. G.; THEODOROU, D. N. A novel monte carlo scheme for the rapid equilibration of atomistic model polymer systems of precisely defined molecular architecture. Physical Review Letters, v. 88, p. 105503, 2002.

47 DODD, L.; BOONE, T.; THEODOROU, D. A concerted rotation algorithm for atomistic monte carlo simulation of polymer melts and glasses. Molecular Physics, v. 78, n. 4, p. 961-996, 1993.

48 DEEM, M. W.; BADER, J. S. A configurational bias monte carlo method for linear and cyclic peptides. Molecular Physics, v. 87, n. 6, p. 1245-1260, 1996.

49 WU, M. G.; DEEM, M. W. Efficient monte carlo methods for cyclic peptides. Molecular Physics, v. 97, n. 4, p. 559-580, 1999.

50 SIEPMANN, J. I.; FRENKEL, D. Configurational bias Monte Carlo: a new sampling scheme for flexible chains. Molecular Physics, v. 75, n. 1, p. 59-70, 1992.

51 ROSENBlUth, M. N.; ROSENBLUTH, A. W. Monte Carlo calculation of the average extension of molecular chains. The Journal of Chemical Physics, v. 23, n. 2, p. 356, 1955.

52 SEPEHRI, A.; LOEFFLER, T. D.; CHEN, B. Improving the efficiency of configurational-bias Monte Carlo: a density-guided method for generating bending angle trials for linear and branched molecules. The Journal of Chemical Physics, v. 141, n. 7, p. 074102, 2014.

53 MARTIN, M. G.; SIEPMANN, J. I. Novel configurational-bias monte carlo method for branched molecules. transferable potentials for phase equilibria. 2. united-atom description of branched alkanes. The Journal of Physical Chemistry B, v. 103, n. 21, p. 4508-4517, 1999.

54 MACEDONIA, M. D.; MAGINN, E. J. A biased grand canonical Monte Carlo method for simulating adsorption using all-atom and branched united atom models. Molecular Physics, v. 96, n. 9, p. 1375-1390, 1999. 
55 ESSELINK, K.; LOYENS, L. D. J. C.; SMIT, B. Parallel monte carlo simulations. Physical Review E, v. 51, n. 2, p. 1560-1568, 1995.

56 WICK, C. D.; SIEPMANN, J. I. Self-adapting fixed-end-point configurational-bias Monte Carlo method for the regrowth of interior segments of chain molecules with strong intramolecular interactions. Macromolecules, v. 33, n. 19, p. 7207-7218, 2000.

57 CHEN, Z.; ESCOBEDO, F. A. A configurational-bias approach for the simulation of inner sections of linear and cyclic molecules. The Journal of Chemical Physics, v. 113, n. 24, p. 11382-11392, 2000.

58 MARTIN, M. G.; FRISCHKNECHT, A. L. Using arbitrary trial distributions to improve intramolecular sampling in configurational-bias Monte Carlo. Molecular Physics, v. 104, n. 15, p. $2439-2456,2006$.

59 SEPEHRI, A.; LOEFFLER, T. D.; CHEN, B. Improving the efficiency of configurational-bias Monte Carlo: A jacobian-gaussian scheme for generating bending angle trials for linear and branched molecules. Journal of Chemical Theory and Computation, v. 13, n. 4, p. 1577-1583, 2017.

60 SEPEHRI, A.; LOEFFLER, T. D.; CHEN, B. Improving the efficiency of configurational-bias Monte Carlo: Extension of the jacobian-gaussian scheme to interior sections of cyclic and polymeric molecules. Journal of Chemical Theory and Computation, v. 13, n. 9, p. 4043-4053, 2017.

61 ERRINGTON, J. R.; PANAGIOTOPOULOS, A. Z. New intermolecular potential models for benzene and cyclohexane. The Journal of Chemical Physics, v. 111, n. 21, p. 9731, 1999.

62 BOURASSEAU, E.; UNGERER, P.; BOUTIN, A. Prediction of equilibrium properties of cyclic alkanes by Monte Carlo simulation-new anisotropic united atoms intermolecular potential-new transfer bias method. The Journal of Physical Chemistry B, v. 106, n. 21, p. 5483-5491, 2002.

63 MAGINN, E. J.; SHAH, J. K.; MARINRIMOLDI, E.; KHAN, S.; RAI, N.; ROSCH, T.; PALUCH, A. Cassandra userguide v1.1: Computational atomistic simulation software at notre dame for research advances. 2015.

64 OPENMP Application Program Interface Version 3.1. 2011. < http://www.openmp.org/ wp-content/uploads/OpenMP3.1.pdf $>$. Acessado em 2017-06-22.

65 JORGENSEN, W. L.; TIRADO-RIVES, J. Potential energy functions for atomic-level simulations of water and organic and biomolecular systems. Proceedings of the National Academy of Sciences, v. 102, n. 19, p. 6665-6670, 2005.

66 JORGENSEN, W. L.; MAXWELL, D. S.; TIRADO-RIVES, J. Development and testing of the OPLS all-atom force field on conformational energetics and properties of organic liquids. Journal of the American Chemical Society, v. 118, n. 45, p. 11225-11236, 1996.

67 KAMINSKI, G. A.; FRIESNER, R. A.; TIRADO-RIVES, J.; JORGENSEN, W. L. Evaluation and reparametrization of the OPLS-AA force field for proteins via comparison with accurate quantum chemical calculations on peptides. Journal of Physical Chemistry B, v. 105, n. 28, p. 6474-6487, 2001. 
68 CORNELL, W. D.; CIEPLAK, P.; BAYLY, C. I.; GOULD, I. R.; MERZ, K. M.; FERGUSON, D. M.; SPELLMEYER, D. C.; FOX, T.; CALDWELL, J. W.; KOLLMAN, P. A. A second generation force field for the simulation of proteins, nucleic acids, and organic molecules. Journal of the American Chemical Society, v. 117, n. 19, p. 5179-5197, 1995.

69 WANG, J.; CIEPLAK, P.; KOLLMAN, P. A. How well does a restrained electrostatic potential (RESP) model perform in calculating conformational energies of organic and biological molecules? Journal of Computational Chemistry, v. 21, n. 12, p. 1049-1074, 2000.

70 LORENTZ, H. A. Ueber die anwendung des satzes vom virial in der kinetischen theorie der gase. Annalen der Physik, v. 248, n. 1, p. 127-136, 1881.

71 BERTHELOT, D. Sue le mélange des gaz. Comptes Rendus Hebdomadaires des Séances de l'Académie des Sciences, v. 126, p. 1703-1706, 1898.

72 KARDAR, M. Statistical physics of particles. Cambridge: Cambridge University Press, 2007.

73 KAMPEN, N. V. Stochastic Processes in Physics and Chemistry. 3rd. ed. Amsterdam: Elsevier, 2007.

74 PERISTERAS, L. D.; ECONOMOU, I. G.; THEODOROU, D. N. Structure and volumetric properties of linear and triarm star polyethylenes from atomistic Monte Carlo simulation using new internal rearrangement moves. Macromolecules, v. 38, n. 2, p. 386-397, 2005.

75 SWENDSEN, R. H. How the maximum step size in Monte Carlo simulations should be adjusted. Physics Procedia, v. 15, p. 81-86, 2011.

76 MURRAY, G. Rotation About an Arbitrary Axis in 3 Dimensions. <http:

//inside.mines.edu/fs_home/gmurray/ArbitraryAxisRotation/>. Acessado em 2017-04-26.

77 OWICKI, J. C. Optimization of sampling algorithms in monte carlo calculations on fluids. In: Computer Modeling of Matter. [S.I.]: American Chemical Society, 1978. cap. 14 , p. 159-171.

78 BIGOT, B.; JORGENSEN, W. L. Sampling methods for monte carlo simulations of n-butane in dilute solution. The Journal of Chemical Physics, v. 75, n. 4, p. 1944, 1981.

79 LOGSUMEXP. <https://en.wikipedia.org/wiki/LogSumExp>. Acessado em 2016-11-11.

80 RIBEIRO, A. A. S. T.; HORTA, B. A. C.; DE ALENCASTRO, R. B. MKTOP: a program for automatic construction of molecular topologies. Journal of the Brazilian Chemical Society, v. 19, p. 1433-1435, 2008.

81 BUSSI, G.; DONADIO, D.; PARRINELLO, M. Canonical sampling through velocity rescaling. The Journal of Chemical Physics, v. 126, n. 1, p. 014101, 2007.

82 BERENDSEN, H. J. C.; POSTMA, J. P. M.; GUNSTEREN, W. F. van; DINOLA, A.; HAAK, J. R. Molecular dynamics with coupling to an external bath. The Journal of Chemical Physics, v. 81, n. 8, p. 3684-3690, 1984.

83 HOOVER, W. G. Canonical dynamics: Equilibrium phase-space distributions. Physical Review A, v. 31, n. 3, p. 1695-1697, 1985. 
84 MORGON, N. H.; COUTINHO, K. Métodos de Química Teórica E Modelagem Molecular. 1a. ed. São Paulo: Editora Livraria da Física, 2007.

$85 \mathrm{KOCH}$, W.; HOLTHAUSEN, M. C. A Chemist's Guide to Density Functional Theory. 2nd. ed. Weinheim: WILEY-VCH, 2012.

86 ENGEL, E.; DREIZLER, R. M. Density Functional Theory: An advanced course. 1st. ed. Berlin: Springer, 2011.

87 ULLRICH, C. Time-Dependent Density-Functional Theory: Concepts and applications. 1st. ed. New York: Oxford University Press, 2012.

88 MARQUES, M. A. L.; GROSS, E. K. U. Time-dependent density functional theory. Annual Review of Physical Chemistry, v. 55, n. 1, p. 427-455, 2004.

89 CASIDA, M. E.; HUIX-ROTLLANT, M. Progress in time-dependent density-functional theory. Annual Review of Physical Chemistry, v. 63, n. 1, p. 287-323, 2011.

90 HOHENBERG, P.; KOHN, W. Inhomogeneous electron gas. Physical Review, v. 136, n. 3B, p. B864-B871, 1964.

$91 \mathrm{KOHN}$, W.; SHAM, L. J. Self-consistent equations including exchange and correlation effects. Physical Review, v. 140, n. 4A, p. A1133-A1138, 1965.

92 DAMASCENO, M. V. A.; CABRAL, B. J. C.; COUTINHO, K. Structure and electronic properties of hydrated mesityl oxide: a sequential quantum mechanics/molecular mechanics approach. Theoretical Chemistry Accounts, v. 131, n. 5, p. 1214, 2012.

93 JORGENSEN, W. L.; MCDONALD, N. A.; SELMI, M.; RABLEN, P. R. Importance of polarization for dipolar solutes in low-dielectric media: 1,2-dichloroethane and water in cyclohexane. Journal of the American Chemical Society, v. 117, n. 47, p. 11809-11810, 1995.

94 TANABE, K. Calculation of infrared band intensities and determination of energy differences of rotational isomers of 1,2-dichloro-, 1,2-dibromo- and 1-chloro-2-bromoethane. Spectrochimica Acta Part A: Molecular Spectroscopy, v. 28, n. 3, p. 407-424, 1972.

95 WIBERG, K. B.; KEITH, T. A.; FRISCH, M. J.; MURCKO, M. Solvent effects on 1,2-dihaloethane gauche/trans ratios. The Journal of Physical Chemistry, v. 99, n. 22, p. 9072-9079, 1995.

96 JORGENSEN, W. L.; BINNING, R. C.; BIGOT, B. Structures and properties of organic liquids - n-butane and 1,2-dichloroethane and their conformational equilibria. Journal of the American Chemical Society, v. 103, n. 15, p. 4393-4399, 1981.

97 WILHELM, E.; SCHANO, R.; BECKER, G.; FINDENEGG, G. H.; KOHLER, F. Molar heat capacity at constant volume. binary mixtures of 1,2-dicholroethane and 1,2-dibromoethane with cyclohexane. Transactions of the Faraday Society, v. 65, p. 1443-1455, 1969.

98 WADSÖ, I. Heats of vaporization of organic compounds. ii. chlorides, bromides, and iodides. Acta Chemica Scandinavica, v. 22, p. 2438-2444, 1968.

99 DARDEN, T.; YORK, D.; PEDERSEN, L. Particle mesh Ewald: an Nlog(N) method for Ewald sums in large systems. The Journal of Chemical Physics, v. 98, n. 12, p. 10089-10092, 1993. 
100 GRAY JR, H. F.; RASMUSSEN, R. S.; TUNNICLIFF, D. D. The infrared and ultraviolet absorption spectra of two isomers of mesityl oxide. Journal of the American Chemical Society, v. 69, p. 1630-1631, 1947.

101 KOSOWER, E. M. The effect of solvent on spectra. ii. correlation of spectral absorption data with z-values. Journal of the American Chemical Society, v. 80, p. 3261-3267, 1958.

102 CEZAR, H. M.; CANUTO, S.; COUTINHO, K. Solvent effect on the syn/anti conformational stability: A comparison between conformational bias Monte Carlo and molecular dynamics methods. International Journal of Quantum Chemistry, 2018. No prelo.

103 STROSS, F. H.; MONGER, J. M.; FINCH, H. V. The isolation and purification of two isomers of mesityl oxide. Journal of the American Chemical Society, v. 69, p. 1627-1628, 1947.

104 JORGENSEN, W. L.; BUCKNER, J. K.; BOUDON, S.; TIRADO-RIVES, J. Efficient computation of absolute free energies of binding by computer simulations. application to the methane dimer in water. The Journal of Chemical Physics, v. 89, n. 6, p. 3742-3746, 1988.

105 GEORG, H. C.; COUTINHO, K.; CANUTO, S. A look inside the cavity of hydrated $\alpha$-cyclodextrin: A computer simulation study. Chemical Physics Letters, v. 413, n. 1, p. 16 $-21,2005$.

106 BERENDSEN, H. J. C.; GRIGERA, J. R.; STRAATSMA, T. P. The missing term in effective pair potentials. Journal of Physical Chemistry, v. 91, n. 24, p. 6269-6271, 1987.

107 HESS, B.; BEKKER, H.; BERENDSEN, H. J. C.; FRAAIJE, J. G. E. M. Lincs: A linear constraint solver for molecular simulations. Journal of Computational Chemistry, v. 18, n. 12, p. 1463-1472, 1997.

108 WANG, H.; WANG, L.; SHEN, S.; ZHANG, W.; LI, M.; DU, L.; ZHENG, X.; PHILLIPS, D. L. Effects of hydrogen bond and solvent polarity on the $\mathrm{c}=\mathrm{o}$ stretching of bis(2-thienyl)ketone in solution. The Journal of Chemical Physics, v. 136, n. 12, p. 124509, 2012.

109 COUTINHO, K.; SAAVEDRA, N.; CANUTO, S. Theoretical analysis of the hydrogen bond interaction between acetone and water. Journal of Molecular Structure: THEOCHEM, v. 466, p. 69-75, 1999.

110 FRISCH, M. J.; TRUCKS, G. W.; SCHLEGEL, H. B.; SCUSERIA, G. E.; ROBB, M. A.; CHEESEMAN, J. R.; SCALMANI, G.; BARONE, V.; MENNUCCI, B.; PETERSSON, G. A.; NAKATSUJI, H.; CARICATO, M.; LI, X.; HRATCHIAN, H. P.; IZMAYLOV, A. F.; BLOINO, J.; ZHENG, G.; SONNENBERG, J. L.; HADA, M.; EHARA, M.; TOYOTA, K.; FUKUDA, R.; HASEGAWA, J.; ISHIDA, M.; NAKAJIMA, T.; HONDA, Y.; KITAO, O.; NAKAI, H.; VREVEN, T.; MONTGOMERY Jr., J. A.; PERALTA, J. E.; OGLIARO, F.; BEARPARK, M.; HEYD, J. J.; BROTHERS, E.; KUDIN, K. N.; STAROVEROV, V. N.; KOBAYASHI, R.; NORMAND, J.; RAGHAVACHARI, K.; RENDELL, A.; BURANT, J. C.; IYENGAR, S. S.; TOMASI, J.; COSSI, M.; REGA, N.; MILLAM, J. M.; KLENE, M.; KNOX, J. E.; CROSS, J. B.; BAKKEN, V.; ADAMO, C.; JARAMILLO, J.; GOMPERTS, R.; STRATMANN, R. E.; YAZYEV, O.; AUSTIN, A. J.; CAMMI, R.; POMELLI, C.; OCHTERSKI, J. W.; MARTIN, R. L.; MOROKUMA, K.; 
ZAKRZEWSKI, V. G.; VOTH, G. A.; SALVADOR, P.; DANNENBERG, J. J.; DAPPRICH, S.; DANIELS, A. D.; FARKAS, Ö.; FORESMAN, J. B.; ORTIZ, J. V.; CIOSLOWSKI, J.; FOX, D. J. Gaussian 09 Revision D.01. Gaussian Inc. Wallingford CT 2009.

111 BRENEMAN, C.; WIBERG, K. Determining atom-centered monopoles from molecular electrostatic potentials. the need for high sampling density in formamide conformational analysis. Journal of Computational Chemistry, v. 11, p. 361-373, 1990.

112 COUTINHO, K.; GEORG, H.; FONSECA, T.; LUDWIG, V.; CANUTO, S. An efficient statistically converged average configuration for solvent effects. Chemical Physics Letters, v. 437, n. 1, p. 148-152, 2007.

113 PRICE, M. L. P.; OSTROVSKY, D.; JORGENSEN, W. L. Gas-phase and liquid-state properties of esters, nitriles, and nitro compounds with the OPLS-AA force field. Journal of Computational Chemistry, v. 22, n. 13, p. 1340-1352, 2001.

114 REICHARDT, C. Solvatochromic dyes as solvent polarity indicators. Chemical Reviews, v. 94, n. 8, p. 2319-2358, 1994.

115 COUTINHO, K. Modelagem Molecular: Efeito do Meio (Solvente) em

Propriedades Eletrônicas e Estruturais. 2012. 93 p. Tese de Livre Docência - Instituto de Física, Universidade de São Paulo, São Paulo, 2012.

116 COUTINHO, K.; CANUTO, S. DICE v2.9. São Paulo: Universidade de São Paulo, 2013. A Monte Carlo program for molecular liquid simulation. 

Apêndices 



\section{APÊNDICE A}

\section{Desempenho e paralelização do DICE}

No decorrer do projeto, o código DICE ${ }^{[29]}$ sofreu modificações que impactam diretamente no desempenho e usabilidade do programa, dando origem a versão 3.0. Dentre essas mudanças, a implementação da lista de vizinhos, paralelização e otimização do código tiveram um impacto positivo na performance frente a versão 2.9 do DICE. ${ }^{[116]}$ Neste apêndice alguns resultados referentes ao ganho de performance serão apresentados. Todos os testes foram realizados em uma máquina com dois processadores Xeon E5-2670 @ 2.60GHz e 64 GB de memória. No caso dos testes de paralelização, foi utilizado como número máximo de threads o número de núcleos reais disponíveis (16).

Após realizar o profiling do código, foi detectado que a subrotina de cálculo de energia era responsável por consumir a maior parte do tempo de execução, cerca de $86 \%$ do tempo total. Essa estimativa, foi feita utilizando o profiler Valgrind e o visualizador KCachegrind, gerando o grafo de chamadas exibido na figura 29. O teste envolveu a simulação de um sistema composto por 1000 moléculas de água SPC/E no ensemble $N P T$, considerando apenas $2 \times 10^{5}$ passos de MC para o profiling e $10^{8}$ passos de MC para a comparação do desempenho entre versões. As subrotinas energy e energy_all são utilizadas, respectivamente, para calcular a variação de energia potencial total após o movimento de rotação e translação de uma molécula, e calculo da energia potencial total da caixa toda. Essa última subrotina, para cálculo da energia potencial total, é utilizada nos movimentos de volume, utilizados no ensemble NPT.

Por serem responsáveis pelo maior gasto de tempo computacional, essas subrotinas foram reescritas, buscando otimizações com branch prediction e implementando uma lista de vizinhos. ${ }^{[13]}$ Com a lista de vizinhos, o tempo gasto para calcular a energia é reduzido, pois as distâncias entre centro de massa não precisam ser computadas para todas as moléculas da caixa. Essas mudanças forneceram ao DICE 3.0 um speedup $S=\frac{t_{\text {old }}}{t_{\text {new }}}$ de $26 \%$ frente à versão 2.9 .

A implementação da lista de vizinhos facilitou também a paralelização do código. Adotando a estratégia de dividir a interação da lista de vizinhos entre diferentes threads, o 


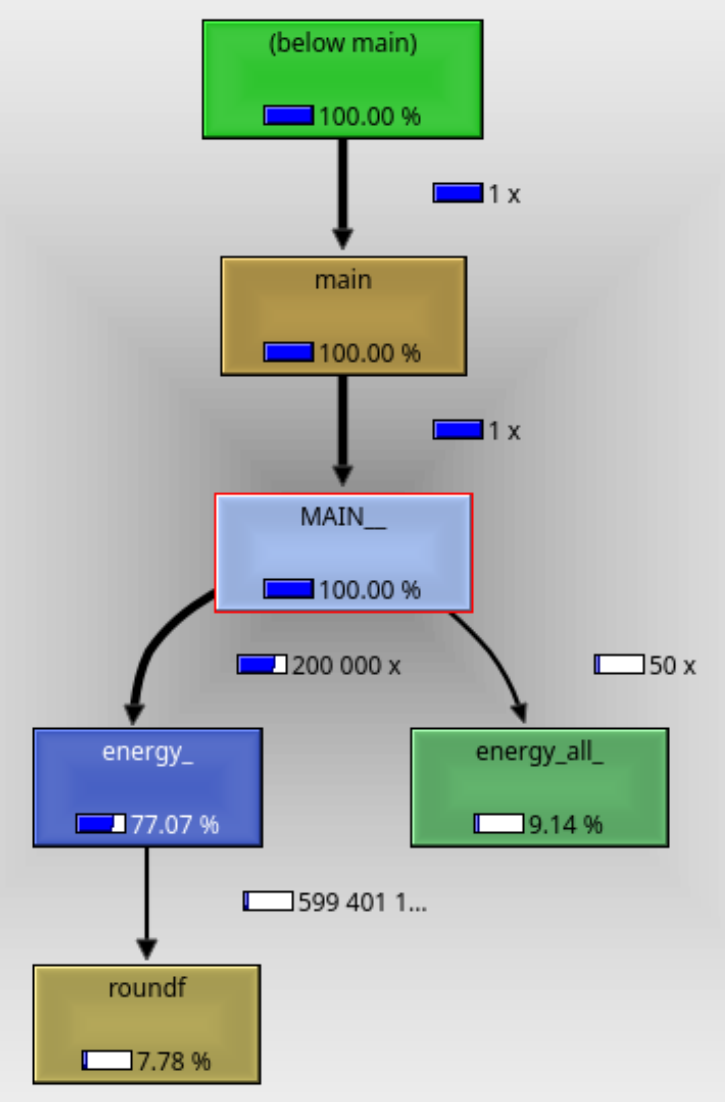

Figura 29 - Grafo de chamadas do Valgrind do programa DICE na versão 2.9.

DICE foi paralelizado com API do OpenMP, que permite a paralelização com esquema de memória compartilhada. Além de dividir a carga das interações da lista de vizinhos, alguns loops adicionais que consumiam um tempo de CPU considerável foram paralelizados. No caso da implementação do algoritmo CBMC, a paralelização se deu pela divisão do cálculo da energia potencial da interação do fragmento inserido em cada um dos $\kappa_{\phi}$ possíveis ângulos de inserção, já que para cada ângulo, o cálculo da energia é independente.

Para verificar a eficácia da paralelização, dois tamanhos de sistema foram estudados: 4000 e 10000 moléculas de água SPC/E. No caso das simulações com 4000 moléculas, foram realizados $1.6 \times 10^{7}$ passos de MC para cada simulação, enquanto que para as simulações de 10000 moléculas, $2 \times 10^{7}$ passos de MC foram feitos. Para cada tamanho de sistema, foram feitas simulações utilizando 1, 2, 4, 8 e 16 threads. As curvas de speedup $S=\frac{t(1)}{t(n)}$, onde $n$ é o número de threads e $t(n)$ indica o tempo da simulação com $n$ threads, são exibidas na figura 30 .

Como é possível notar na figura 30, o speedup em ambas as simulações está longe do ideal, onde dobrar o número de threads diminui o tempo pela metade. A razão para isso é que parte do código continua serial, e além disso, a distribuição da carga entre processos não é igual e há também o overhead devido à criação e gerenciamento das threads. Contudo, como 


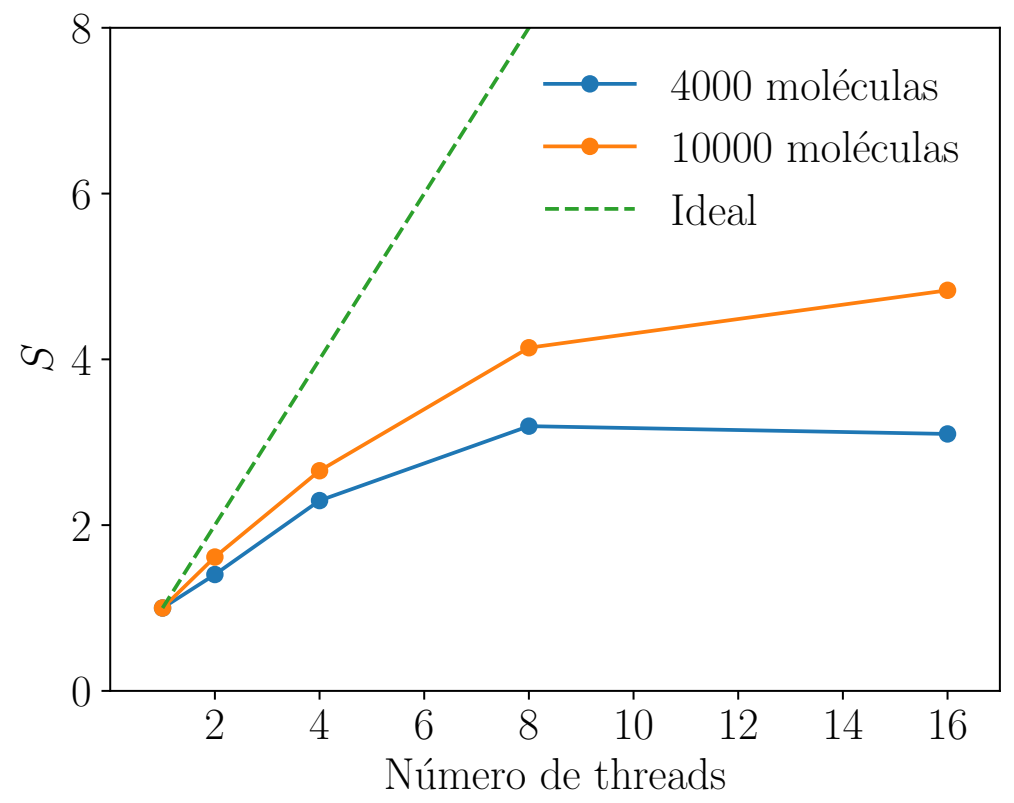

Figura 30 - Speedup $S$ da paralelização em função no número de threads para os dois sistemas teste: com 4000 e 10000 moléculas de água SPC/E.

o objetivo principal deste projeto de doutorado não era paralelização e otimização do código, e sim a implementação de um método MC para a amostragem de flexibilidade intramolecular, o desempenho pode ser considerado satisfatório, já que com um custo relativamente pequeno para a implementação da paralelização, é possível realizar simulações na metade do tempo utilizando alguns poucos núcleos de processamento. 



\section{APÊNDICE B}

\section{Ferramentas do DICEtools}

Diversas ferramentas estão incluídas no DICEtools para facilitar a utilização do DICE com moléculas flexíveis e o algoritmo CBMC e também para tornar mais fácil a análise de dados. Neste apêndice, os nomes e funcionalidades de algumas dessas ferramentas são listadas. Informações adicionais sobre as funcionalidades e como utilizar cada um dos scripts podem ser obtidos rodando os scripts com a opção -h na linha de comando.

\section{- fragGen}

O fragGen é um script que recebe a geometria de uma molécula em algum formato padrão (por exemplo .xyz ou .pdb) e cria dois arquivos: um com a extensão .dfr que contém informações sobre os fragmentos, conectividade dos átomos e topologia da molécula, e outro arquivo .txt contendo a geometria e campos para a inclusão dos parâmetros não ligados. As constantes do campo de força escolhido devem ser inseridas posteriormente de maneira manual pelo usuário.

\section{- gromacs2dice}

O gromacs2dice é um script que recebe um arquivo de topologia do GROMACS, utilizando o campo de forças OPLS-AA ou AMBER, e a geometria da molécula em um formato padrão e retorna os arquivos . dfr e .txt a serem utilizados pelo DICE, já com a parametrização do campo de força nas unidades corretas.

\section{- clean_dof_dfr}

É um script utilizado para remover de um arquivo .dfr (passado via parâmetro de linha de comando) os graus de liberdade desnecessários devido à utilização de fragmentos rígidos. Por exemplo, ao rodar o fragGen o usuário decide por deixar um dos fragmentos rígidos. Então, o clean_dof_dfr remove todos os ângulos, diedros e diedros impróprios daquele fragmento do arquivo .dfr.

\section{- plot_eff_tors}

O plot_eff_tors é um script utilizado para gerar a curva de energia potencial total, 
energia de diedro e energia dos termos não ligados, associados a rotação em torno de um ângulo de diedro informado pelo usuário. O script recebe como parâmetros os arquivos .txt, .dfr e os 4 átomos associados ao diedro em torno do qual a rotação será realizada. Com isso, o script considera as duas partes divididas pelo diedro de rotação como rígidas e calcula a energia num número de pontos informado pelo usuário. O script também tem a opção de receber arquivos para gerar um arquivo de entrada do Gaussian com as geometrias em cada ponto da rotação.

\section{- plot_en_angle_gaussian_scan}

Esse script é utilizado para obter a curva de energia de um scan em torno de um ângulo de diedro realizado com o Gaussian, partindo do input do plot_eff_tors.

\section{- clustering_traj}

O clustering_traj é um script para realizar o clustering sobre estruturas de uma trajetória. O script suporta diversos formatos e tem como saída, além dos clusters e classificação de cada estrutura, informações como matriz de distância entre cada configuração, e um dendrograma que auxilia na escolha do parâmetro de similaridade. Mais informações sobre esse script podem ser encontradas na página do github do script $<$ https://github. com/hmcezar/clustering-traj>.

\section{- calculate_dihedrals, calculate_angles, distance_evolution}

Os scripts calculate_dihedrals, calculate_angle e distance_evolution são utilizados para, dado um conjuntos de átomos, calcular o ângulo de diedro, ângulo entre átomos e a distância entre os átomos informados. Os valores desses ângulos e distâncias são os informados para todos os snapshots da trajetória.

\section{- estimate_variance_timeseries}

O estimate_variance_timeseries recebe um arquivo contendo uma serie de números em sequência, um número de intervalos no qual esse conjunto será dividido e valores mínimos e máximos que são utilizados para classificar cada valor da série como pertencente a aquela categoria ou não. Com isso, o script calcula o valor médio de número que se encaixou na categoria e estima o desvio padrão dos valores baseado no valor em cada um dos sub intervalos. Esse script foi o utilizado para estimar a incerteza nas populações nessa tese.

\section{- probability_interval}

Dado um arquivo contendo o uma sequência de dados (por exemplo, ângulos de diedro) e um intervalo $[\min , \max ]$, dá a porcentagem de valores da sequência que se encontram naquele intervalo. Esse script pode ser utilizado para estimar a população de conformações partindo dos ângulos de diedro.

\section{- get_solute_xyz}

O get_solute_xyz recebe uma trajetória de simulação do DICE em .xyz e o número 
de átomos do soluto, retornando um .xyz com as configurações do soluto em cada ponto da trajetória. Esse script é útil para ser utilizado antes de análises que consideram somente o soluto, por reduzir o tamanho dos arquivos, o que pode acelerar a execução de outras ferramentas.

\section{- dihedral_step_evolution}

Esse script é utilizado para plotar a evolução de um certo ângulo com os passos de simulação. Ele recebe como entrada o arquivo contendo os ângulos e um multiplicador, que indica a frequência com que os snapshots foram salvos durante a simulação. 



\section{APÊNDICE C}

\section{Arquivos de entrada octano}

Nos parágrafos abaixo, uma breve descrição dos arquivos de entrada do DICE é apresentada, para que o leitor possa compreender os parâmetros utilizados. Uma descrição completa dos arquivos de entrada pode ser encontrada no manual do DICE. ${ }^{[29]}$

O arquivo .in contém parâmetros para a simulação como número de moléculas, temperatura, número de passos, etc. $\mathrm{O}$ arquivo .txt contém a geometria das moléculas, cargas e parâmetros de Lennard-Jones. Já o arquivo . dfr contém os parâmetros do campo de força para a molécula flexível desejada, além de conter informações sobre a fragmentação da molécula.

No arquivo .txt, para a parte onde os átomos de cada molécula são descritos, as colunas indicam, respectivamente, índice $g(r)$, número atômico, coordenada Cartesiana $\mathbf{x}$, coordenada Cartesiana y, coordenada Cartesiana z, carga, $\epsilon$ e $\sigma$. O arquivo .dfr tem um formato parecido com os arquivos de topologia do GROMACS, e as constantes aparecem, para o caso de comprimento de ligação e ângulos, como constante de mola e posição de equilíbrio. As constantes dos diedros no arquivo . dfr aparecem na ordem $V_{1}, V_{2}, V_{3}, f_{1}, f_{2} f_{3}$.

As unidades de energia são $\mathrm{kcal} / \mathrm{mol}$, distâncias em $\AA$ e ângulos em ${ }^{\circ}$. 
DICE input: nvt.in

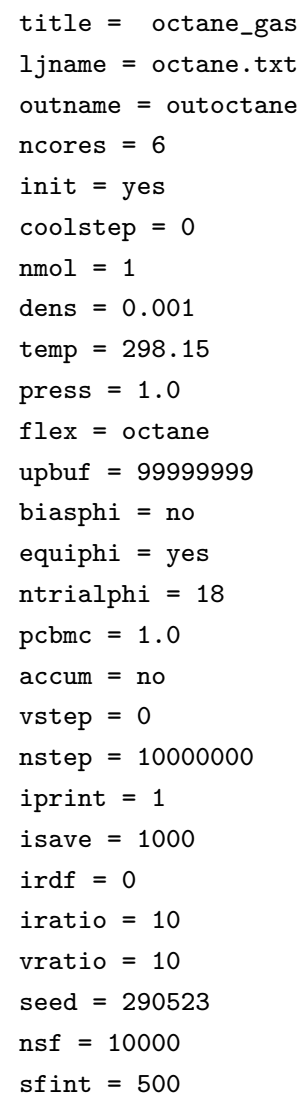


DICE input: octane.txt

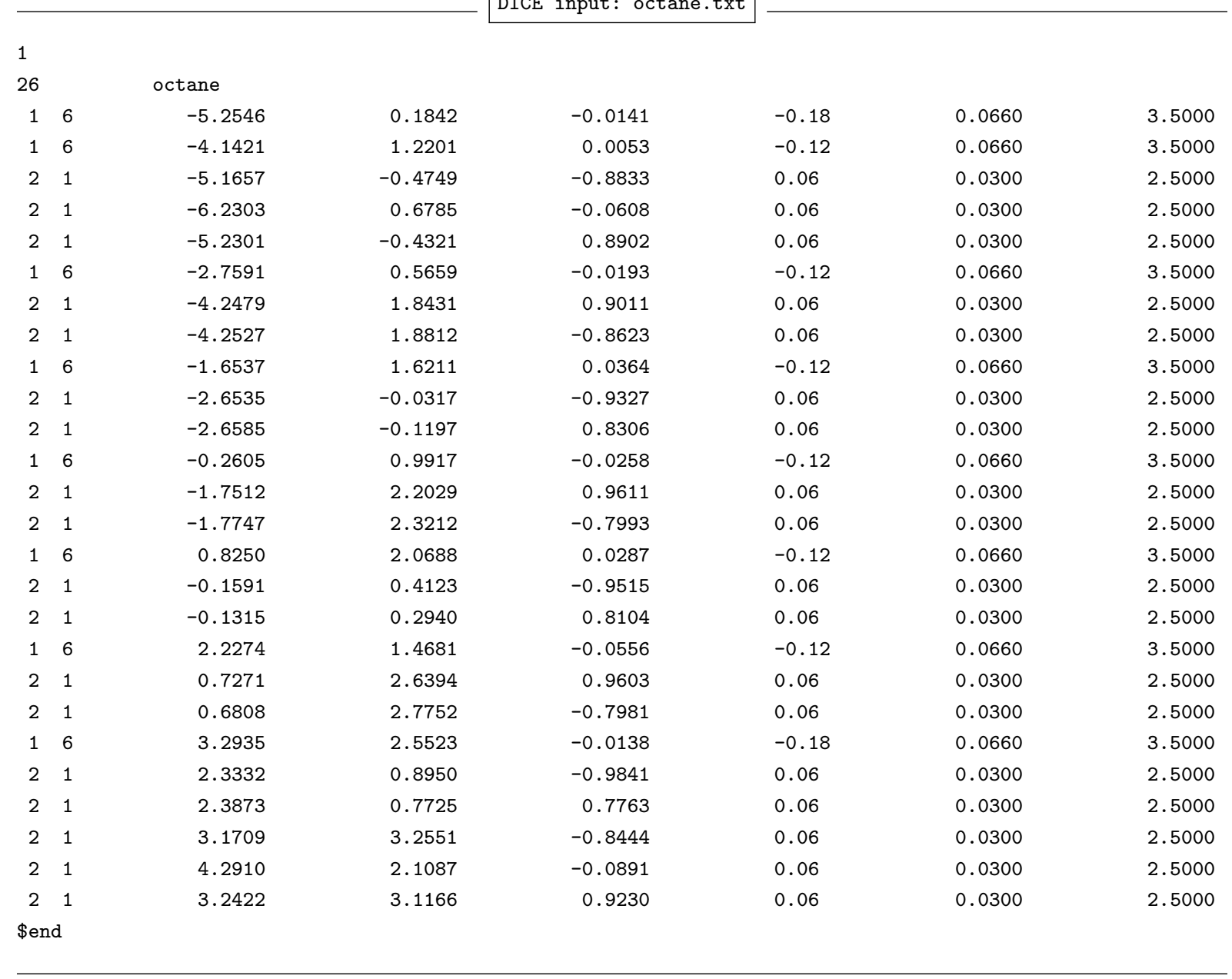


DICE input: octane.dfr

\begin{tabular}{lccccccc} 
\$atoms & fragments & \multicolumn{2}{l}{} & & \multicolumn{2}{l}{} \\
1 & 1 & 2 & 5 & 4 & 3 & F \\
2 & 2 & 6 & 1 & 7 & 8 & F \\
3 & 6 & 9 & 2 & 11 & 10 & F \\
4 & 9 & 12 & 6 & 13 & 14 & F \\
5 & 12 & 15 & 9 & 17 & 16 & F \\
6 & 15 & 18 & 12 & 19 & 20 & F \\
7 & 18 & 21 & 15 & 23 & 22 & F \\
8 & 21 & 18 & 26 & 25 & 24 & F
\end{tabular}

\$end atoms fragments

\$fragment connection

$\begin{array}{ll}1 & 2 \\ 2 & 3 \\ 3 & 4 \\ 4 & 5 \\ 5 & 6 \\ 6 & 7 \\ 7 & 8\end{array}$

\$end fragment connection

\begin{tabular}{|c|c|c|c|}
\hline \multicolumn{4}{|l|}{ \$bond } \\
\hline 15 & 340.0 & 1.09 & \\
\hline 14 & 340.0 & 1.09 & \\
\hline 13 & 340.0 & 1.09 & \\
\hline 12 & 268.0 & 1.52 & \\
\hline 28 & 340.0 & 1.1 & \\
\hline 27 & 340.0 & 1.1 & \\
\hline 26 & 268.0 & 1.53 & \\
\hline 611 & 340.0 & 1.1 & \\
\hline 610 & 340.0 & 1.1 & \\
\hline 69 & 268.0 & 1.53 & \\
\hline 914 & 340.0 & 1.1 & \\
\hline 913 & 340.0 & 1.1 & \\
\hline 912 & 268.0 & 1.53 & \\
\hline 1217 & 340.0 & 1.1 & \\
\hline 1216 & 340.0 & 1.1 & \\
\hline 1215 & 268.0 & 1.53 & \\
\hline 1520 & 340.0 & 1.1 & \\
\hline 1519 & 340.0 & 1.1 & \\
\hline 1518 & 268.0 & 1.53 & \\
\hline 1823 & 340.0 & 1.1 & \\
\hline 1822 & 340.0 & 1.1 & \\
\hline 1821 & 268.0 & 1.52 & \\
\hline 2126 & 340.0 & 1.1 & \\
\hline 2125 & 340.0 & 1.09 & \\
\hline 2124 & 340.0 & 1.09 & \\
\hline \multicolumn{4}{|c|}{ \$end bond } \\
\hline \multicolumn{4}{|l|}{ \$angle } \\
\hline 128 & harmonic & 37.5 & 109.081 \\
\hline 127 & harmonic & 37.5 & 109.06 \\
\hline 126 & harmonic & 58.35 & 111.727 \\
\hline 215 & harmonic & 37.5 & 110.885 \\
\hline 214 & harmonic & 37.5 & 110.147 \\
\hline 213 & harmonic & 37.5 & 111.143 \\
\hline $\begin{array}{lll}2 & 6 & 11\end{array}$ & harmonic & 37.5 & 109.778 \\
\hline 2610 & harmonic & 37.5 & 109.421 \\
\hline
\end{tabular}




$\begin{array}{llllcc}2 & 6 & 9 & \text { harmonic } & 58.35 & 110.966 \\ 3 & 1 & 5 & \text { harmonic } & 33.0 & 108.373 \\ 3 & 1 & 4 & \text { harmonic } & 33.0 & 108.103 \\ 4 & 1 & 5 & \text { harmonic } & 33.0 & 108.086 \\ 6 & 2 & 8 & \text { harmonic } & 37.5 & 109.692 \\ 6 & 2 & 7 & \text { harmonic } & 37.5 & 110.065 \\ 6 & 9 & 14 & \text { harmonic } & 37.5 & 109.479 \\ 6 & 9 & 13 & \text { harmonic } & 37.5 & 109.421 \\ 6 & 9 & 12 & \text { harmonic } & 58.35 & 111.916 \\ 7 & 2 & 8 & \text { harmonic } & 33.0 & 107.098 \\ 9 & 6 & 11 & \text { harmonic } & 37.5 & 109.703 \\ 9 & 6 & 10 & \text { harmonic } & 37.5 & 109.688 \\ 9 & 12 & 17 & \text { harmonic } & 37.5 & 109.743 \\ 9 & 12 & 16 & \text { harmonic } & 37.5 & 109.6 \\ 9 & 12 & 15 & \text { harmonic } & 58.35 & 110.805 \\ 10 & 6 & 11 & \text { harmonic } & 33.0 & 107.207 \\ 12 & 9 & 14 & \text { harmonic } & 37.5 & 109.394 \\ 12 & 9 & 13 & \text { harmonic } & 37.5 & 109.431 \\ 12 & 15 & 20 & \text { harmonic } & 37.5 & 109.447 \\ 12 & 15 & 19 & \text { harmonic } & 37.5 & 109.467 \\ 12 & 15 & 18 & \text { harmonic } & 58.35 & 111.834 \\ 13 & 9 & 14 & \text { harmonic } & 33.0 & 107.078 \\ 15 & 12 & 17 & \text { harmonic } & 37.5 & 109.709 \\ 15 & 12 & 16 & \text { harmonic } & 37.5 & 109.719 \\ 15 & 18 & 23 & \text { harmonic } & 37.5 & 109.962 \\ 15 & 18 & 22 & \text { harmonic } & 37.5 & 109.974 \\ 15 & 18 & 21 & \text { harmonic } & 58.35 & 111.206 \\ 16 & 12 & 17 & \text { harmonic } & 33.0 & 107.192 \\ 18 & 15 & 20 & \text { harmonic } & 37.5 & 109.374 \\ 18 & 15 & 19 & \text { harmonic } & 37.5 & 109.506 \\ 18 & 21 & 26 & \text { harmonic } & 37.5 & 110.964 \\ 18 & 21 & 25 & \text { harmonic } & 37.5 & 110.415 \\ 18 & 21 & 24 & \text { harmonic } & 37.5 & 110.965 \\ 19 & 15 & 20 & \text { harmonic } & 33.0 & 107.096 \\ 21 & 18 & 23 & \text { harmonic } & 37.5 & 109.204 \\ 21 & 18 & 22 & \text { harmonic } & 37.5 & 109.151 \\ 22 & 18 & 23 & \text { harmonic } & 33.0 & 107.252 \\ 24 & 21 & 26 & \text { harmonic } & 33.0 & 108.18 \\ 24 & 21 & 25 & \text { harmonic } & 33.0 & 108.096 \\ 25 & 21 & 26 & \text { harmonic } & 33.0 & 108.113\end{array}$

\$end angle

\section{\$dihedral}

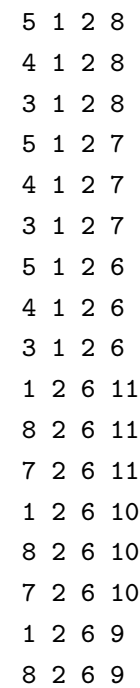

OPLS
OPLS
OPLS
OPLS
OPLS
OPLS
OPLS
OPLS
OPLS
OPLS
OPLS
OPLS
OPLS
OPLS
OPLS
OPLS
OPLS

$\begin{array}{ll}-0.0 & -0.0 \\ -0.0 & -0.0 \\ -0.0 & -0.0 \\ -0.0 & -0.0 \\ -0.0 & -0.0 \\ -0.0 & -0.0 \\ -0.0 & -0.0 \\ -0.0 & -0.0 \\ -0.0 & -0.0 \\ -0.0 & -0.0 \\ -0.0 & -0.0 \\ -0.0 & -0.0 \\ -0.0 & -0.0 \\ -0.0 & -0.0 \\ -0.0 & -0.0 \\ 1.3 & -0.05 \\ -0.0 & -0.0\end{array}$

$\begin{array}{cc}0.3 & 0.0 \\ 0.3 & 0.0 \\ 0.3 & 0.0 \\ 0.3 & 0.0 \\ 0.3 & 0.0 \\ 0.3 & 0.0 \\ 0.3 & 0.0 \\ 0.3 & 0.0 \\ 0.3 & 0.0 \\ 0.3 & 0.0 \\ 0.3 & 0.0 \\ 0.3 & 0.0 \\ 0.3 & 0.0 \\ 0.3 & 0.0 \\ 0.3 & 0.0 \\ 0.2 & 0.0 \\ 0.3 & 0.0\end{array}$

0.0
0.0
0.0
0.0
0.0
0.0
0.0
0.0
0.0
0.0
0.0
0.0
0.0
0.0
0.0
0.0
0.0

0.0

0.0 


\begin{tabular}{|c|c|c|c|c|c|c|c|c|}
\hline $\begin{array}{lll}7 & 269\end{array}$ & OPLS & -0.0 & -0.0 & 0.3 & 0.0 & 0.0 & 0.0 & 0.0 \\
\hline $\begin{array}{llll}2 & 6 & 9 & 14\end{array}$ & OPLS & -0.0 & -0.0 & 0.3 & 0.0 & 0.0 & 0.0 & 0.0 \\
\hline $\begin{array}{llll}11 & 69 & 14\end{array}$ & OPLS & -0.0 & -0.0 & 0.3 & 0.0 & 0.0 & 0.0 & 0.0 \\
\hline 106914 & OPLS & -0.0 & -0.0 & 0.3 & 0.0 & 0.0 & 0.0 & 0.0 \\
\hline $\begin{array}{llll}2 & 6 & 9 & 13\end{array}$ & OPLS & -0.0 & -0.0 & 0.3 & 0.0 & 0.0 & 0.0 & 0.0 \\
\hline $\begin{array}{llll}11 & 69 & 13\end{array}$ & OPLS & -0.0 & -0.0 & 0.3 & 0.0 & 0.0 & 0.0 & 0.0 \\
\hline $\begin{array}{llll}10 & 69 & 13\end{array}$ & OPLS & -0.0 & -0.0 & 0.3 & 0.0 & 0.0 & 0.0 & 0.0 \\
\hline $\begin{array}{llll}2 & 6 & 9 & 12\end{array}$ & OPLS & 1.3 & -0.05 & 0.2 & 0.0 & 0.0 & 0.0 & 0.0 \\
\hline $\begin{array}{llll}11 & 6 & 9 & 12\end{array}$ & OPLS & -0.0 & -0.0 & 0.3 & 0.0 & 0.0 & 0.0 & 0.0 \\
\hline 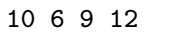 & OPLS & -0.0 & -0.0 & 0.3 & 0.0 & 0.0 & 0.0 & 0.0 \\
\hline $\begin{array}{llll}6 & 9 & 12 & 17\end{array}$ & OPLS & -0.0 & -0.0 & 0.3 & 0.0 & 0.0 & 0.0 & 0.0 \\
\hline $\begin{array}{llll}14 & 9 & 12 & 17\end{array}$ & OPLS & -0.0 & -0.0 & 0.3 & 0.0 & 0.0 & 0.0 & 0.0 \\
\hline $\begin{array}{llll}13 & 9 & 12 & 17\end{array}$ & OPLS & -0.0 & -0.0 & 0.3 & 0.0 & 0.0 & 0.0 & 0.0 \\
\hline $\begin{array}{llll}6 & 9 & 12 & 16\end{array}$ & OPLS & -0.0 & -0.0 & 0.3 & 0.0 & 0.0 & 0.0 & 0.0 \\
\hline $\begin{array}{llll}14 & 9 & 12 & 16\end{array}$ & OPLS & -0.0 & -0.0 & 0.3 & 0.0 & 0.0 & 0.0 & 0.0 \\
\hline $\begin{array}{llll}13 & 9 & 12 & 16\end{array}$ & OPLS & -0.0 & -0.0 & 0.3 & 0.0 & 0.0 & 0.0 & 0.0 \\
\hline $\begin{array}{llll}6 & 9 & 12 & 15\end{array}$ & OPLS & 1.3 & -0.05 & 0.2 & 0.0 & 0.0 & 0.0 & 0.0 \\
\hline $\begin{array}{llll}14 & 9 & 12 & 15\end{array}$ & OPLS & -0.0 & -0.0 & 0.3 & 0.0 & 0.0 & 0.0 & 0.0 \\
\hline $\begin{array}{llll}13 & 9 & 12 & 15\end{array}$ & OPLS & -0.0 & -0.0 & 0.3 & 0.0 & 0.0 & 0.0 & 0.0 \\
\hline $\begin{array}{llll}9 & 12 & 15 & 20\end{array}$ & OPLS & -0.0 & -0.0 & 0.3 & 0.0 & 0.0 & 0.0 & 0.0 \\
\hline $\begin{array}{llll}17 & 12 & 15 & 20\end{array}$ & OPLS & -0.0 & -0.0 & 0.3 & 0.0 & 0.0 & 0.0 & 0.0 \\
\hline $\begin{array}{llll}16 & 12 & 15 & 20\end{array}$ & OPLS & -0.0 & -0.0 & 0.3 & 0.0 & 0.0 & 0.0 & 0.0 \\
\hline $\begin{array}{llll}9 & 12 & 15 & 19\end{array}$ & OPLS & -0.0 & -0.0 & 0.3 & 0.0 & 0.0 & 0.0 & 0.0 \\
\hline $\begin{array}{llll}17 & 12 & 15 & 19\end{array}$ & OPLS & -0.0 & -0.0 & 0.3 & 0.0 & 0.0 & 0.0 & 0.0 \\
\hline $\begin{array}{llll}16 & 12 & 15 & 19\end{array}$ & OPLS & -0.0 & -0.0 & 0.3 & 0.0 & 0.0 & 0.0 & 0.0 \\
\hline $\begin{array}{llll}9 & 12 & 15 & 18\end{array}$ & OPLS & 1.3 & -0.05 & 0.2 & 0.0 & 0.0 & 0.0 & 0.0 \\
\hline $\begin{array}{llll}17 & 12 & 15 & 18\end{array}$ & OPLS & -0.0 & -0.0 & 0.3 & 0.0 & 0.0 & 0.0 & 0.0 \\
\hline $\begin{array}{llll}16 & 12 & 15 & 18\end{array}$ & OPLS & -0.0 & -0.0 & 0.3 & 0.0 & 0.0 & 0.0 & 0.0 \\
\hline $\begin{array}{llll}12 & 15 & 18 & 23\end{array}$ & OPLS & -0.0 & -0.0 & 0.3 & 0.0 & 0.0 & 0.0 & 0.0 \\
\hline $\begin{array}{llll}20 & 15 & 18 & 23\end{array}$ & OPLS & -0.0 & -0.0 & 0.3 & 0.0 & 0.0 & 0.0 & 0.0 \\
\hline $\begin{array}{llll}19 & 15 & 18 & 23\end{array}$ & OPLS & -0.0 & -0.0 & 0.3 & 0.0 & 0.0 & 0.0 & 0.0 \\
\hline $\begin{array}{llll}12 & 15 & 18 & 22\end{array}$ & OPLS & -0.0 & -0.0 & 0.3 & 0.0 & 0.0 & 0.0 & 0.0 \\
\hline $\begin{array}{llll}20 & 15 & 18 & 22\end{array}$ & OPLS & -0.0 & -0.0 & 0.3 & 0.0 & 0.0 & 0.0 & 0.0 \\
\hline $\begin{array}{llll}19 & 15 & 18 & 22\end{array}$ & OPLS & -0.0 & -0.0 & 0.3 & 0.0 & 0.0 & 0.0 & 0.0 \\
\hline $\begin{array}{llll}12 & 15 & 18 & 21\end{array}$ & OPLS & 1.3 & -0.05 & 0.2 & 0.0 & 0.0 & 0.0 & 0.0 \\
\hline $\begin{array}{llll}20 & 15 & 18 & 21\end{array}$ & OPLS & -0.0 & -0.0 & 0.3 & 0.0 & 0.0 & 0.0 & 0.0 \\
\hline $\begin{array}{llll}19 & 15 & 18 & 21\end{array}$ & OPLS & -0.0 & -0.0 & 0.3 & 0.0 & 0.0 & 0.0 & 0.0 \\
\hline $\begin{array}{llll}15 & 18 & 21 & 26\end{array}$ & OPLS & -0.0 & -0.0 & 0.3 & 0.0 & 0.0 & 0.0 & 0.0 \\
\hline $\begin{array}{llll}23 & 18 & 21 & 26\end{array}$ & OPLS & -0.0 & -0.0 & 0.3 & 0.0 & 0.0 & 0.0 & 0.0 \\
\hline $\begin{array}{llll}22 & 18 & 21 & 26\end{array}$ & OPLS & -0.0 & -0.0 & 0.3 & 0.0 & 0.0 & 0.0 & 0.0 \\
\hline $\begin{array}{llll}15 & 18 & 21 & 25\end{array}$ & OPLS & -0.0 & -0.0 & 0.3 & 0.0 & 0.0 & 0.0 & 0.0 \\
\hline $\begin{array}{lllll}23 & 18 & 21 & 25\end{array}$ & OPLS & -0.0 & -0.0 & 0.3 & 0.0 & 0.0 & 0.0 & 0.0 \\
\hline $\begin{array}{lllll}22 & 18 & 21 & 25\end{array}$ & OPLS & -0.0 & -0.0 & 0.3 & 0.0 & 0.0 & 0.0 & 0.0 \\
\hline $\begin{array}{llll}15 & 18 & 21 & 24\end{array}$ & OPLS & -0.0 & -0.0 & 0.3 & 0.0 & 0.0 & 0.0 & 0.0 \\
\hline $\begin{array}{llll}23 & 18 & 21 & 24\end{array}$ & OPLS & -0.0 & -0.0 & 0.3 & 0.0 & 0.0 & 0.0 & 0.0 \\
\hline $\begin{array}{llll}22 & 18 & 21 & 24\end{array}$ & OPLS & -0.0 & -0.0 & 0.3 & 0.0 & 0.0 & 0.0 & 0.0 \\
\hline
\end{tabular}




\section{Arquivos de entrada 1,2-dicloroetano}

Nos parágrafos abaixo, uma breve descrição dos arquivos de entrada do DICE é apresentada, para que o leitor possa compreender os parâmetros utilizados. Uma descrição completa dos arquivos de entrada pode ser encontrada no manual do DICE. ${ }^{[29]}$

O arquivo .in contém parâmetros para a simulação como número de moléculas, temperatura, número de passos, etc. $\mathrm{O}$ arquivo .txt contém a geometria das moléculas, cargas e parâmetros de Lennard-Jones. Já o arquivo . dfr contém os parâmetros do campo de força para a molécula flexível desejada, além de conter informações sobre a fragmentação da molécula.

No arquivo .txt, para a parte onde os átomos de cada molécula são descritos, as colunas indicam, respectivamente, índice $g(r)$, número atômico, coordenada Cartesiana $\mathbf{x}$, coordenada Cartesiana y, coordenada Cartesiana z, carga, $\epsilon$ e $\sigma$. O arquivo .dfr tem um formato parecido com os arquivos de topologia do GROMACS, e as constantes aparecem, para o caso de comprimento de ligação e ângulos, como constante de mola e posição de equilíbrio. As constantes dos diedros no arquivo . dfr aparecem na ordem $V_{1}, V_{2}, V_{3}, f_{1}, f_{2} f_{3}$.

As unidades de energia são $\mathrm{kcal} / \mathrm{mol}$, distâncias em $\AA$ e ângulos em ${ }^{\circ}$. 
DICE input: npt.in

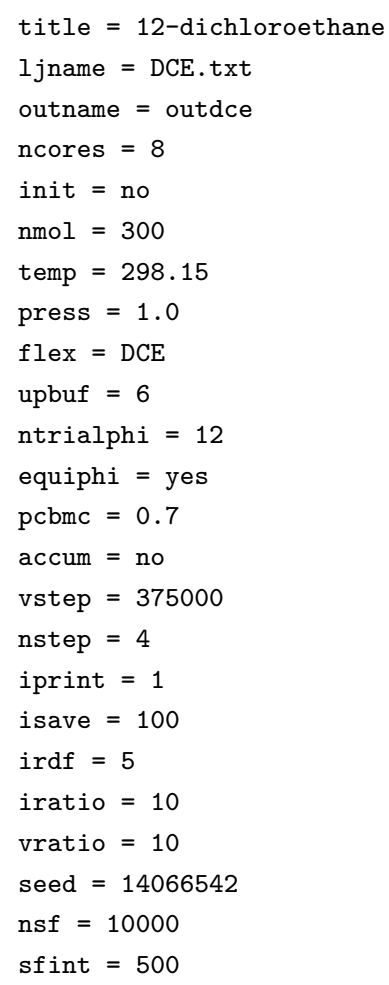


DICE input: DCE.txt

\begin{tabular}{|c|c|c|c|c|c|c|}
\hline & DCE & & & & & \\
\hline 17 & 0.055 & 0.0 & -2.18 & -0.200 & 0.3 & 3.4 \\
\hline 26 & -0.584 & 0.0 & -0.494 & -0.006 & 0.066 & 3.5 \\
\hline 31 & -1.193 & 0.89 & -0.336 & 0.103 & 0.03 & 2.5 \\
\hline 31 & -1.193 & -0.89 & -0.336 & 0.103 & 0.03 & 2.5 \\
\hline 26 & 0.584 & 0.0 & 0.494 & -0.006 & 0.066 & 3.5 \\
\hline 31 & 1.193 & -0.89 & 0.336 & 0.103 & 0.03 & 2.5 \\
\hline 31 & 1.193 & 0.89 & 0.336 & 0.103 & 0.03 & 2.5 \\
\hline 17 & -0.055 & 0.0 & 2.18 & -0.200 & 0.3 & 3.4 \\
\hline nd & & & & & & \\
\hline
\end{tabular}




\section{DICE input: DCE.dfr}

\begin{tabular}{lcccccc}
\multicolumn{2}{l}{ \$atoms } & fragments & & & & \\
1 & 1 & 2 & 5 & 4 & 3 & F \\
2 & 5 & 2 & 8 & 7 & 6 & F
\end{tabular}

\$end atoms fragments

\$fragment connection

1

\$end fragment connection

\$bond

$\begin{array}{llll}1 & 2 & 245.0 & 1.781 \\ 2 & 3 & 340.0 & 1.09 \\ 2 & 4 & 340.0 & 1.09 \\ 2 & 5 & 268.0 & 1.529 \\ 5 & 6 & 340.0 & 1.09 \\ 5 & 7 & 340.0 & 1.09 \\ 5 & 8 & 245.0 & 1.781\end{array}$

\$end bond

\$angle

$\begin{array}{llllll}1 & 2 & 3 & \text { harmonic } & 51.0 & 107.600 \\ 1 & 2 & 4 & \text { harmonic } & 51.0 & 107.600 \\ 1 & 2 & 5 & \text { harmonic } & 69.0 & 109.800 \\ 3 & 2 & 4 & \text { harmonic } & 33.0 & 107.800 \\ 3 & 2 & 5 & \text { harmonic } & 37.5 & 110.700 \\ 4 & 2 & 5 & \text { harmonic } & 37.5 & 110.700 \\ 2 & 5 & 6 & \text { harmonic } & 37.5 & 110.700 \\ 2 & 5 & 7 & \text { harmonic } & 37.5 & 110.700 \\ 2 & 5 & 8 & \text { harmonic } & 69.0 & 109.800 \\ 6 & 5 & 7 & \text { harmonic } & 33.0 & 107.800 \\ 6 & 5 & 8 & \text { harmonic } & 51.0 & 107.600 \\ 7 & 5 & 8 & \text { harmonic } & 51.0 & 107.600\end{array}$

\$end angle

\$dihedral

\begin{tabular}{rrrlllllrrr}
1 & 2 & 5 & 6 & OPLS & 0.0 & 0.0 & 0.4 & 0.0 & 0.0 & 0.0 \\
1 & 2 & 5 & 7 & OPLS & 0.0 & 0.0 & 0.4 & 0.0 & 0.0 & 0.0 \\
1 & 2 & 5 & 8 & OPLS & -0.25 & 0.0 & 0.0 & 0.0 & 0.0 & 0.0 \\
3 & 2 & 5 & 6 & OPLS & 0.0 & 0.0 & 0.318 & 0.0 & 0.0 & 0.0 \\
3 & 2 & 5 & 7 & OPLS & 0.0 & 0.0 & 0.318 & 0.0 & 0.0 & 0.0 \\
3 & 2 & 5 & 8 & OPLS & 0.0 & 0.0 & 0.4 & 0.0 & 0.0 & 0.0 \\
4 & 2 & 5 & 6 & OPLS & 0.0 & 0.0 & 0.318 & 0.0 & 0.0 & 0.0 \\
4 & 2 & 5 & 7 & OPLS & 0.0 & 0.0 & 0.318 & 0.0 & 0.0 & 0.0 \\
4 & 2 & 5 & 8 & OPLS & 0.0 & 0.0 & 0.4 & 0.0 & 0.0 & 0.0 \\
\hline
\end{tabular}

\$end dihedral 


\section{APÊNDICE $E$}

\section{Arquivos de entrada óxido mesityl}

Nos parágrafos abaixo, uma breve descrição dos arquivos de entrada do DICE é apresentada, para que o leitor possa compreender os parâmetros utilizados. Uma descrição completa dos arquivos de entrada pode ser encontrada no manual do DICE. ${ }^{[29]}$

$\mathrm{O}$ arquivo .in contém parâmetros para a simulação como número de moléculas, temperatura, número de passos, etc. $\mathrm{O}$ arquivo .txt contém a geometria das moléculas, cargas e parâmetros de Lennard-Jones. Já o arquivo . dfr contém os parâmetros do campo de força para a molécula flexível desejada, além de conter informações sobre a fragmentação da molécula.

No arquivo .txt, para a parte onde os átomos de cada molécula são descritos, as colunas indicam, respectivamente, índice $g(r)$, número atômico, coordenada Cartesiana x, coordenada Cartesiana y, coordenada Cartesiana z, carga, $\epsilon$ e $\sigma$. O arquivo .dfr tem um formato parecido com os arquivos de topologia do GROMACS, e as constantes aparecem, para o caso de comprimento de ligação e ângulos, como constante de mola e posição de equilíbrio. As constantes dos diedros no arquivo . dfr aparecem na ordem $V_{1}, V_{2}, V_{3}, f_{1}, f_{2} f_{3}$.

As unidades de energia são $\mathrm{kcal} / \mathrm{mol}$, distâncias em $\AA$ e ângulos em ${ }^{\circ}$. 
DICE input: npt.in

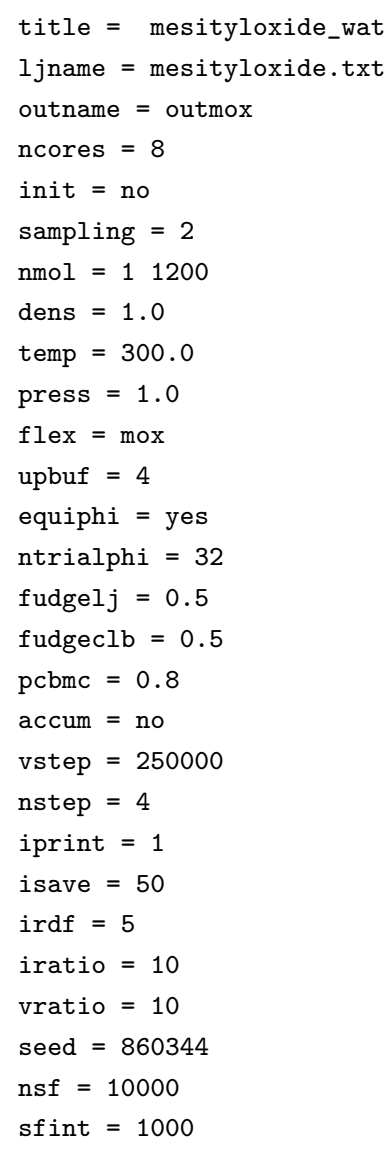


DICE input: mesityloxide.txt polarizado água

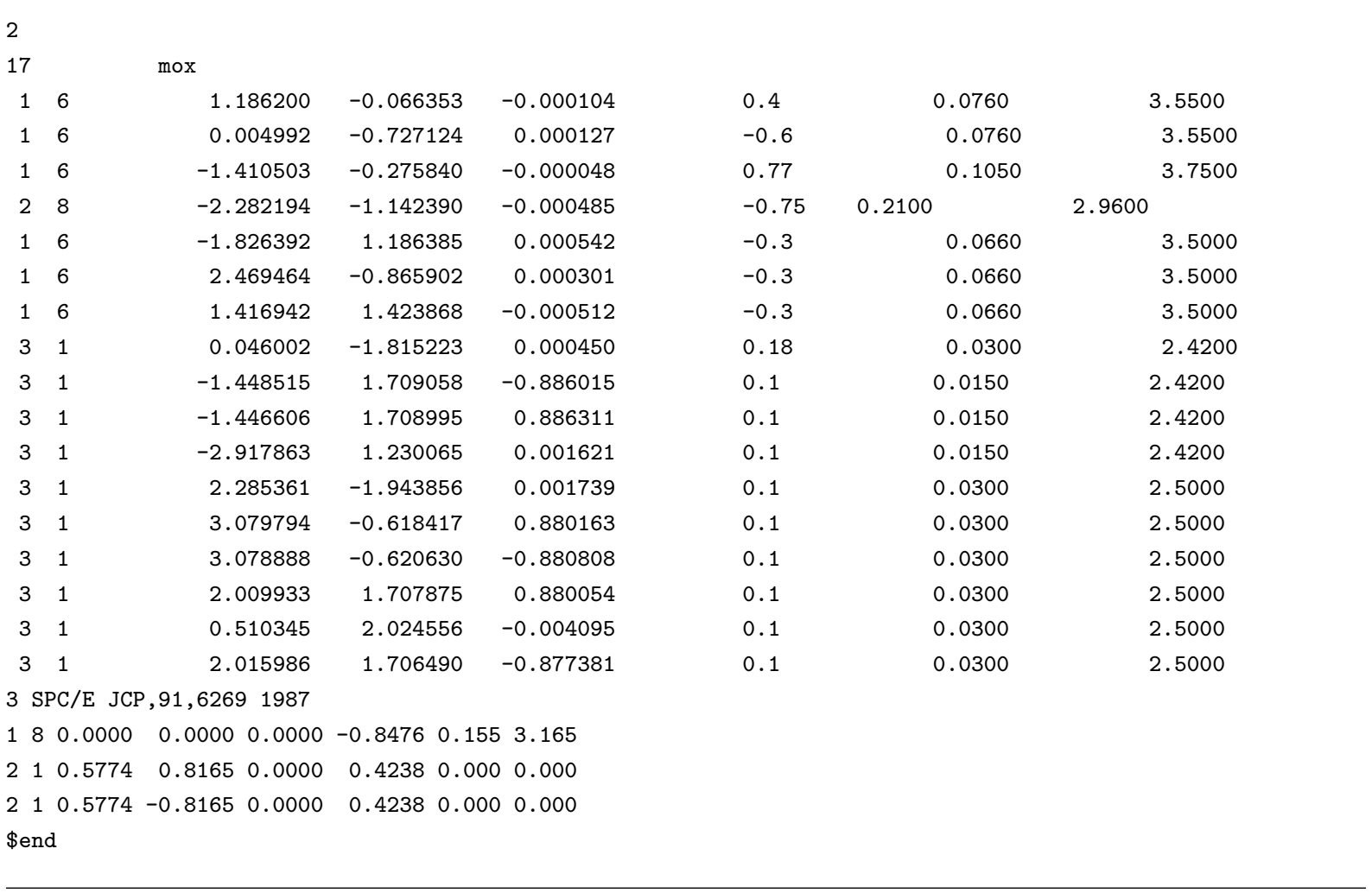


DICE input: mesityloxide.txt polarizado metanol

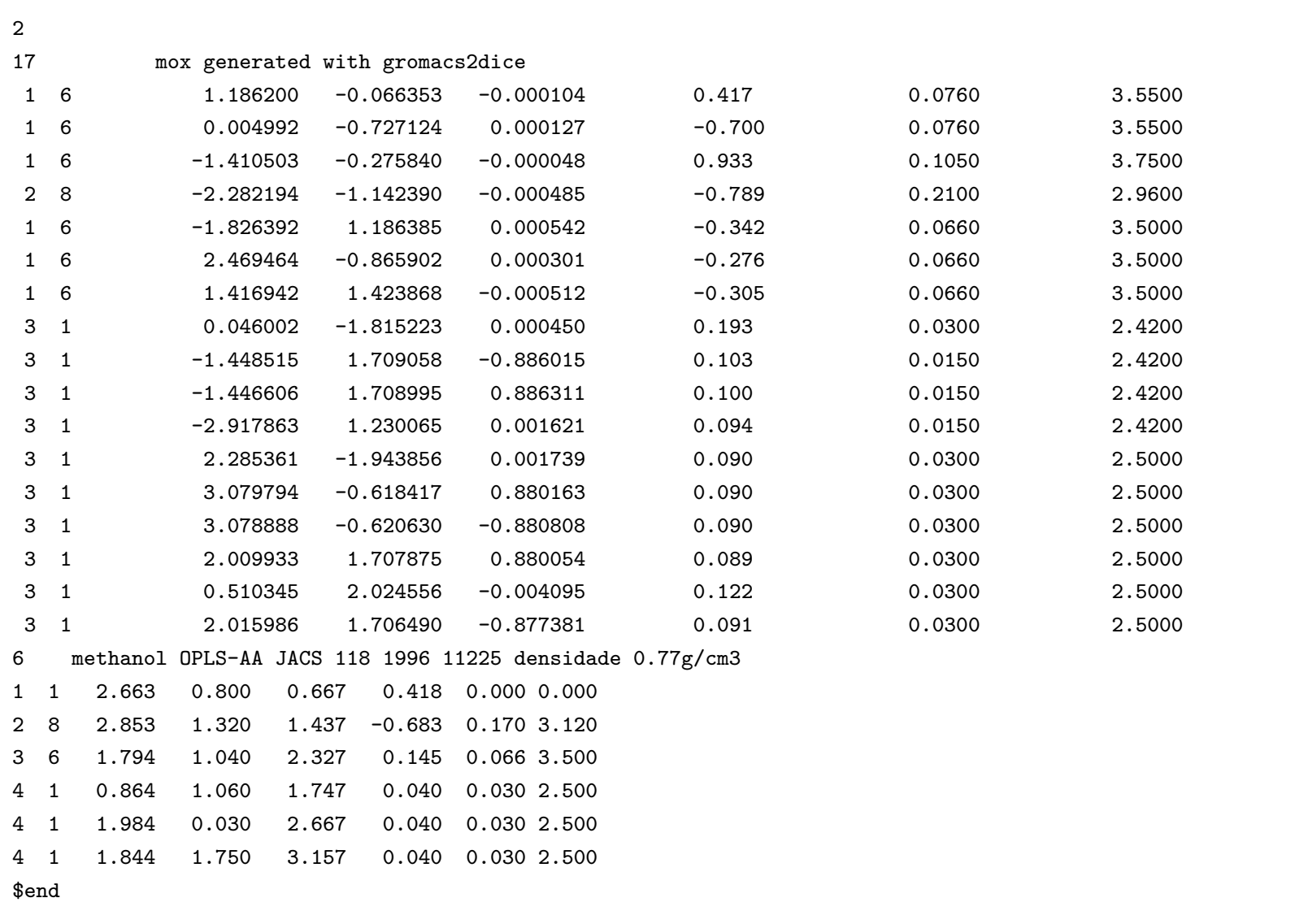


DICE input: mesityloxide.txt polarizado acetonitrila

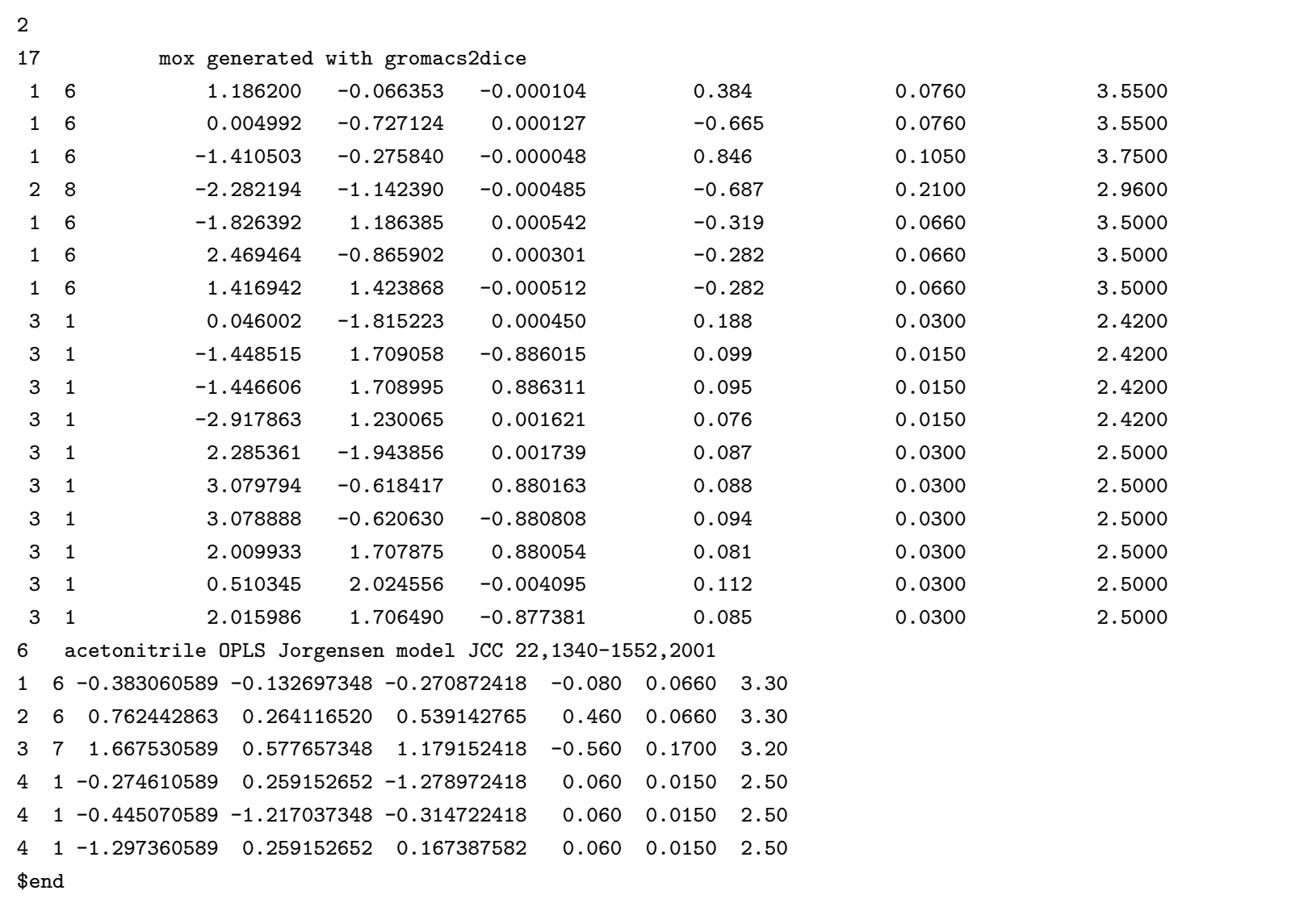


DICE input: mox.dfr

$\begin{array}{lllllllll}\text { \$atoms } & \text { fragments } & & & & & & & \\ 1 & 1 & 7 & 6 & 2 & 3 & 8 & & \mathrm{~F} \\ 2 & 3 & 5 & 2 & 4 & \mathrm{M} & & \\ 3 & 5 & 3 & 11 & 10 & 9 & \mathrm{~F} & \\ 4 & 6 & 1 & 13 & 12 & 14 & \mathrm{~F} & \\ 5 & 7 & 1 & 16 & 15 & 17 & \mathrm{~F} & \end{array}$

\$end atoms fragments

\$fragment connection

$\begin{array}{ll}1 & 4 \\ 1 & 5 \\ 1 & 2 \\ 2 & 3\end{array}$

\$end fragment connection

$\begin{array}{llcc}\text { \$bond } & & \\ 1 & 7 & 317.0 & 1.5080 \\ 1 & 6 & 317.0 & 1.5120 \\ 1 & 2 & 549.0 & 1.3535 \\ 2 & 8 & 340.0 & 1.0889 \\ 2 & 3 & 410.0 & 1.4857 \\ 3 & 5 & 317.0 & 1.5202 \\ 3 & 4 & 570.0 & 1.2291 \\ 5 & 11 & 340.0 & 1.0923 \\ 5 & 10 & 340.0 & 1.0963 \\ 5 & 9 & 340.0 & 1.0963 \\ 6 & 14 & 340.0 & 1.0990 \\ 6 & 13 & 340.0 & 1.0990 \\ 6 & 12 & 340.0 & 1.0936 \\ 7 & 17 & 340.0 & 1.0989 \\ 7 & 16 & 340.0 & 1.0875 \\ 7 & 15 & 340.0 & 1.0990 \\ \$ \text { \$end bond } & & \end{array}$

\$angle

1717

1716

$\begin{array}{lll}1 & 7 & 15\end{array}$

1614

$\begin{array}{lll}1 & 6 & 13\end{array}$

$\begin{array}{lll}1 & 6 & 12\end{array}$

128

123

$\begin{array}{lll}2 & 1 & 7\end{array}$

216

235

234

328

$\begin{array}{lll}3 & 5 & 11\end{array}$

3510

359

435

$\begin{array}{lll}6 & 17\end{array}$

$\begin{array}{lll}9 & 5 & 11\end{array}$

9510

$10 \quad 5 \quad 11$

$\begin{array}{lll}12 & 6 & 14\end{array}$

$\begin{array}{ccc}\text { harmonic } & 35.0 & 109.7417 \\ \text { harmonic } & 35.0 & 114.7257 \\ \text { harmonic } & 35.0 & 109.7393 \\ \text { harmonic } & 35.0 & 110.6340 \\ \text { harmonic } & 35.0 & 110.6379 \\ \text { harmonic } & 35.0 & 112.2333 \\ \text { harmonic } & 35.0 & 117.0643 \\ \text { harmonic } & 85.0 & 133.0941 \\ \text { harmonic } & 70.0 & 128.0244 \\ \text { harmonic } & 70.0 & 118.8519 \\ \text { harmonic } & 70.0 & 123.5601 \\ \text { harmonic } & 80.0 & 117.4863 \\ \text { harmonic } & 35.0 & 109.8416 \\ \text { harmonic } & 35.0 & 108.1687 \\ \text { harmonic } & 35.0 & 111.3490 \\ \text { harmonic } & 35.0 & 111.3430 \\ \text { harmonic } & 80.0 & 118.9536 \\ \text { harmonic } & 70.0 & 113.1237 \\ \text { harmonic } & 33.0 & 109.0341 \\ \text { harmonic } & 33.0 & 107.8594 \\ \text { harmonic } & 33.0 & 109.0430 \\ \text { harmonic } & 33.0 & 108.3238 \\ \text { harmonic } & 33.0 & 108.3248\end{array}$




$\begin{array}{llllll}13 & 6 & 14 & \text { harmonic } & 33.0 & 106.4772 \\ 15 & 7 & 17 & \text { harmonic } & 33.0 & 106.1862 \\ 15 & 7 & 16 & \text { harmonic } & 33.0 & 108.0421 \\ 16 & 7 & 17 & \text { harmonic } & 33.0 & 108.0437 \\ \text { \$end angle } & & & \end{array}$

\$dihedral

61717

$\begin{array}{llll}2 & 1 & 7 & 17\end{array}$

61716

21716

$\begin{array}{llll}6 & 1 & 7 & 15\end{array}$

$\begin{array}{llll}2 & 1 & 7 & 15\end{array}$

$\begin{array}{llll}7 & 1 & 6 & 14\end{array}$

$\begin{array}{llll}2 & 1 & 6 & 14\end{array}$

$\begin{array}{llll}7 & 1 & 6 & 13\end{array}$

21613

$\begin{array}{llll}7 & 1 & 6 & 12\end{array}$

$\begin{array}{llll}2 & 1 & 6 & 12\end{array}$

$\begin{array}{llll}7 & 1 & 2 & 8\end{array}$

$\begin{array}{llll}6 & 1 & 2 & 8\end{array}$

$\begin{array}{llll}7 & 1 & 2 & 3\end{array}$

6123

1235

8235

1234

8234

23511

$\begin{array}{llll}4 & 3 & 5 & 11\end{array}$

23510

43510

2359

4359

OPLS

OPLS

OPLS

OPLS

OPLS

OPLS

OPLS

OPLS

OPLS

OPLS

OPLS

OPLS

OPLS

OPLS

OPLS

OPLS

OPLS

OPLS

OPLS

OPLS

OPLS

OPLS

OPLS

$-0.0$

$-0.0$

0.3

0.0

$-0.0$

$-0.372$

0.0

0.0

0.0

$\begin{array}{lll}-0.0 & -0.0 & 0.3\end{array}$

$\begin{array}{lll}0.0 & -0.0 & -0.372\end{array}$

$-0.0$

$-0.0$

0.3

$0.0 \quad-0.0$

$-0.0$

$-0.0$

$-0.372$

$0.0 \quad-0.0$

0.3

$-0.0$

$-0.0$

$-0.372$

$0.0 \quad-0.0$

0.3

$-0.0$

$-0.372$

0.0

$-0.0$

0.3

$-0.0$

$-0.0$

$-0.372$

14.0

14.0

$-0.0$

$-0.0$

0.0

0.0

0.0

$-0.0$

14.0

$-0.0 \quad 14.0$

$-0.0$

$-0.0$

$1.4 \quad 5.2$

$-0.0$

$-0.0$

$-4.7$

0.0

0.0

0.0

$\begin{array}{lll}0.0 & 0.0 & 0.0\end{array}$

$\begin{array}{lll}0.0 & 0.0 & 0.0\end{array}$

$-1.8 \quad 4.3$

0.7

$-1.9$

$-0.0$

$-0.0$

$-0.0 \quad-0.0$

0.366

0.0

0.0

0.0

0.0

0.0

0.0

0.0

0.0

0.0

0.0

0.0

0.0

$\begin{array}{lll}0.0 & 0.0 & 0.0\end{array}$

$\begin{array}{lll}0.0 & 0.0 & 0.0\end{array}$

$-0.0 \quad-0.0$

$-0.0$

0.0

0.0

0.0

$\begin{array}{lll}0.0 & 0.0 & 0.0\end{array}$

$\begin{array}{lll}0.0 & 0.0 & 0.0\end{array}$

$\begin{array}{lll}0.0 & 0.0 & 0.0\end{array}$

$\begin{array}{lll}0.0 & 0.0 & 0.0 \\ 0.0 & 0.0 & 0.0\end{array}$

$\begin{array}{lll}0.0 & 0.0 & 0.0\end{array}$

$-0.0 \quad-0.0$

0.366

0.0

0.0

$\begin{array}{lll}0.0 & 0.0 & 0.0\end{array}$

$\begin{array}{lll}0.0 & 0.0 & 0.0\end{array}$

$-0.0 \quad-0.0$

$-0.0$

0.366

OPLS

\$end dihedral

$-0.0$

$-0.0$

$-0.0$

0.0

0.0

0.0

0.0

0.0

0.0

0.0

0.0

$-0.0$

0.0

0.0

0.0

$-0.0$

0.0

0.0

0.0

\$improper dihedral

$\begin{array}{llllll}7 & 6 & 1 & 2 & 15.0 & 180.0 \\ 1 & 8 & 2 & 3 & 15.0 & 180.0 \\ 2 & 5 & 3 & 4 & 10.5 & 180.0\end{array}$

\$end improper dihedral

180.0 